NASA/TM-1999-209097

ARL-MR-439
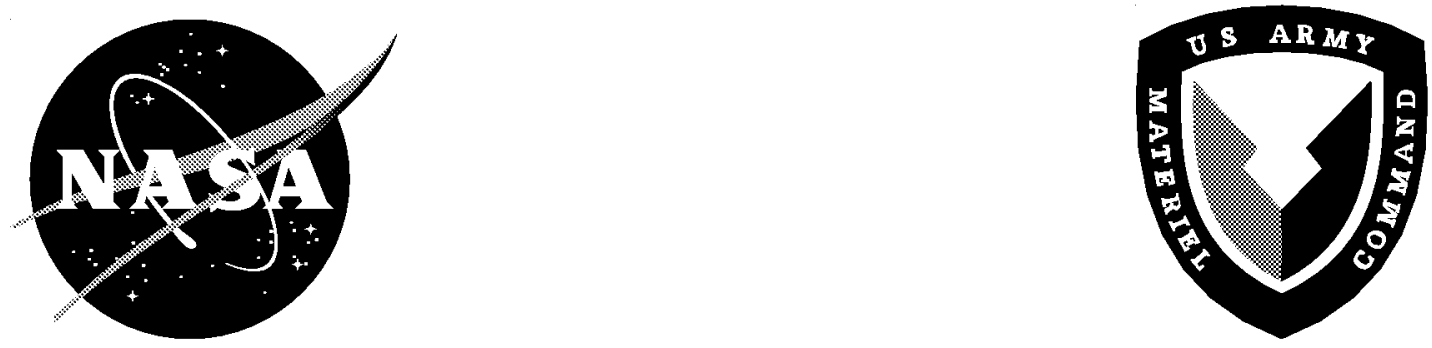

\title{
Testing and Analysis of Composite Skin/Stringer Debonding Under Multi-Axial Loading
}

Ronald Krueger and Michael K. Cvitkovich

Langley Research Center, Hampton, Virginia

T. Kevin O'Brien

U.S. Army Research Laboratory

Vehicle Technology Center

Langley Research Center, Hampton, Virginia

Pierre J. Minguet

Boeing, Philadelphia, Pennsylvania 


\section{The NASA STI Program Office ... in Profile}

Since its founding, NASA has been dedicated to the advancement of aeronautics and space science. The NASA Scientific and Technical Information (STI) Program Office plays a key part in helping NASA maintain this important role.

The NASA STI Program Office is operated by Langley Research Center, the lead center for NASA's scientific and technical information. The NASA STI Program Office provides access to the NASA STI Database, the largest collection of aeronautical and space science STI in the world. The Program Office is also NASA's institutional mechanism for disseminating the results of its research and development activities. These results are published by NASA in the NASA STI Report Series, which includes the following report types:

- TECHNICAL PUBLICATION. Reports of completed research or a major significant phase of research that present the results of NASA programs and include extensive data or theoretical analysis. Includes compilations of significant scientific and technical data and information deemed to be of continuing reference value. NASA counterpart of peer-reviewed formal professional papers, but having less stringent limitations on manuscript length and extent of graphic presentations.

- TECHNICAL MEMORANDUM. Scientific and technical findings that are preliminary or of specialized interest, e.g., quick release reports, working papers, and bibliographies that contain minimal annotation. Does not contain extensive analysis.

- CONTRACTOR REPORT. Scientific and technical findings by NASA-sponsored contractors and grantees.
- CONFERENCE PUBLICATION. Collected papers from scientific and technical conferences, symposia, seminars, or other meetings sponsored or co-sponsored by NASA.

- SPECIAL PUBLICATION. Scientific, technical, or historical information from NASA programs, projects, and missions, often concerned with subjects having substantial public interest.

- TECHNICAL TRANSLATION. Englishlanguage translations of foreign scientific and technical material pertinent to NASA's mission.

Specialized services that complement the STI Program Office's diverse offerings include creating custom thesauri, building customized databases, organizing and publishing research results ... even providing videos.

For more information about the NASA STI Program Office, see the following:

- Access the NASA STI Program Home Page at http://www.sti.nasa.gov

- E-mail your question via the Internet to help@sti.nasa.gov

- Fax your question to the NASA STI Help Desk at (301) 621-0134

- Phone the NASA STI Help Desk at (301) 621-0390

- Write to: NASA STI Help Desk NASA Center for AeroSpace Information 7121 Standard Drive Hanover, MD 21076-1320 
NASA/TM-1999-209097

ARL-MR-439
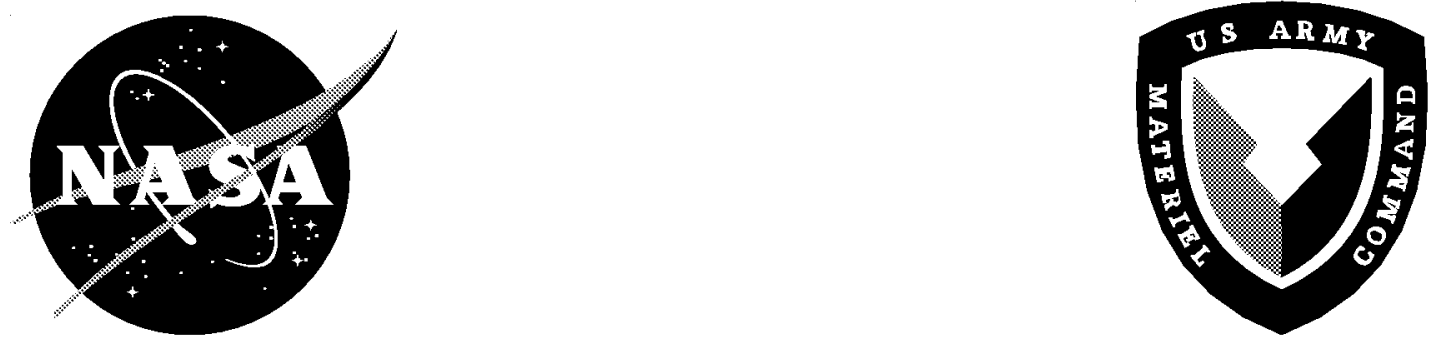

\section{Testing and Analysis of Composite Skin/Stringer Debonding Under Multi-Axial Loading}

Ronald Krueger and Michael K. Cvitkovich

Langley Research Center, Hampton, Virginia

T. Kevin O'Brien

U.S. Army Research Laboratory

Vehicle Technology Center

Langley Research Center, Hampton, Virginia

Pierre J. Minguet

Boeing, Philadelphia, Pennsylvania

National Aeronautics and

Space Administration

Langley Research Center

Hampton, Virginia 23681-2199

February 1999 
The use of trademarks or names of manufacturers in the report is for accurate reporting and does not constitute an official endorsement, either expressed or implied, of such products or manufacturers by the National Aeronautics and Space Administration or the U.S. Army.

Available from:

NASA Center for AeroSpace Information (CASI)

7121 Standard Drive

Hanover, MD 21076-1320

(301) 621-0390
National Technical Information Service (NTIS) 5285 Port Royal Road

Springfield, VA 22161-2171

(703) 605-6000 


\title{
TESTING AND ANALYSIS OF COMPOSITE SKIN/STRINGER DEBONDING UNDER MULTI-AXIAL LOADING
}

\author{
Ronald Krueger*, Michael K. Cvitkovich*, T. Kevin O'Brien**, and Pierre J. Minguet*** \\ * National Research Council Research Associate \\ ** U.S. Army Research Laboratory, Vehicle Technology Center \\ NASA Langley Research Center \\ Hampton, VA 23681 \\ **** Boeing \\ Philadelphia, PA 19142
}

\begin{abstract}
The objective of this work was to investigate the damage mechanisms in composite bonded skin/stringer constructions under uniaxial and biaxial (in-plane/out-of-plane) loading conditions as typically experienced by aircraft crown fuselage panels. The specimens for all tests were identical and consisted of a tapered composite flange, representing a stringer or frame, bonded onto a composite skin. Tests were performed under monotonic loading conditions in tension, three-point bending, and combined tension/bending to evaluate the debonding mechanisms between the skin and the bonded stringer. For combined tension/bending testing, a unique servohydraulic load frame was used that was capable of applying both in-plane tension and out-of-plane bending loads simultaneously. Specimen edges were examined on the microscope to document the damage occurrence and to identify typical damage patterns. The observations showed that, for all three load cases, failure initiated in the flange, near the flange tip, causing the flange to almost fully debond from the skin.

A two-dimensional plane-strain finite element model was developed to analyze the different test cases using a geometrically nonlinear solution. For all three loading conditions, principal stresses exceeded the transverse strength of the material in the flange area. Additionally, delaminations of various lengths were simulated in two locations where delaminations were observed. The analyses showed that unstable delamination propagation is likely to occur in one location at the loads corresponding to matrix ply crack initiation for all three load cases. However, the current two-dimensional plane-strain finite element model may not fully account for the
\end{abstract}


complex three-dimensional damage pattern observed. A detailed investigation of this damage pattern may require a local three-dimensional analysis of the damaged area.

\section{KEY WORDS}

Composite materials, testing, finite element analysis, fracture mechanics, skin/flange interface, secondary bonding.

\section{INTRODUCTION}

Carbon epoxy composite structures are widely used by today's aircraft manufacturers to reduce weight. Co-curing, co-bonding, and secondary bonding have become the most promising processes to replace traditional mechanical fastening methods. Composite materials have been introduced fairly recently into primary structures of commercial airplanes. The failure processes in composites are not as well understood as in metals. Previous investigations of the failure of secondary bonded structures were conducted with specimens cut from a full-size panel to verify the integrity of the bondline between the skin and the flange or frame [1]. However, these panels were rather expensive to produce and there was a need for a test configuration that would allow detailed observations of the failure mechanism at the skin/flange interface. A simpler specimen configuration was proposed in reference 2 with the investigations focusing on the failure mechanisms of a bonded skin/flange configuration loaded in bending and transverse shear [2-5]. These loading conditions may be appropriate for a variety of applications, but in many cases composite structures may experience both bending and membrane loads during in-flight service. The failure mechanisms under multi-axial loading may be complex in that they do not represent a simple combination of the various load components but involve interaction between the loads.

The first objective of this work was to investigate the damage mechanisms in composite bonded skin/stringer structures under monotonic tension, three-point bending, and combined tension/bending loading conditions. For combined tension/bending testing, a unique servohydraulic load frame was used that was capable of applying axial tension and transverse bending loads simultaneously [6,7]. Microscopic investigations of the specimen edges were performed to document the damage occurrence and to identify typical damage patterns.

The second objective of this work was to develop an analytical methodology to accurately predict the damage observed during the experiments. All three load cases were analyzed using a detailed two-dimensional plane-strain finite element model. Both linear and geometrically nonlinear simulations were performed. A stress analysis was used to predict the location and orientation of 
the first transverse crack based on the principal transverse tension stress distribution in the flange tip area. A fracture mechanics approach was utilized to determine when a delamination would grow from this transverse crack. Mode I and mode II strain energy release rate contributions, $G_{\mathrm{I}}$ and $G_{\Pi}$, were calculated for all load cases using the virtual crack closure technique $[8,9]$ and compared to existing mixed-mode fracture toughness data.

\section{EXPERIMENTAL INVESTIGATION}

\section{MATERIALS AND SPECIMEN PREPARATION}

The specimens tested in this investigation consisted of a bonded skin and flange assembly as shown in Figure 1. All specimens were machined from the same panels and were similar to the specimens used in the previous monotonic and fatigue tests reported in references 2 through 5 . Both the skin and the flange laminates had a multidirectional lay-up. The skin lay-up, consisting of 14 plies, was [0/45/90/-45/45/-45/0] and the flange lay-up, consisting of 10 plies, was [45/90/$45 / 0 / 90]_{s}$.

Both skin and flange were made from IM6/3501-6 graphite/epoxy prepreg tape with a nominal ply thickness of $0.188 \mathrm{~mm}$. First, the flange and skin laminates were cured separately. The flange parts were then cut into $50.0 \mathrm{~mm}$ long strips. A previous investigation had indicated that the angle at the flange tip has a significant influence on the strength [2]. A $20^{\circ}$ taper angle was suggested in a previous investigation, however, a $27^{\circ}$ taper was machined along the edges. Subsequently, the flange was adhesively bonded to the skin using a $177^{\circ} \mathrm{C}$ cure film adhesive from American Cyanamid (CYTEC 1515). A grade-5 film was used to yield a nominally $0.127-\mathrm{mm}$ thick bondline. However, because some of the adhesive flowed outwards during cure, the bondline thickness averaged $0.102 \mathrm{~mm}$. A diamond saw was used to cut the panels into 25.4-mm wide by $203.2-\mathrm{mm}$ long specimens (the specimen length is the only difference to specimens used in previous studies $[2,3,5]$ which were $127.0 \mathrm{~mm}$ long). Each specimen was then equipped with two strain gages, one located in the center of the flange and the other located on the skin as close to the flange tip as possible (Figure 1). Ply properties and adhesive material properties were measured at Boeing and are part of the standard design database for the V-22 tiltrotor aircraft. Typical material properties for the composite tape and the adhesive material as taken from reference 2 are summarized in Table 1. 


\section{EXPERIMENTAL PROCEDURE}

A total of five tension tests were performed in a servohydraulic load frame in displacement control. The actuator speed was controlled at $0.4 \mathrm{~mm} / \mathrm{min}$. The specimens were mounted in hydraulic grips to give a gage length of $127.0 \mathrm{~mm}$ as shown in Figure 2. An extensometer with a $25.4 \mathrm{~mm}$ gage length was mounted on the backside of the specimen and centered on the flange tip as shown in Figure 2. The tests were terminated when the flange debonded unstably from one of the flange tips.

Five bending tests were performed in a servohydraulic load frame at a monotonic rate of $1.52 \mathrm{~mm} / \mathrm{min}$. A photograph of the three-point bending test fixture is shown in Figure 3 . The configuration used was similar to the one used in previous studies $[2,5]$. The bottom support had a $127.0 \mathrm{~mm}$ span. Mid-span deflections were recorded using a spring loaded direct current displacement transducer (DCDT) contacting the center of the flange as shown in Figure 3. The tests were stopped after the flange debonded unstably to the center of the specimen.

Tests under combined membrane and bending loading conditions were performed in the axial tension and bending (ATB) servohydraulic load frame shown in Figure 4. In this ATB load frame designed at the NASA Langley Research Center, the axial load cell is incorporated in the top grip that rotates with the upper specimen part (see close-up in Figure 5) [6, 7]. The specimens were mounted into the machine with great care placed on correct alignment of the specimen and the top grip/load cell set-up. The specimens were initially preloaded in load control to an axial tension load of $17.8 \mathrm{kN}$, which is $85 \%$ of the average damage initiation load determined for the tension test. While maintaining this preload, a transverse bending load was then applied in displacement control until flange debonding occurred. Maximum specimen deflections at the top grip contact point were recorded using a spring loaded linear variable differential transformer (LVDT).

The first specimen was tested with a gage length of $127.0 \mathrm{~mm}$. The transverse load was applied at a constant rate of $1.52 \mathrm{~mm} / \mathrm{min}$ (in accordance with three-point bending tests). As the stroke was increased, the specimen failed near the lower grip without evidence of flange debonding. As a result, the gage length was reduced to $101.6 \mathrm{~mm}$ for the four remaining specimens. The shortening allowed the lower flange tip to be closer to the bottom grip which increased the bending moment at the lower flange tip so that flange debonding occurred before skin failure. The transverse displacement rate was tripled to $4.57 \mathrm{~mm} / \mathrm{min}$ to reduce testing time caused by the large specimen deflections necessary for damage initiation. 


\section{TEST RESULTS}

In Figures 6 to 11, typical results of each test are shown as plots of load versus displacement or strain versus load. For each loading configuration, the plots of load versus displacement and strain are from the same specimen. The strain-load curves are shown for flange strain and skin strain. The loads, flange and skin strains are reported in Tables 2 and 3 (tension and three-point bending tests) for the point of possible damage initiation as well as for the flange debond load. In Table 4 (ATB tests), the results are presented for the flange debond load only, since no damage initiation prior to failure was observed in these tests.

For tension specimens, the load-displacement curves were slightly nonlinear over a wide range as shown in Figure 6. Possible damage initiation was assumed when a small initial load drop was observed prior to flange debonding. At this point, a crack in one flange tip or even a small delamination along one flange corner was observed. In one specimen, no initial load drop or visible damage could be detected prior to flange debond. In general, the initial load drop occurred above $90 \%$ of the flange debond load. Figure 7 shows the slightly nonlinear strain-load response until flange debonding. In all specimens, a load drop was also accompanied by a decrease in strain.

Typical plots for the three-point bending tests are shown in Figures 8 and 9. The load versus mid-span deflection curves of all three-point bending specimens showed nonlinear behavior at higher loads indicating possible damage initiation. Sometimes this behavior was accompanied by a minor load decrease (see Figure 8). However, no cracks or delaminations could be observed prior to ultimate flange failure. In all specimens, the nonlinearity or initial load decrease was again detected above $90 \%$ of the flange debond load. Both skin and flange strains showed linear behavior before flange debonding (see Figure 9). No decrease in load or strain was observed on the strain-load response prior to flange debonding.

In contrast to tension and three-point bending tests, the transverse load versus transverse displacement curves obtained from the ATB tests showed no indication of damage formation until just prior to skin failure for all specimens. Flange debonding could not be identified from these plots. A typical example is shown in Figure 10. Figure 11 shows a characteristic strain versus transverse load response starting from the strain caused by the axial load. Although Figure 11 shows linear behavior, the strain curves in some specimens deviated slightly from linearity prior to flange debonding. Flange debonding as detected during the experiments always occurred at maximum flange strain and was sometimes accompanied by a drop in skin strain. 


\section{MICROSCOPIC INVESTIGATION}

Photographs of the polished specimen edges were taken under a light microscope after testing was completed to document the occurrence of matrix cracks and delaminations. Damage was documented based on location at each of the four flange corners identified in Figure 12. Corners 1 and 4 and corners 2 and 3 had identical damage patterns. Typical damage patterns which were similar for all three loading configurations are shown in Figure 13. These drawings are based on the micrographs taken after the tests. Figure 14 presents two such photomicrographs for a three-point bending specimen. In general, failure in tension and three-point bending specimens occurred on one flange tip only, with no clear preference for either flange tip. Due to the moment distribution resulting from the loading and boundary conditions of the ATB test, failure in the ATB specimens occurred at the flange tip with the higher bending moment only, i.e., the flange tip closer to the lower grip.

At corners 1 and 4, a delamination running in the $90^{\circ} / 45^{\circ}$ flange ply interface (delamination A) initiated from a matrix crack in the $90^{\circ}$ flange ply as shown in Figure 13(a). At longer delamination lengths, new matrix cracks formed and branched into both the lower $45^{\circ}$ as well as the upper $90^{\circ}$ flange ply. However, no branching into the adhesive bondline was observed.

At corners 2 and 3 a matrix crack formed at the flange tip in the $90^{\circ}$ flange ply that subsequently ran through the lower $45^{\circ}$ flange ply and the bondline into the skin. Subsequently, a split (delamination B1) formed from the tip of that matrix crack within the top $0^{\circ}$ skin ply as depicted in Figure 13(b). In some cases, a second delamination (delamination B2) was observed below the first in the top $0^{\circ} / 45^{\circ}$ skin ply interface. Both delaminations were present over a long distance until delamination B1 stopped and delamination B2 continued.

\section{ANALYTICAL INVESTIGATION}

\section{FINITE ELEMENT ANALYSIS}

The finite element (FE) method was used to analyze the test specimens for each loading case. The goal of this investigation was to study damage initiation using a stress analysis and the potential for delamination propagation using a fracture mechanics approach. FE models for one undamaged and two damaged specimens were developed and loads and boundary conditions were applied to simulate the three load cases. The two-dimensional cross section of the specimens was modeled using eight-noded quadrilateral plane strain elements using quadratic shape functions and a reduced $(2 \times 2)$ integration scheme. The models are shown in Figures 15 and 16. For the entire investigation, the ABAQUS geometric nonlinear analysis procedure was used. For the tension and 
three-point bending loading cases, the results of linear analyses were compared to those of nonlinear analyses. For the ATB test, only the ABAQUS nonlinear solution was used since this allowed the axial load to rotate with the specimen as it deformed under the transverse load and accounted for the membrane stiffening effect caused by the axial load.

For the model of the undamaged specimen, a refined mesh was used in the critical area of the $90^{\circ}$ flange ply where cracking was observed in the test specimens. An outline and two detailed views of the mesh are shown in Figure 15. Outside the mesh refinement area, all plies were modeled with one element through the ply thickness. In the refined region, two elements were used per ply thickness except for the first three individual flange plies above the bondline and the skin ply below the bondline which were modeled with four elements. Three elements through the thickness were used for the adhesive film. The model consisted of 6492 elements and 19975 nodes and had 39888 degrees of freedom. The properties used to simulate the behavior of the graphite/epoxy material and the adhesive were measured at Boeing and are part of the standard design database for the V-22 tilt-rotor aircraft. Typical properties as taken from reference 2 are summarized in Table 1.

Based upon the experimental observations shown in Figures 13 and 14, a "damaged" model was also developed that included discrete matrix cracks and delaminations. The mesh described for the undamaged specimen was also used for this model, except for the critical area around the flange tip where delaminations were modeled as shown in Figure 16 (a) for corners 1 and 4 and Figure 16 (b) for corners 2 and 3. The initial matrix crack was modeled perpendicular to the flange taper. Damage was modeled at one flange tip only as shown in Figure 16. At the opposite taper, the mesh used in the model of the undamaged specimen was employed. This procedure was used to simulate the occurrence of damage onset only. In order to keep the FE mesh simple and avoid skewed elements, the split in the $0^{\circ}$ ply (marked as "Delamination B1" in Figures 13 (b) and 14 (b)) was modeled as a delamination propagating between the adhesive film and the top $0^{\circ}$ ply of the skin (Figure 16 (b)). It is assumed that this slight alteration in geometry does not significantly influence the computed energy release rates. For the prediction of delamination growth, the fracture toughness values obtained from standard specimens with unidirectional layup were used as described below. It is inherent to a two dimensional plane strain FE model that the geometry, boundary conditions and other properties are constant through the entire width. This may not always capture the true nature of the problem. As shown in Figures 13 and 14, the delamination pattern changed from corner 3 to corner 4 from a delamination running in the $90^{\circ} / 45^{\circ}$ interface to a delamination propagating between the adhesive film and the top $0^{\circ}$ ply of the skin. This three dimensional effect can not be accounted for in the current model.

The schematics of the specimen, boundary conditions, and load cases applied in the simulations are shown in Figure 17 for the tension and three-point bending cases and in Figure 18 
for the combined tension and bending case. For the tension and bending case, the mean loads reported for the point of damage initiation in Tables 2 and 3 were applied. At this point, matrix cracks are likely to form. For the simulation of the combined tension and bending loads in the ATB test, the top grip, the load cell, and the load pin were also modeled using three-noded quadratic beam elements as shown in Figure 18. A rectangular beam cross section was selected to model the square cross section of the top grip and load pin and a circular beam cross section was used for the model of the cylindrical load cell. The beams were connected to the two-dimensional plane strain model of the specimen using multi-point constraints to enforce appropriate translations and rotations. As shown in Figure 18, nodes 1-29 along the edge of the plane strain model were constrained to move as a plane with the same rotation as beam node $A$. To be consistent with the ATB tests, a constant axial load, $P$, was applied in a first load step while transverse loads remained zero. In a second load step, the axial load was kept constant while the load orientation rotated with the specimen as it deformed under the transverse load. In the FE simulation this transverse load was applied as a prescribed displacement which corresponded to the mean of the transverse stroke $(31 \mathrm{~mm}$ ) reported in Table 4. For the beam model of the steel parts (top grip, load cell, and load pin), a Young's Modulus of $210 \mathrm{GPa}$ and a Poisson's Ratio of 0.3 were used as material input data.

The Virtual Crack Closure Technique (VCCT) described in references 8 and 9 was used to calculate strain energy release rates for the delaminations. The mode I and mode II components of the strain energy release rate, $G_{\mathrm{I}}$ and $G_{\mathrm{I}}$, were calculated as

$$
G_{\mathrm{I}}=-\frac{1}{2 \Delta a}\left[Y_{\mathrm{i}}^{\prime}\left(v_{\mathrm{m}}^{\prime}-v_{\mathrm{m}}^{\prime}\right)+Y_{\mathrm{j}}^{\prime}\left(v_{1}^{\prime}-v_{1^{*}}^{\prime}\right)\right]
$$

and

$$
G_{\mathrm{II}}=-\frac{1}{2 \Delta a}\left[X_{\mathrm{i}}^{\prime}\left(u_{\mathrm{m}}^{\prime}-u_{\mathrm{m}^{*}}^{\prime}\right)+X_{\mathrm{j}}^{\prime}\left(u_{1}^{\prime}-u_{1^{*}}^{\prime}\right)\right]
$$

where $\Delta a$ is the length of the elements at the crack tip, $\mathrm{X}_{\mathrm{i}}{ }^{\prime}$ and $\mathrm{Y}_{\mathrm{i}}{ }^{\prime}$ are the forces at the delamination tip at node $i$, and $\mathrm{u}_{\mathrm{m}}{ }^{\prime}$ and $\mathrm{v}_{\mathrm{m}}{ }^{\prime}$ are the relative displacements at the corresponding node $\mathrm{m}$ behind the delamination tip as shown in Figure 19. Similar definitions are applicable for the forces at node $\mathbf{j}$ and displacements at node 1. Both forces and displacements were transformed into a local coordinate system $\left(x^{\prime}, y^{\prime}\right)$, that defined the normal and tangential coordinate directions at the delamination tip in the deformed configuration. The total strain energy release rate, $G_{\mathrm{T}}$, was obtained by summing the individual mode components as

$$
G_{\mathrm{T}}=G_{\mathrm{I}}+G_{\mathrm{II}} .
$$


The mode III component is zero for the plane strain case. The data required to perform the VCCT in equations (1) to (3) were accessed from the ABAQUS result file. The calculations were performed in a separate post processing step using nodal displacements and nodal forces at the local elements in the vicinity of the delamination front.

\section{ANALYSIS RESULTS}

\section{Global Response}

First, the global response of the specimens was computed at load levels corresponding to the damage initiation loads observed in the experiments. The load-displacement and the load-strain behavior computed for all three load cases were compared to the corresponding experimental results. This global response was used to examine whether the FE model, the boundary conditions, the load cases and the material properties used in the model were accurate. Note that the experimental data only represent one typical specimen, thus not accounting for any experimental scatter. Displacements were reported at the locations where they were taken in the experiments. Strains were computed at a single location corresponding to the center of the strain gage. A schematic of the deformed geometries, the boundary conditions, and the load cases applied in the simulations are shown in Figure 20 for all three load cases.

In the schematic of the deformed FE tension model in Figure 20(a), the elongation of the specimen caused by the applied tensile load is shown along with the bending effect caused by the load eccentricity. The load versus displacement plot in Figure 21 shows that the linear and nonlinear FE simulations are in good agreement. Moreover, there is very marginal difference between the analyses and the experiments, the model therefore accurately captured the global response. In Figure 22, a comparison of measured strains and computed results is shown. The strain-load responses for the skin are again in good agreement between the experiments and both analyses. For the flange strains the nonlinear analysis yielded results which were in agreement with the experiments. Strains obtained from the linear analysis were very low. Hence, a geometrically nonlinear FE analysis is necessary to account for the effects due to the load eccentricity in the flange region, the asymmetric layup with respect to the neutral axis and the membrane stiffening effect.

In the three-point bending test, the vertical displacement at the flange tip (Figure 3) was of the order of the skin thickness for the load level investigated. Hence, a geometrically nonlinear FE solution procedure may also be needed in this case. Both linear and nonlinear analyses were performed and computed displacements and strains were compared. The load-displacement plot in Figure 23 and the strain-load plot in Figure 24 show that both simulations and the experiments are 
within $10 \%$ of each other. Since the linear and nonlinear analyses are within $1 \%$, a linear analysis is sufficient for the load level investigated, i.e., the mean load obtained form experiments for damage initiation. Higher load levels, however, might require a nonlinear analysis.

For the tension/bending loading case the load-displacement and strain-load plots in Figures 25 and 26 show that the nonlinear FE simulation and the experiments are within $20 \%$ of each other. A possible explanation for the stiffer response of the numerical model based on the difference in axial modulus measured in tension and bending is given in the appendix.

\section{Local Response}

The local response was studied in the critical area of the $90^{\circ}$ flange ply where cracking was observed in the experiments. The goal of these FE analyses was to investigate damage initiation using a stress analysis and the potential for delamination propagation using a fracture mechanics approach.

The stress analysis was used to study the initial failure in the form of matrix cracks from which delaminations may start to grow. As shown in Figures 13 and 14, the first crack always occurred in the $90^{\circ}$ flange ply closest to the skin. Results from previous investigations [2, 3] suggested that the local force and moment resultants, may be used to characterize damage onset. As shown in Figure 27, force and moment resultants per unit width were calculated from the normal stress $\sigma_{x x}$ at the flange tip. Resultants were computed for damage initiation and flange debond load level based on stresses obtained from linear and nonlinear FE analyses. Results plotted in Figure 28 show that the three-point bending test is free of axial tension as the force resultants $N_{\mathrm{xx}}$ are zero as expected. A bending moment is present in the tension specimen caused by the load eccentricity in the flange region and the asymmetric layup of the combined skin and flange laminate with respect to the neutral axis. For the ATB test, calculated force and moment resultants lie between computed pure tension and pure bending values.

Earlier investigations [2,3] also indicated that the maximum ply principal transverse tensile stress may cause the initial failure in the form of matrix cracks from which delaminations may start to grow. Failure, therefore, may occur when the computed principal tensile stress in the 2-3 plane of the ply (normal to the fiber direction) exceeds the transverse tensile strength of this ply. In this model, the ply 2-3 plane for a $90^{\circ}$ ply coincides with the global x-y plane of the model. Maximum principal stresses can therefore be taken straight from the finite element results. The vector plot in Figure 29 shows the trajectories of the maximum principle tensile stresses in the flange ply. At the $-45^{\circ} / 90^{\circ}$ and $90^{\circ} / 45^{\circ}$ interface, multiple vectors are displayed since the stresses were not averaged across boundaries for elements with different material properties. Comparing the trajectories in 
Figure 29 with the damage patterns shown in Figures 13 and 14 shows that the crack starts to grow perpendicular to the trajectory of the maximum principle tension stress. Computed maximum principal tension stresses $\sigma_{\max }$ in the elements with labeled element numbers in the $90^{\circ}$ ply in Figure 29 are presented in Table 5 and compared in Figure 30. For all three loading conditions, maximum principal tensile stresses computed for the damage initiation load level have similar magnitudes. Towards the center of the ply, principal stresses exceeded the failure strength of 61.1 MPa as found for a similar type of material (AS4/3501-6 in [10]) and hence ply cracks may develop. Consequently, the stress analysis based on the comparison of computed stresses with failure strengths appears to be an appropriate method to determine the location of the initial failure and the orientation of the resulting crack.

A fracture mechanics approach was used to investigate delamination growth once the initial crack had formed. It had been shown that care must be exercised in interpreting the values for $G_{\text {I }}$ and $G_{\text {II }}$ obtained using the virtual crack closure technique for interfacial cracks between two orthotropic solids [11]. Therefore, it had been suggested to use element lengths $\Delta a$ at the crack tip in such a manner that the computed results are insensitive to the variation of $\Delta a$. For practical applications the element size (length and height) should not be less than $1 / 10$ of a ply thickness because the assumption that each ply can be modeled as a continuum is no longer valid. The element size at the crack tip also should not exceed the ply thickness as this requires smearing properties of individual plies. For the current investigation, the element length $\Delta a$ was chosen to be $1 / 4$ of the ply thickness for the delamination in the $90^{\circ} / 45^{\circ}$ flange ply interface and $1 / 3$ of the bondline thickness for the simulated propagation along the $0^{\circ}$ skin ply/adhesive film interface.

The initial crack was modeled on one flange tip perpendicular to the flange taper as suggested by the microscopic investigation and the stress analysis described in the previous paragraph. Recall that the models of the discrete cracks and delaminations are shown in Figure 16. During the analyses, the delaminations were extended by adding new nodes at the crack tip and in front of the crack tip. These nodes were then assigned to the elements on one side of the crack thus creating a row of disconnected elements which simulated the delamination. Strain energy release rates were computed at each tip location for the flange debond load observed in the experiment. The delamination lengths, $a$, are measured from the end of the initial matrix crack as shown in Figure 16 . For corners 1 and 4 (delamination in the $90^{\circ} / 45^{\circ}$ flange ply interface), the delamination was extended to $0.6 \mathrm{~mm}$ which corresponds to a length where matrix crack branches were observed in the experiments as shown in Figures 13(a) and 14(a). The results are plotted in Figures 31 through 33 for all three loading conditions. Initial mode I and mode II values, computed at delamination onset ( $a=0.034 \mathrm{~mm}$, i.e., delamination length equal to the length of the first element as shown in Figure 16(a)), are similar for each type of test as shown in Table 6. 
In Figures 31 through $33, G_{\text {II }}$ for all load cases increases monotonically while $G_{\mathrm{I}}$ begins to level off. Computed mixed mode ratios $\mathrm{G}_{\mathrm{II}} / \mathrm{G}_{\mathrm{T}}$ for all the load cases are shown in Figure 34 .

For the simulated propagation along the $0^{\circ}$ skin ply/adhesive film interface (corners 2 and 3 ) the delamination was extended to $1.6 \mathrm{~mm}$. Plots of strain energy release rates computed for various delamination lengths are given in Figures 35 through 37 . The computed values at delamination onset ( $a=0.04 \mathrm{~mm}$, i.e., delamination length equal to the length of the first element as shown in Figure 16(b)) are given in Table 7. Comparing all load cases, computed $G_{\text {I }}$ results appear to have similar magnitudes. Mode II values, however, differ noticeably. As shown in Figures 35 through 37 , at $a<0.2 \mathrm{~mm}$ the mode I contribution decreases with increasing delamination length. The mode II contribution and the total strain energy release rate, however, increase with increasing delamination length. For $a>0.2 \mathrm{~mm}$, the mode I contribution and the total strain energy release rate increase slowly with increasing delamination length for the bending load case mode and decrease slowly for the pure tension and the combined tension/bending load case. For all three load cases, the mode II contribution continues to increase at a much slower rate with increasing delamination length. Corresponding mixed mode ratios $\mathrm{G}_{\mathrm{I}} / \mathrm{G}_{\mathrm{T}}$ are shown in Figure 38. The results discussed above will be used in a mixed-mode failure investigation to determine whether delamination onset and unstable propagation are possible at the applied loads where damage was observed in the experiments.

\section{MIXED-MODE FAILURE INVESTIGATION}

Accurate mixed-mode failure criteria are necessary for the prediction of delamination growth. A bilinear mixed-mode failure criterion was suggested in reference 12 for AS4/3501-6, a material similar to IM6/3501-6. The mixed-mode failure response was presented by plotting the mode I component of the mixed-mode fracture toughness versus the respective mode II component. A different approach to present the data was suggested in reference 13 where mixed-mode fracture toughness values, $G_{\mathrm{c}}$, were plotted versus the mixed mode ratio $G_{\mathrm{II}} / G_{\mathrm{T}}$ (see Figure 39$)$. When this ratio is zero, $G_{\mathrm{c}}$ is simply the mode I fracture toughness, $G_{\mathrm{Ic}}$. Alternatively, $G_{\mathrm{c}}$ becomes the mode II fracture toughness, $G_{\text {IIc }}$, when the mixed-mode ratio equals unity. An equation resulting from a least square regression cubic curve fit to these data defines the mixed-mode delamination fracture criterion for each ratio as:

$$
G_{\mathrm{c}}=75.3+214.7 \cdot\left(\frac{G_{\mathrm{II}}}{G_{\mathrm{T}}}\right)-70.5 \cdot\left(\frac{G_{\mathrm{II}}}{G_{\mathrm{T}}}\right)^{2}+327.4 \cdot\left(\frac{G_{\mathrm{II}}}{G_{\mathrm{T}}}\right)^{3}
$$


Hence, for a given mixed-mode ratio, growth is possible when the total mixed-mode strain energy release rate exceeds the critical value.

In the current study, computed total strain energy release rates, $G_{\mathrm{T}}$, were compared to the critical value, $G_{\mathrm{c}}$, for the appropriate mixed mode ratio $\left(G_{\mathrm{II}} / G_{\mathrm{T}}\right)$ for each load case in order to determine the potential for delamination growth. Values calculated for delamination onset ( $a=0.034 \mathrm{~mm}$, i.e., delamination length equal to the length of the first element as shown in Figure $16(\mathrm{a})$ ) in the $90^{\circ} / 45^{\circ}$ flange ply interface are below the fracture toughness data as shown in Table 6 and Figure 40. Consequently, onset is unlikely to occur at the load corresponding to damage initiation for all three tests. Propagation in the $0^{\circ}$ skin ply/adhesive film interface, on the other hand, will occur in all three cases as the computed results for delamination onset ( $a=0.04 \mathrm{~mm}$, i.e., delamination length equal to the length of the first element as shown in Figure 16(b))_are much higher than the reported fracture toughness values as shown in Table 7 and Figure 41. It is important to recall that in the experiments the failure was observed as a split in the $0^{\circ}$ ply as shown in Figures 13 (b) and 14 (b). This failure was modeled as a delamination propagating between the adhesive film and the top $0^{\circ}$ ply of the skin as shown in Figure 16 (b) only in order to avoid skewed elements. Hence, for predicting growth of the split in the $0^{\circ}$ ply it is appropriate to compare energy release rates computed for the $0^{\circ}$ skin ply/adhesive film interface with fracture toughness values obtained from standard tests. Unstable propagation is likely since the calculated $G_{\mathrm{T}}$-values remain above the mixed-mode fracture toughnesses over the entire simulated length as shown in Figures 35 to 37 . This assumption is confirmed by the experimental results of this study.

The above findings suggest that once a matrix crack has formed, a delamination (delamination B1 from Figure 14) will also form and grow in an unstable manner between the adhesive film and the top $0^{\circ}$ skin ply. The second delamination observed in the $90^{\circ} / 45^{\circ}$ flange ply interface (delamination A from Figure 14) requires more energy to initiate than available at the load levels used in this FE analysis, i.e., the loads corresponding to possible matrix ply crack initiation. The energy for this second delamination may come from an increase in load or may be caused by an increase in $G_{\mathrm{T}}$ due to the presence of the first delamination in the $0^{\circ}$ skin ply/adhesive film interface. These two possibilities are studied in detail in the following paragraphs. The response of the numerical model with respect to the difference in axial moduli measured in tension and bending is discussed in the appendix at the end of the paper. This discussion includes the effect of a lowered axial modulus on computed strain energy release rates for specimens subjected to bending and combined tension/bending loading.

First, strain energy release rates were calculated at the flange debond load observed in the experiment. Results for the second delamination in the $90^{\circ} / 45^{\circ}$ flange ply interface are shown in 
Figure 42 and are included in Table 6. Strain energy release rates are higher, however, they still remain below the fracture toughness. This suggests that delamination growth is unlikely.

Second, the possibility of an increase in $G_{\mathrm{T}}$ due to the presence of the first delamination was investigated. On one flange side a delamination of $10 \mathrm{~mm}$ was simulated between the adhesive film and the top $0^{\circ}$ skin ply as an initial disbond. This length was kept constant during the remainder of the investigation. At the opposite taper, the delamination in the $90^{\circ} / 45^{\circ}$ flange ply interface was modeled as described in the previous paragraph. The model is shown in Figure 43. Again, the second delamination was extended to $0.6 \mathrm{~mm}$ which corresponds to a length where matrix crack branches were observed in the experiments. The total strain energy release rates computed at loads corresponding to possible damage initiation are plotted in Figure 44 for all three loading cases. The values computed previously for the condition without the assumed initial disbond $\left(G_{\mathrm{T}}\right.$ from Figures 31 through 33 ) were included in Figure 44 for comparison. For both conditions, $G_{\mathrm{T}}$ increases monotonically with growing delamination length. For the tension and combined tension/bending load case computed values are smaller for the condition where delamination formation was assumed between the adhesive film and the top $0^{\circ}$ skin ply. The computed values at delamination onset $(a=0.034 \mathrm{~mm}$, i.e., delamination length equal to the length of the first element as seen in Figure 43) are shown in Figure 45 for delamination onset and flange debond load. Values for both load levels are again below the fracture toughness data, which suggests that delamination growth in the $90^{\circ} / 45^{\circ}$ flange ply interface is also unlikely in the presence of a $10 \mathrm{~mm}$ long delamination in the $0^{\circ}$ skin ply/adhesive film interface. Based upon this study it can be concluded that delamination growth in the $90^{\circ} / 45^{\circ}$ flange ply interface cannot be explained using strain energy release rates based on two dimensional plane strain FE analyses. The observed three-dimensional delamination pattern seen in the specimens could not be accounted for with the current model. A detailed and more accurate investigation should include a local three-dimensional analysis of the delaminated area.

\section{CONCLUDING REMARKS}

The damage mechanisms in composite bonded skin/stringer constructions under uniaxial and biaxial (in-plane/out-of-plane) loading conditions have been investigated using experimental and numerical approaches. Tests were performed under monotonic loading conditions in tension, three-point bending, and combined tension/bending to evaluate the debonding mechanisms between the skin and the bonded stringer or frame. Microscopic investigations of the specimen edges showed that all tests yielded similar damage patterns. For all three load cases, failure initiated in the flange, near the flange tip, causing part of the flange to fully debond from the skin. 
Based upon the experimental findings, a two-dimensional nonlinear plane-strain finite element (FE) analysis was performed using the ABAQUS FE code. For tension and three-point bending tests, linear and geometrically nonlinear simulations were performed. Overall, both computed results were found to be in good agreement with the experimental data. To account for the large displacements observed in the ATB tests, only the geometrically nonlinear analysis was performed. Again, the results were in good agreement with the experiments.

A stress analysis was used to investigate the onset of failure. This approach showed that the location and orientation of the initial transverse ply crack in the flange are dependent on the stress distribution in the critical area near the flange tip. For all three loading conditions, computed maximum principal tensile stresses were almost identical and exceeded the transverse tension strength of the material. A fracture mechanics approach was used to determine the potential for delamination growth from the initial transverse crack. In this approach, delaminations of various lengths originating from the transverse crack as observed in the experiments were simulated. Mode I and mode II strain energy release rate contributions were calculated for all load cases using the virtual crack closure technique. Computed total strain energy release rates were compared to critical values obtained from an existing mixed-mode failure criterion. The results suggest that once a matrix ply crack has initiated in the flange, a delamination will form and grow in an unstable manner between the adhesive film and the top $0^{\circ}$ skin ply as observed in the micrographs. A second delamination located in the $90^{\circ} / 45^{\circ}$ flange ply interface requires more energy to initiate than was computed to be available at loads corresponding to possible damage initiation. Strain energy release rates calculated at the flange debond load observed in the experiment were higher than the initiation values but still remained below the fracture toughness. Computed values also remained below the fracture toughness data in the presence of a $10 \mathrm{~mm}$ delamination modeled in the $0^{\circ}$ skin

ply/adhesive film interface. Consequently, delamination growth in the $90^{\circ} / 45^{\circ}$ flange ply interface cannot be explained using strain energy release rates computed from a two-dimensional plane strain FE analysis. A detailed and more accurate investigation of the observed complex delamination pattern needs to include a local three-dimensional analysis of the damaged area.

\section{APPENDIX}

In the global response analysis, the load-displacement and the strain-load behavior computed for all three load cases were compared to the corresponding experimental results. For the tension specimen the load versus displacement plot (Figure 21) and the strain versus load plot (Figure 22) show that there is little difference between the nonlinear analyses and the experiment. This also holds for the strain-load responses of the skin and the flange as shown in Figure 22. For 
the three-point bending specimen, the load-displacement plot in Figure 23 and the strain-load plot in Figure 24 show that the simulations and the experiments are within $10 \%$ of each other. The plots in Figures 25 and 26 show that the nonlinear FE simulation and the ATB experiment are within $20 \%$ of each other.

The slightly stiffer response of the numerical model may be explained by the fact that the material data used in the FE simulation originate from the literature. For a consistent simulation, material data should be taken from the batch of material that was used to manufacture the specimens. Furthermore, the figures only represent one specimen of each load case and do not include any experimental scatter. The stiffness difference between the model and the experiments, however, is more pronounced for the bending and ATB test than for tension loading. This could be caused by the fact that the axial modulus, $E_{11}$, was measured in tension and not in bending. As reported in [14], axial moduli depend on the type of test method used. Moduli obtained from bending tests may be up to $20 \%$ lower than moduli from tensile tests. This suggests that tensile moduli should be used for the simulation of tensile dominated problems while flexural moduli should be used when modeling bending problems. Therefore, the effect of a $20 \%$ lower axial modulus on the computed global response and on the strain energy release rates of the specimens subjected to bending and combined tension/bending loads was studied in detail.

\section{EFFECT OF LOWERED AXIAL MODULUS ON THE COMPUTED GLOBAL BEHAVIOR}

The effect of a $20 \%$ lower axial modulus on the global response for the bending and combined tension/bending load case was studied first. The new load-displacement and the strain-load responses were computed and compared to the corresponding experimental and previously computed results. For the three-point bending test, the load versus displacement plot in Figure 46 shows that the nonlinear FE simulations for the two different moduli differ by about $20 \%$ as expected. The results suggest that using the lower modulus yields better agreement with the experiments. In Figure 47, a comparison of measured strains and computed results is shown. The strain-load responses for both skin and flange differ about 20\%. Results obtained from the analyses with the lower axial modulus yield a $10 \%$ higher compliance. Computed results taken from the previous analysis, however, are about $10 \%$ stiffer than the experiments. Based on a comparison of the strain results a decision as to which modulus should be used in a simulation is not possible. For the ATB test, the load-displacement plot in Figure 48 shows that the nonlinear FE simulations for both moduli are almost identical. The strain-load responses for the skin and flange are shown in Figure 49. At the end of the tensile preloading, computed strains are about $20 \%$ higher than the values computed previously and the values measured in the tests. The slope 
during the bending phase of the test is almost identical for both computations and the experiment. Ideally, for the simulation of an ATB test, moduli obtained from tensile and flexural tests should be used for input. The tensile modulus would be used to compute the membrane stiffness terms of the element stiffness matrix while the flexural modulus would be used to determine the flexural stiffness terms.

\section{EFFECT OF LOWERED AXIAL MODULUS ON THE COMPUTED STRAIN ENERGY RELEASE RATES}

For a fracture mechanics investigation it is also essential to know how a $20 \%$ lower axial modulus will affect the computed strain energy release rates of the specimens subjected to bending and combined tension/bending loading. As in the earlier investigations, the delamination in the $90^{\circ} / 45^{\circ}$ flange ply interface was extended to $0.6 \mathrm{~mm}$. For the simulated propagation along the $0^{\circ}$ skin ply/adhesive film interface the delamination was extended to $1.6 \mathrm{~mm}$. For comparison, computed strain energy release rates from the earlier studies were included in the plots. The results for the three-point bending loading case are plotted in Figures 50 and 51. As expected, mode I and mode II values were about $20 \%$ higher in those cases where a $20 \%$ lower axial modulus was used in the simulations. For the ATB load case, plots of computed strain energy release rates with increasing delamination length are given in Figures 52 and 53. Computed mode I and mode II values were typically up to $10 \%$ higher when a $20 \%$ lower modulus was used in the simulations. The increase in the mode I component of the strain energy release rate is less pronounced than in the mode II component. This non-uniform behavior may be explained by the fact that only the axial modulus, $E_{11}$, was modified in the simulations. The computed total strain energy release rates at delamination onset ( $a=0.034 \mathrm{~mm}$, i.e., delamination length equal to the length of the first element) are shown in Figures 54 and 55. Values remain below the fracture toughness data, suggesting that delamination growth in the $90^{\circ} / 45^{\circ}$ flange ply interface is unlikely even if the axial modulus was $20 \%$ lower. Propagation in the $0^{\circ}$ skin ply/adhesive film interface will occur as the computed results are higher than the values computed previously and exceed the reported fracture toughness values.

The study shows that computed strain energy release rates are about $20 \%$ higher if a $20 \%$ lower axial modulus is used in the simulation of structures predominantly subjected to bending. For a combined load case, the increase is less pronounced and computed strain energy release rates are about $10 \%$ higher. These results may be used to estimate the effect of a lowered axial modulus on calculated strain energy release rates without performing additional FE analyses. 


\section{ACKNOWLEDGMENTS}

This work was performed as part of a Cooperative Research and Development Agreement (CRDA) between the U.S. Army Research Laboratory, Vehicle Technology Center located at NASA Langley Research Center, and Boeing, Philadelphia.

\section{REFERENCES}

[1] Minguet, P. J., Fedro, M.J., O'Brien, T. K., Martin, R. H., Ilcewicz, L. B., Awerbuch, J., and Wang, A., "Development of a Structural Test Simulating Pressure Pillowing Effects in a Bonded Skin/Stringer/Frame Configuration," Proceedings, Fourth NASA/DoD Advanced Composites Technology Conference, Salt Lake City, UT, June 1993.

[2] Minguet, P. J. and O'Brien, T. K., "Analysis of Test Methods for Characterizing Skin/Stringer Debonding Failures in Reinforced Composite Panels," Composite Materials: Testing and Design, Twelfth Volume, ASTM STP 1274, August 1996, pp. 105-124.

[3] Minguet, P. J. and O'Brien, T. K., "Analy sis of Composite Skin/Stringer Bond Failures Using a Strain Energy Release Rate Approach," Proceedings of the Tenth International Conference on Composite Materials, Vol. I, Woodhead Publishing Ltd., 1995, pp. 245-252.

[4] Minguet, P. J., "Analysis of the Strength of the Interface between Frame and Skin in a Bonded Composite Fuselage Panel," Proceedings of the 38th AIAA/ASME/ASCE/AHS/ASC SSDM Conference and Exhibit, Kissimmee, Florida, 1997, AIAA-97-1342, pp. 2783-2790.

[5] Cvitkovich, M. K., O'Brien, T. K., and Minguet, P. J., "Fatigue Debonding Characterization in Composite Skin/Stringer Configurations," Composite Materials: Fatigue and Fracture, Seventh Volume, ASTM STP 1330, 1998, pp. 97-121.

[6] O'Brien, T. K., Murri, G. B., Hagemeier, R., and Rogers, C., "Combined Tension and Bending Testing of Tapered Composite Laminates," Applied Composite Materials, 1, 1995, pp. 401-413. 
[7] Murri, G. B., O'Brien, T. K., and Rousseau, C. Q., "Fatigue Life Methodology for Tapered Composite Flexbeam Laminates," Journal of the American Helicopter Society, Vol. 43, (2), April 1998, pp. 146-155.

[8] Rybicki, E. F. and Kanninen, M. F., "A Finite Element Calculation of Stress Intensity Factors by a Modified Crack Closure Integral," Eng. Fracture Mech., 9, 1977, pp. 931-938.

[9] Raju, I. S., "Calculation Of Strain-Energy Release Rates With Higher Order And Singular Finite Elements," Eng. Fracture Mech., 28, 1987, pp. 251-274.

[10] O'Brien, T. K. and Salpekar, S. A., "Scale Effects on the Transverse Tensile Strength of Graphite/Epoxy Composites," Composite Materials: Testing and Design, Eleventh Volume, ASTM STP 1206, 1993, pp. 23-52.

[11] Sun, C. T. and Manoharan, M. G., "Strain Energy Release Rates of an Interfacial Crack Between Two Orthotropic Solids," Journal of Composite Materials, Vol. 23, May 1989, pp. 460-478.

[12] Reeder, J. R., "A Bilinear Failure Criterion for Mixed-Mode Delamination," Composite Materials: Testing and Design, Eleventh Volume, ASTM STP 1206, 1993, pp. 303-322.

[13] O'Brien, T. K., "Composite Interlaminar Shear Fracture Toughness, $G_{\text {IIc: }}$ Shear Measurement or Sheer Myth?," Composite Materials: Fatigue and Fracture, Seventh Volume, ASTM STP 1330, 1998, pp. 3-18.

[14] O'Brien, T. K., Murri, G. B., and Salpekar, S. A., "Interlaminar Shear Fracture Toughness and Fatigue Thresholds for Composite Materials," Composite Materials: Fatigue and Fracture, Second Volume, ASTM STP 1012, 1989, pp. 222-250. 
TABLE 1. MATERIAL PROPERTIES.

\begin{tabular}{|c|c|c|c|c|c|c|}
\hline \multicolumn{7}{|c|}{ IM6/3501-6 Unidirectional Graphite/Epoxy Tape [3] } \\
\hline \multirow{3}{*}{\multicolumn{2}{|c|}{$\begin{array}{c}E_{11}=144.7 \mathrm{GPa} \\
v_{12}=0.30 \\
G_{12}=5.2 \mathrm{GPa}\end{array}$}} & \multirow{3}{*}{\multicolumn{3}{|c|}{$\begin{array}{c}E_{22}=9.65 \mathrm{GPa} \\
v_{13}=0.30 \\
G_{13}=5.2 \mathrm{GPa}\end{array}$}} & \multicolumn{2}{|c|}{$E_{33}=9.65 \mathrm{GPa}$} \\
\hline & & & & & \multicolumn{2}{|c|}{$v_{23}=0.45$} \\
\hline & & & & & \multicolumn{2}{|c|}{$G_{23}=3.4 \mathrm{GPa}$} \\
\hline \multicolumn{7}{|c|}{ CYTEC 1515 Adhesive } \\
\hline \multicolumn{2}{|c|}{$E=1.72 \mathrm{GPa}$} & \multicolumn{3}{|c|}{$v=0.30$} & \multicolumn{2}{|c|}{ (assumed isotropic) } \\
\hline \multicolumn{7}{|c|}{ TABLE 2. RESULTS FOR TENSION TESTS. } \\
\hline Specimen & $\begin{array}{c}\text { Damage } \\
\text { initiation } \\
\text { load } \\
\mathrm{kN}\end{array}$ & $\begin{array}{c}\text { Damage } \\
\text { initiation } \\
\text { flange strain } \\
\mu \varepsilon\end{array}$ & $\begin{array}{c}\text { Damage } \\
\text { initiation } \\
\text { skin strain } \\
\mu \varepsilon \\
\end{array}$ & $\begin{array}{c}\text { Flange } \\
\text { debond } \\
\text { load } \\
\mathrm{kN}\end{array}$ & $\begin{array}{l}\text { Flange strain } \\
\text { at flange } \\
\text { debond load } \\
\mu \varepsilon\end{array}$ & $\begin{array}{l}\text { Skin strain } \\
\text { at flange } \\
\text { debond load } \\
\mu \varepsilon\end{array}$ \\
\hline 2 & 20.5 & 1225 & 5619 & 22.8 & 1348 & 6084 \\
\hline 4 & 21.8 & 1419 & 6312 & 23.6 & 1231 & 6685 \\
\hline 6 & 19.9 & 1185 & 5834 & 23.1 & 1187 & 6599 \\
\hline 8 & 20.9 & 1300 & 6051 & 23.0 & 1115 & 6463 \\
\hline 10 & 21.1 & 1360 & 6092 & 21.1 & 1360 & 6092 \\
\hline Mean & 20.9 & 1298 & 5982 & 22.7 & 1248 & 6385 \\
\hline Std. Dev. & 0.7 & 96 & 264 & 0.9 & 105 & 282 \\
\hline $\mathrm{CoV}, \%$ & 3.3 & 7.4 & 4.4 & 4.2 & 8.4 & 4.4 \\
\hline
\end{tabular}

TABLE 3. RESULTS FOR THREE-POINT BENDING TESTS.

\begin{tabular}{ccccccc}
\hline Specimen & $\begin{array}{c}\text { Damage } \\
\text { initiation } \\
\text { load } \\
\mathrm{kN}\end{array}$ & $\begin{array}{c}\text { Damage } \\
\text { initiation } \\
\text { flange strain } \\
\mu \varepsilon\end{array}$ & $\begin{array}{c}\text { Damage } \\
\text { initiation } \\
\text { skin strain } \\
\mu \varepsilon\end{array}$ & $\begin{array}{c}\text { Flange } \\
\text { debond } \\
\text { load } \\
\mathrm{kN}\end{array}$ & $\begin{array}{c}\text { Flange strain } \\
\text { at flange } \\
\text { debond load } \\
\mu \varepsilon\end{array}$ & $\begin{array}{c}\text { Skin strain } \\
\text { at flange } \\
\text { debond load } \\
\mu \varepsilon\end{array}$ \\
\hline 11 & 404 & 3207 & 3811 & 440 & 3508 & 4160 \\
13 & 433 & 3051 & 3691 & 484 & 3405 & 4110 \\
15 & 445 & 3231 & 3659 & 468 & 3408 & 3868 \\
17 & 425 & 3036 & 3657 & 434 & 3103 & 3701 \\
19 & 431 & 3023 & 3481 & 488 & 3428 & 3945 \\
\hline Mean & 428 & 3110 & 3660 & 463 & 3370 & 3957 \\
Std. Dev. & 14.9 & 101 & 118 & 24.4 & 155 & 186 \\
CoV, \% & 3.5 & 3.2 & 3.2 & 5.3 & 4.6 & 4.7 \\
\hline
\end{tabular}


TABLE 4. RESULTS FOR ATB TESTS.

\begin{tabular}{ccccc}
\hline Specimen & $\begin{array}{c}\text { Flange } \\
\text { debond } \\
\text { load, } \mathrm{kN}\end{array}$ & $\begin{array}{c}\text { Stroke at } \\
\text { flange debond } \\
\text { load, mm }\end{array}$ & $\begin{array}{c}\text { Flange strain at } \\
\text { flange debond } \\
\text { load, } \mu \varepsilon\end{array}$ & $\begin{array}{c}\text { Skin strain at } \\
\text { flange debond } \\
\text { load, } \mu \varepsilon\end{array}$ \\
\hline 12 & 2.8 & 31.6 & 1318 & 7199 \\
14 & - & - & - & - \\
16 & 2.9 & 33.2 & 1232 & 7254 \\
18 & 2.9 & 33.9 & 1276 & 7295 \\
20 & 2.2 & 25.1 & 1278 & 7015 \\
\hline Mean & 2.7 & 31.0 & 1276 & 7191 \\
Std. Dev. & 0.3 & 4.0 & 35 & 124 \\
CoV, $\%$ & 11.6 & 13.0 & 2.8 & 1.7 \\
\hline
\end{tabular}

axial load $=17.8 \mathrm{kN}$

TABLE 5. RESULTS FOR FINITE ELEMENT STRESS ANALYSIS.

\begin{tabular}{ccccc}
\hline Specimen & $\begin{array}{c}\text { Element } 1584 \\
\sigma_{\max }, \mathrm{MPa}\end{array}$ & $\begin{array}{c}\text { Element } 1604 \\
\sigma_{\max }, \mathrm{MPa}\end{array}$ & $\begin{array}{c}\text { Element 1624 } \\
\sigma_{\max }, \mathrm{MPa}\end{array}$ & $\begin{array}{c}\text { Element 1644 } \\
\sigma_{\max }, \mathrm{MPa}\end{array}$ \\
\hline Tension & 51.4 & 70.2 & 87.7 & 100.9 \\
Bending & 46.7 & 62.9 & 78.0 & 89.8 \\
ATB & 65.0 & 93.1 & 119.7 & 139.0 \\
\hline
\end{tabular}

for comparison, transverse tensile strength: 61.1 MPa for AS4/3501-6 [12]

TABLE 6. RESULTS FOR DELAMINATION GROWTH IN $90^{\circ} / 45^{\circ}$ INTERFACE.

\begin{tabular}{cccccc}
\hline Specimen & $G_{\mathrm{I}}, \mathrm{J} / \mathrm{m}^{2}$ & $G_{\mathrm{II}}, \mathrm{J} / \mathrm{m}^{2}$ & $G_{\mathrm{T}}, \mathrm{J} / \mathrm{m}^{2}$ & $G_{\mathrm{II}} / G_{\mathrm{T}}$ & $G_{\mathrm{c}}, \mathrm{J} / \mathrm{m}^{2}$ \\
\hline Tension* & 53.4 & 13.3 & 66.7 & 0.200 & 118 \\
Bending* & 42.4 & 10.2 & 53.0 & 0.200 & 118 \\
Tension $^{+}$ & 63.8 & 15.7 & 79.5 & 0.200 & 118 \\
Bending $^{+}$ & 49.5 & 12.4 & 61.9 & 0.200 & 118 \\
ATB $^{+}$ & 67.3 & 24.1 & 91.4 & 0.260 & 132 \\
\hline
\end{tabular}

* results computed at damage initiation load ${ }^{+}$results computed at flange debond load 
TABLE 7. RESULTS FOR DELAMINATION GROWTH IN FILM/0 INTERFACE.

\begin{tabular}{cccccc}
\hline Specimen & $G_{\mathrm{I}}, \mathrm{J} / \mathrm{m}^{2}$ & $G_{\mathrm{II}}, \mathrm{J} / \mathrm{m}^{2}$ & $G_{\mathrm{T}}, \mathrm{J} / \mathrm{m}^{2}$ & $G_{\mathrm{I}} / G_{\mathrm{T}}$ & $G_{\mathrm{c}}, \mathrm{J} / \mathrm{m}^{2}$ \\
\hline Tension* & 362 & 76.8 & 439 & 0.175 & 112 \\
Bending* & 272 & 39.0 & 311 & 0.125 & 101 \\
Tension $^{+}$ & 467 & 93.1 & 530 & 0.189 & 114 \\
Bending $^{+}$ & 318 & 45.9 & 364 & 0.130 & 103 \\
ATB $^{+}$ & 358 & 191 & 549 & 0.349 & 155 \\
\hline
\end{tabular}

* results computed at damage initiation load $\quad{ }^{+}$results computed at flange debond load 


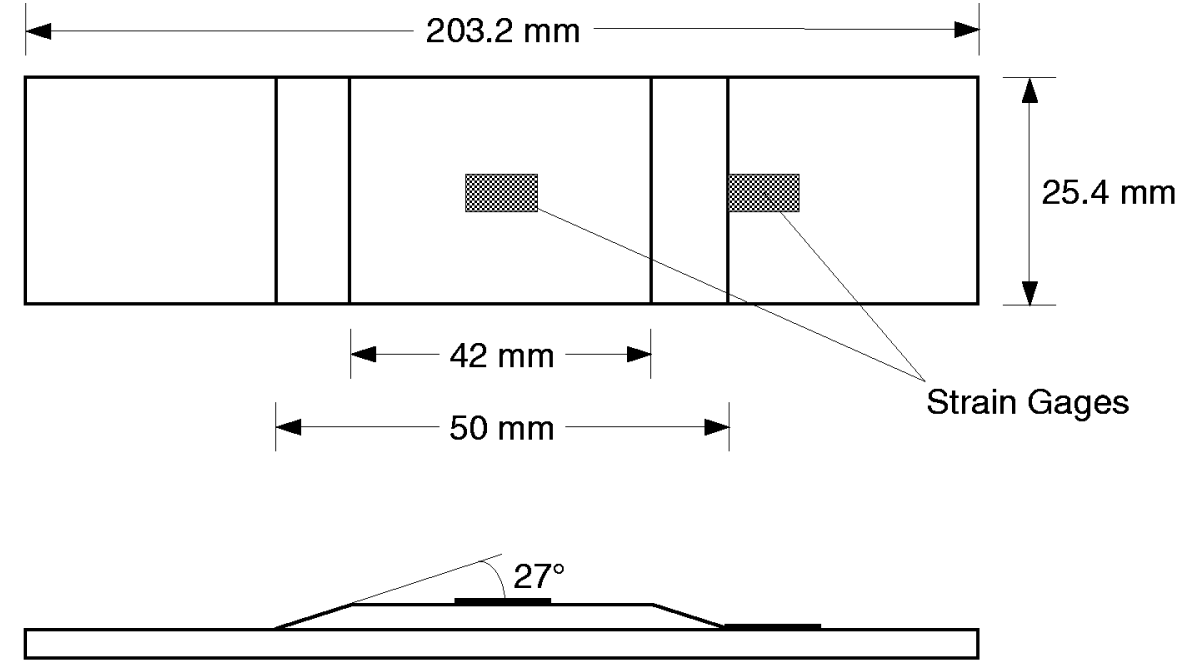

Figure 1. Specimen Configuration.

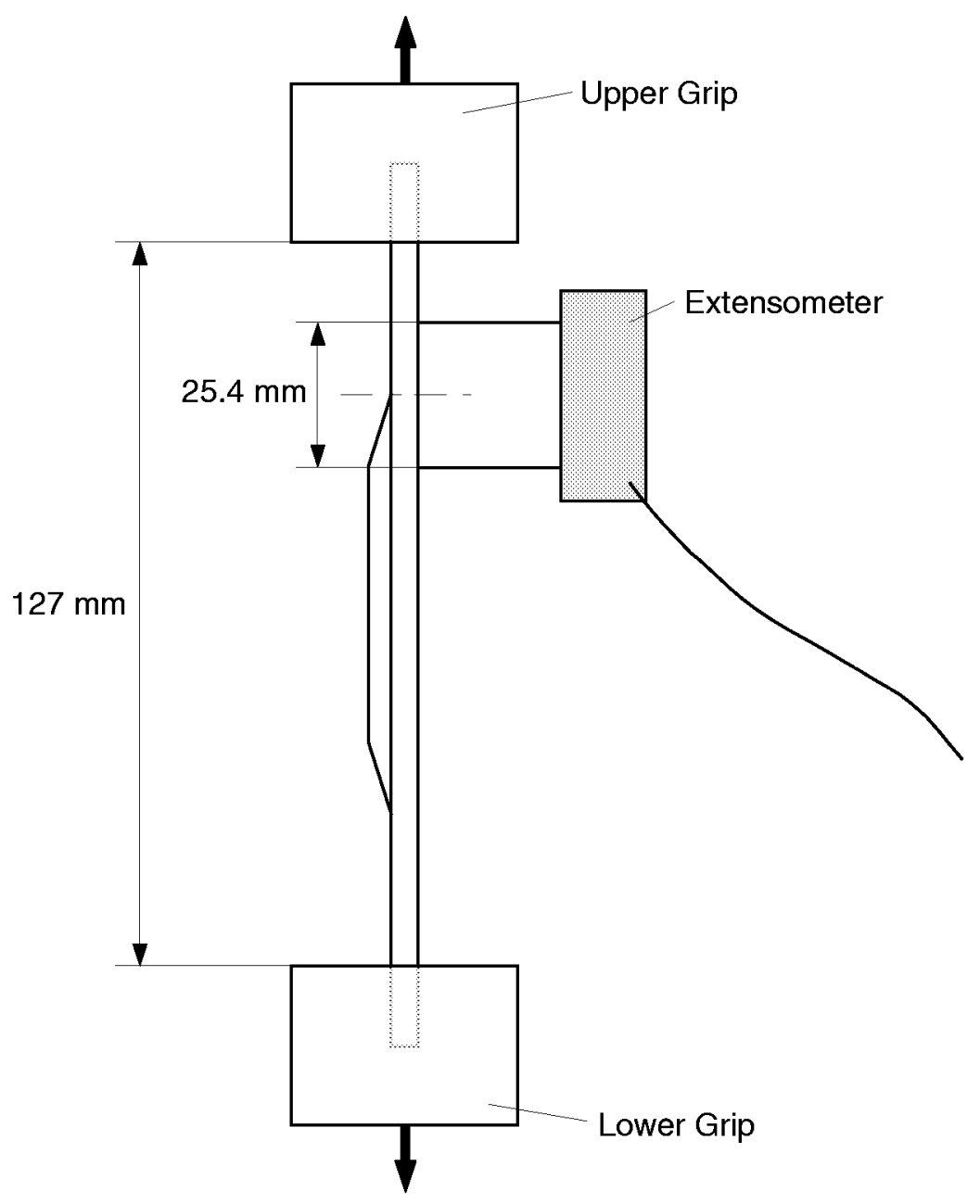

Figure 2. Tension Test Set-Up. 


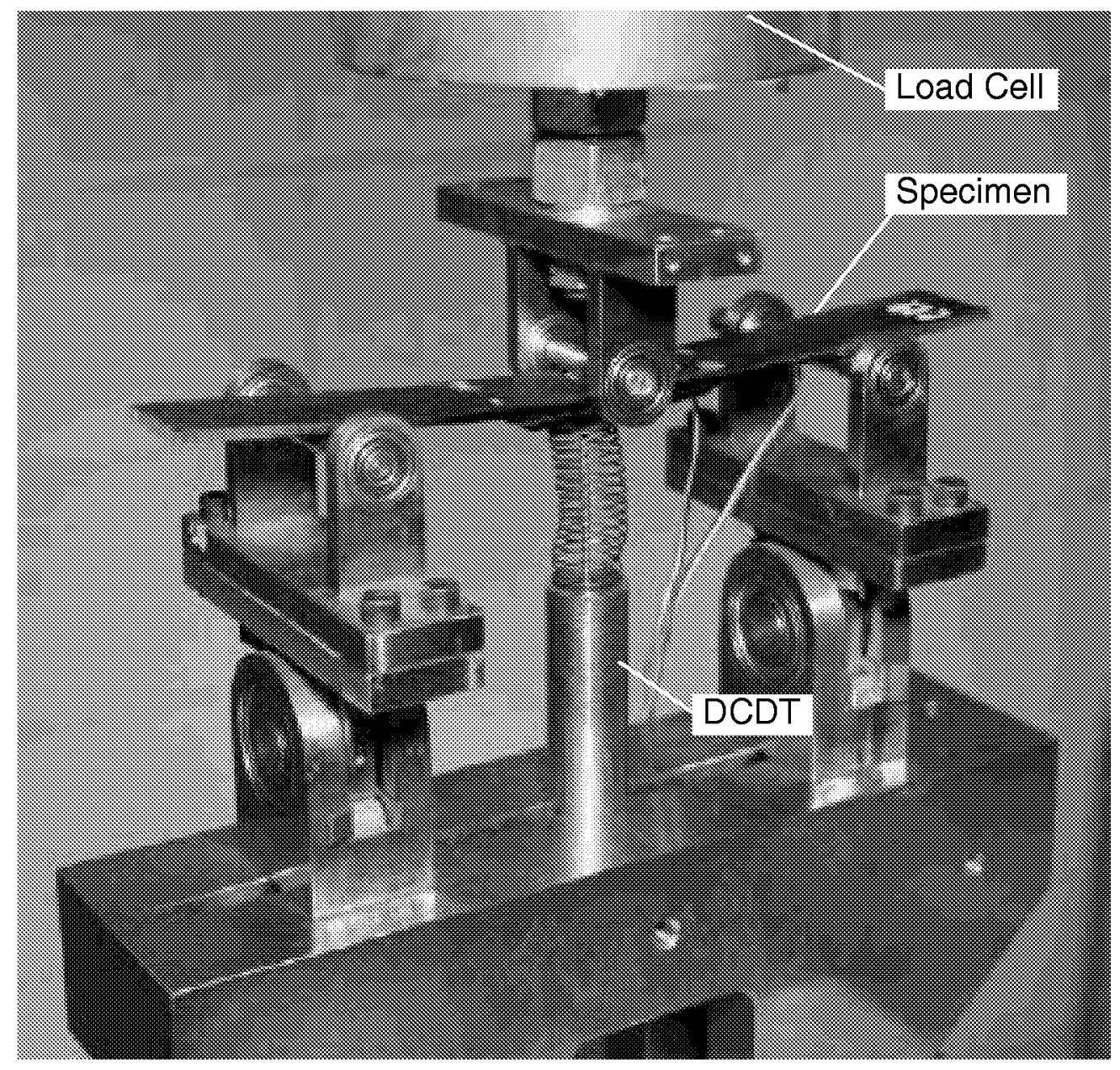

Figure 3. Three-Point Bending Test Set-Up. 


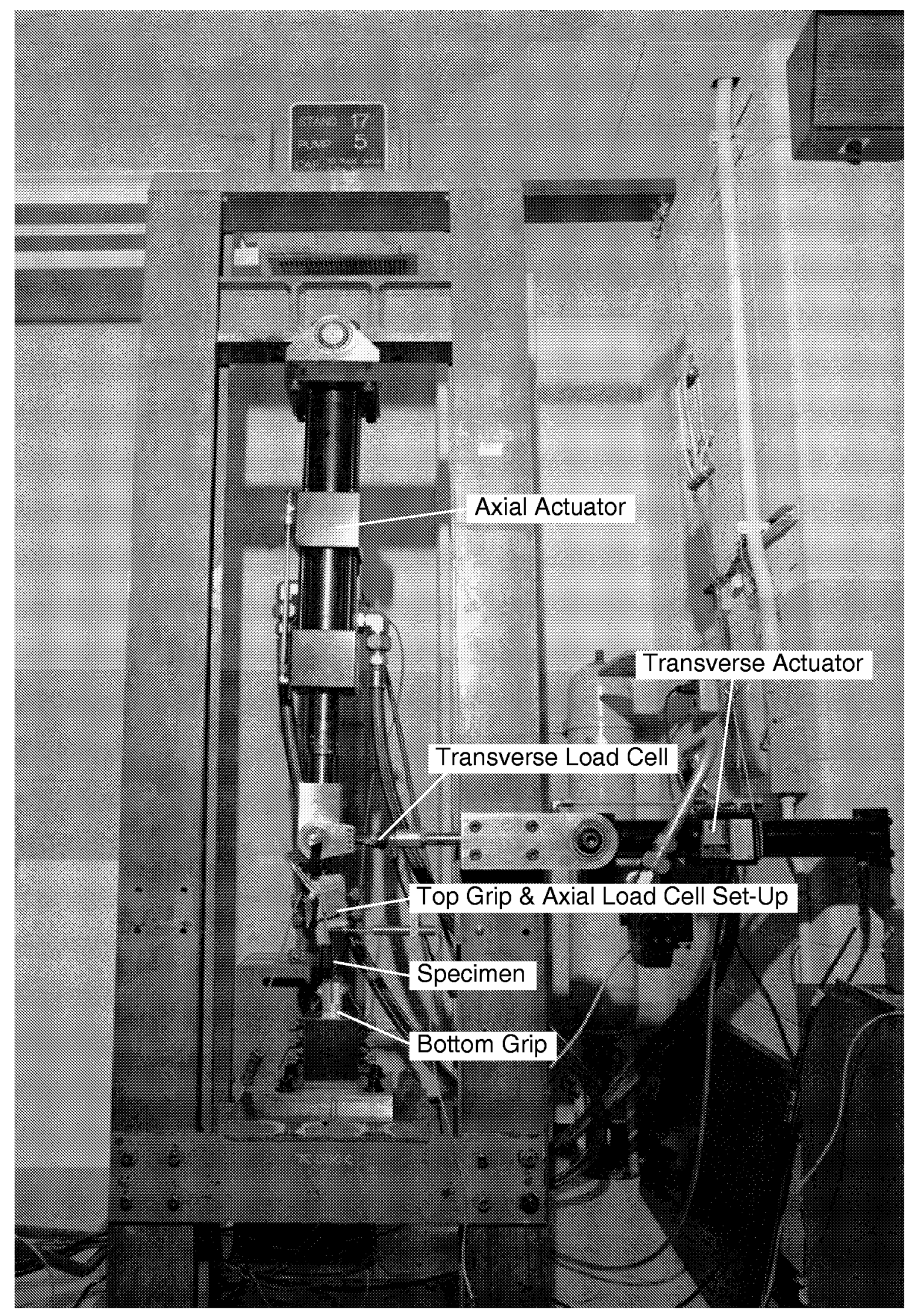

Figure 4. ATB Test Set-Up. 


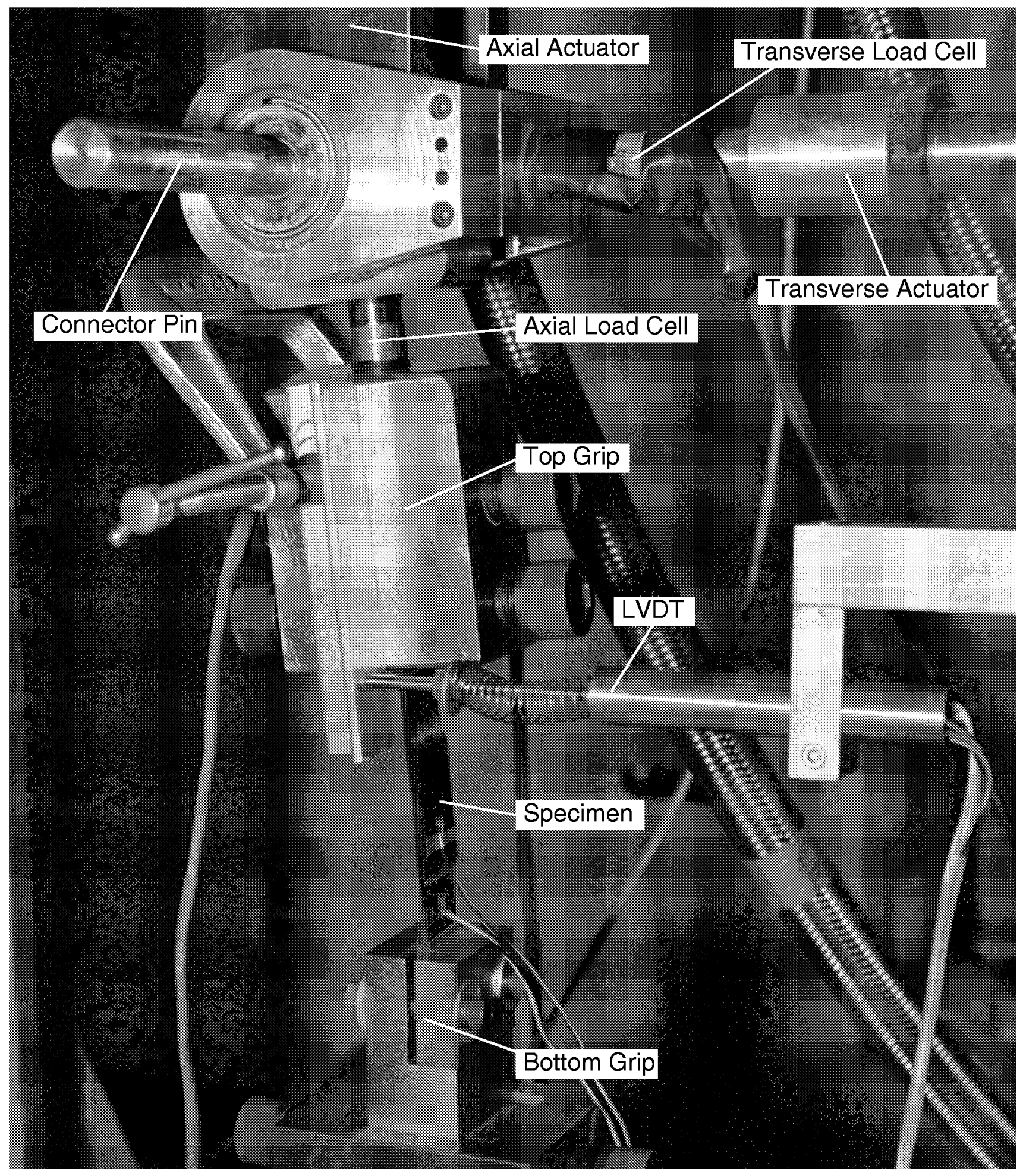

Figure 5. ATB Test Set-Up Close View. 


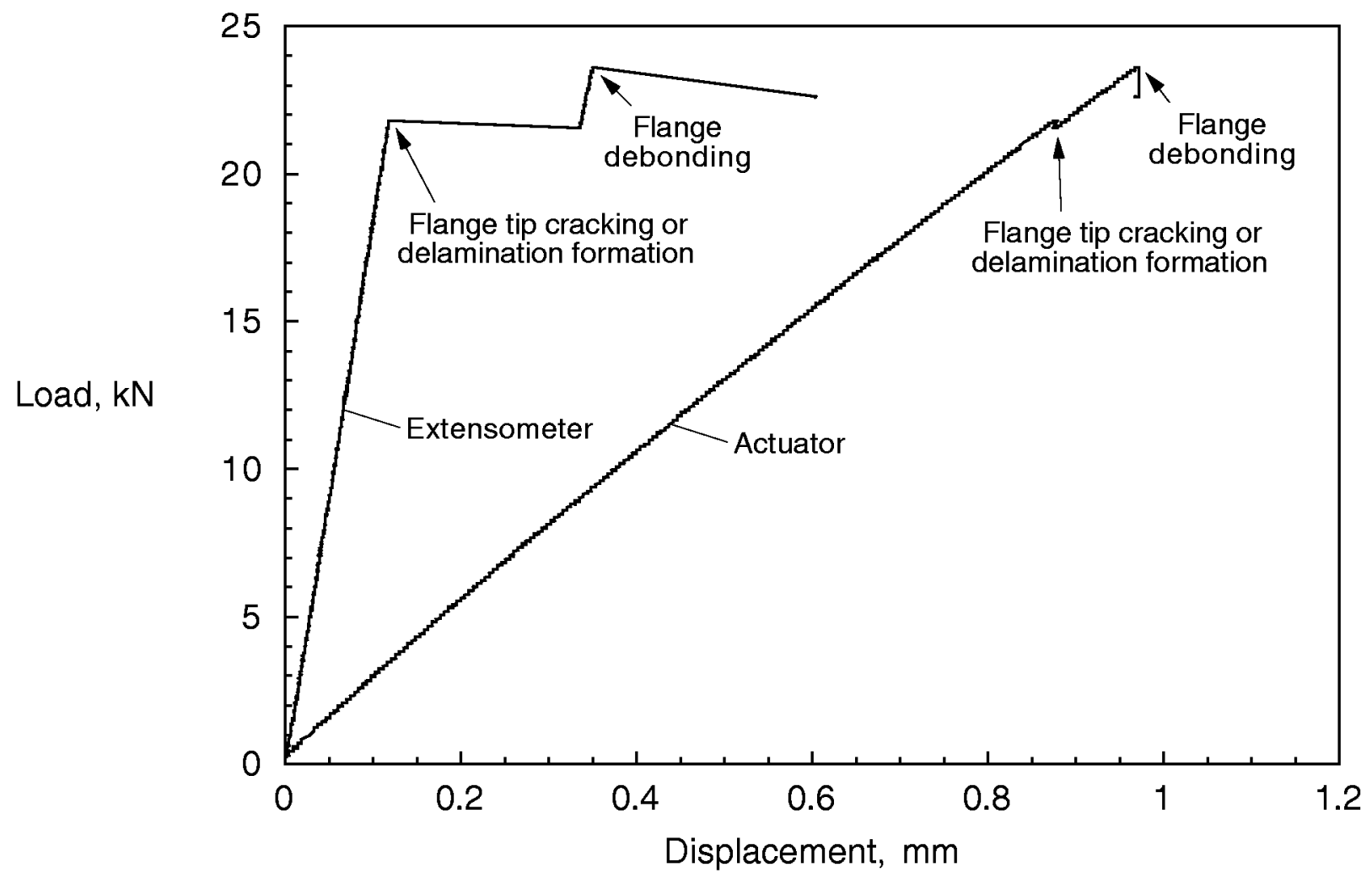

Figure 6. Typical Load-Displacement Plot for Tension Tests.

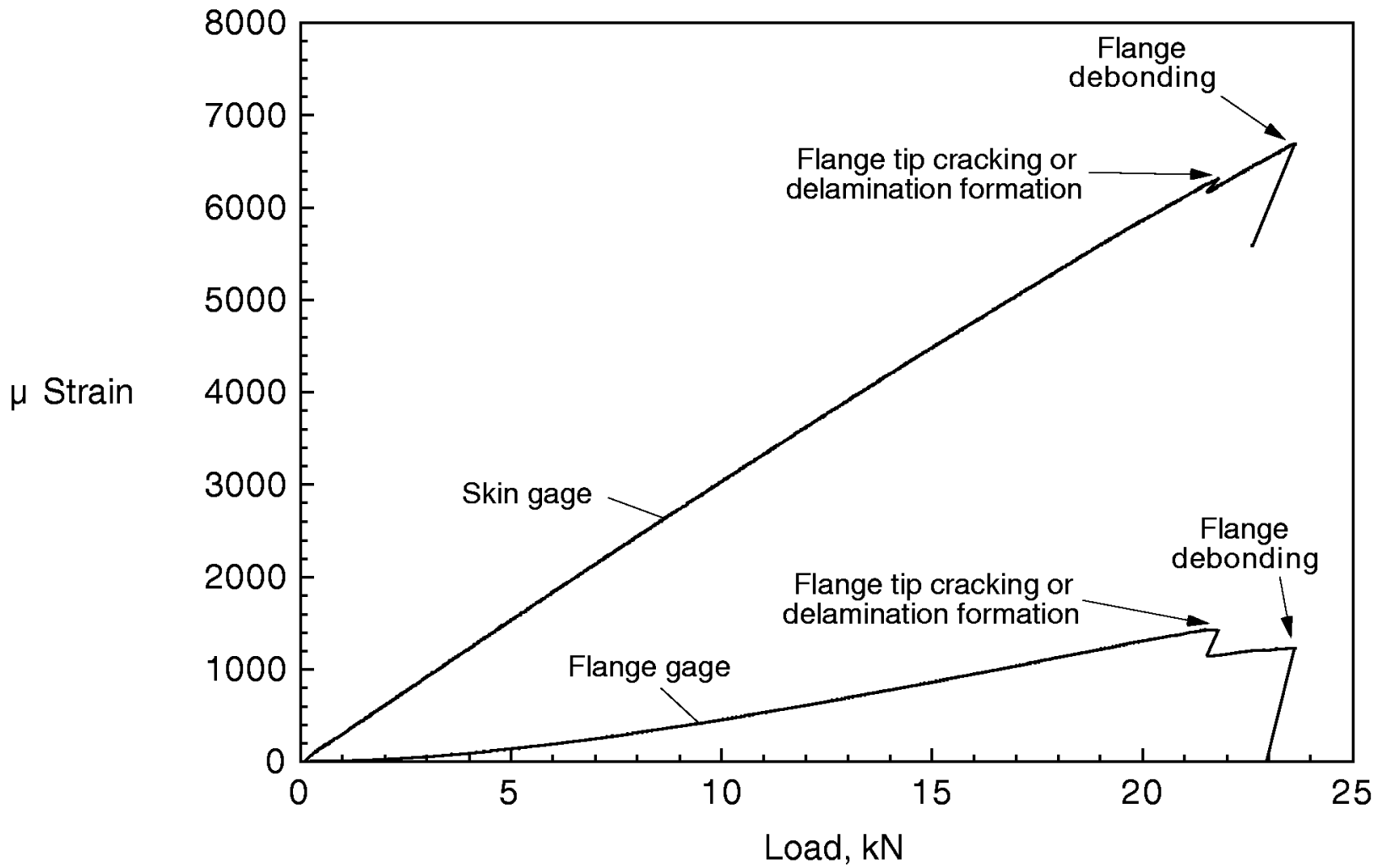

Figure 7. Typical Strain-Load Plot for Tension Tests. 


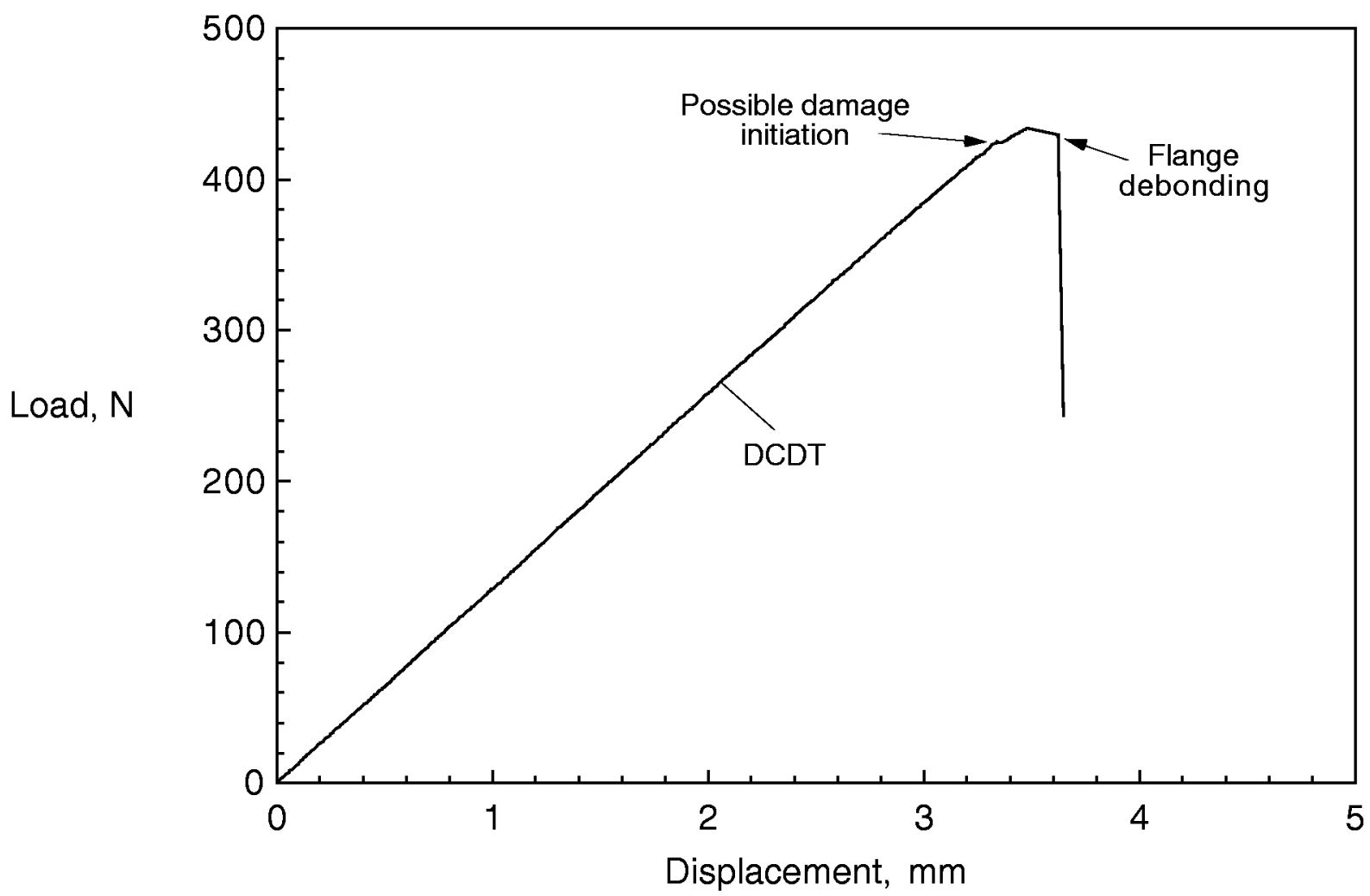

Figure 8. Typical Load-Displacement Plot for Three-Point Bending Tests.

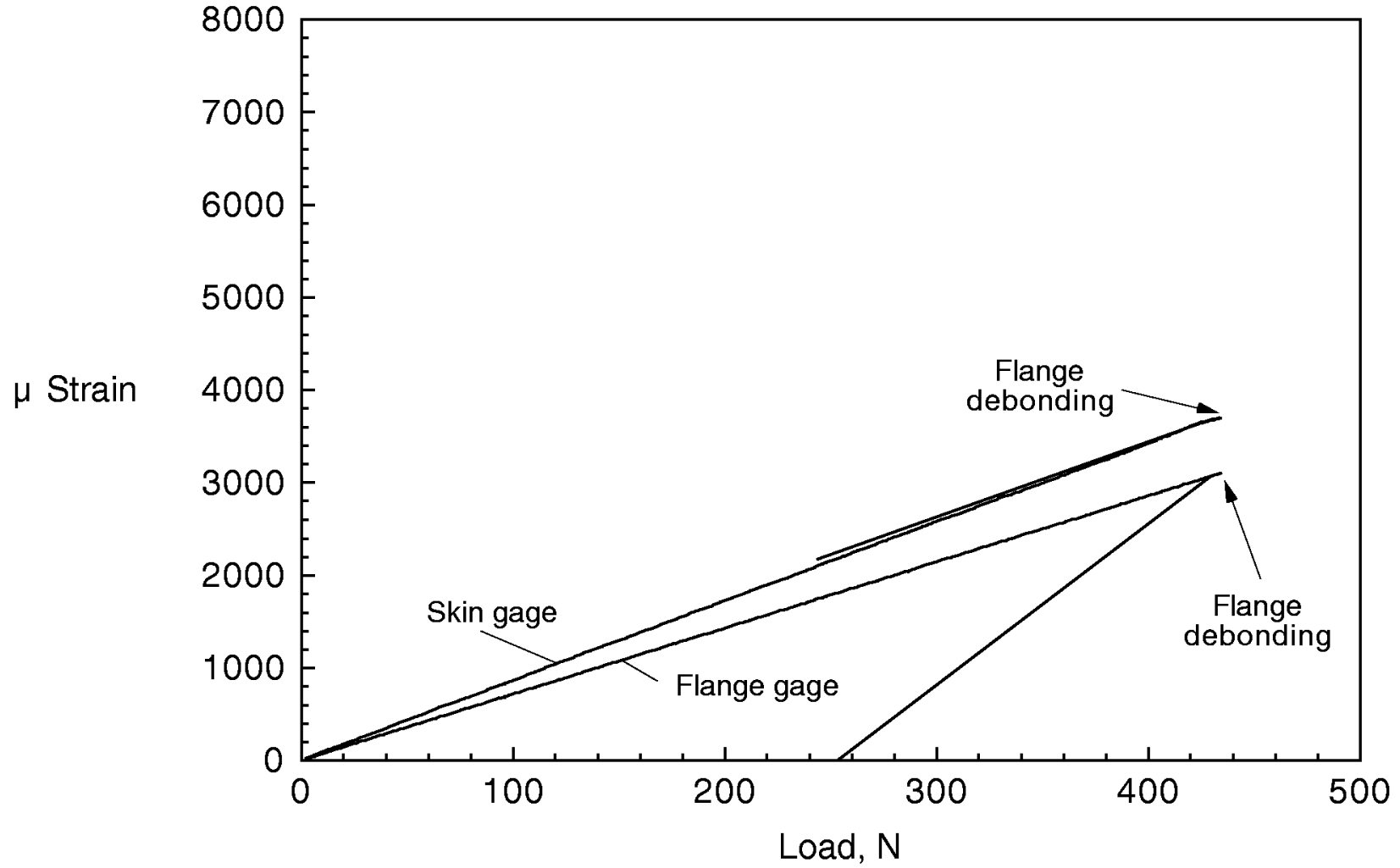

Figure 9. Typical Strain-Load Plot for Three-Point Bending Tests. 


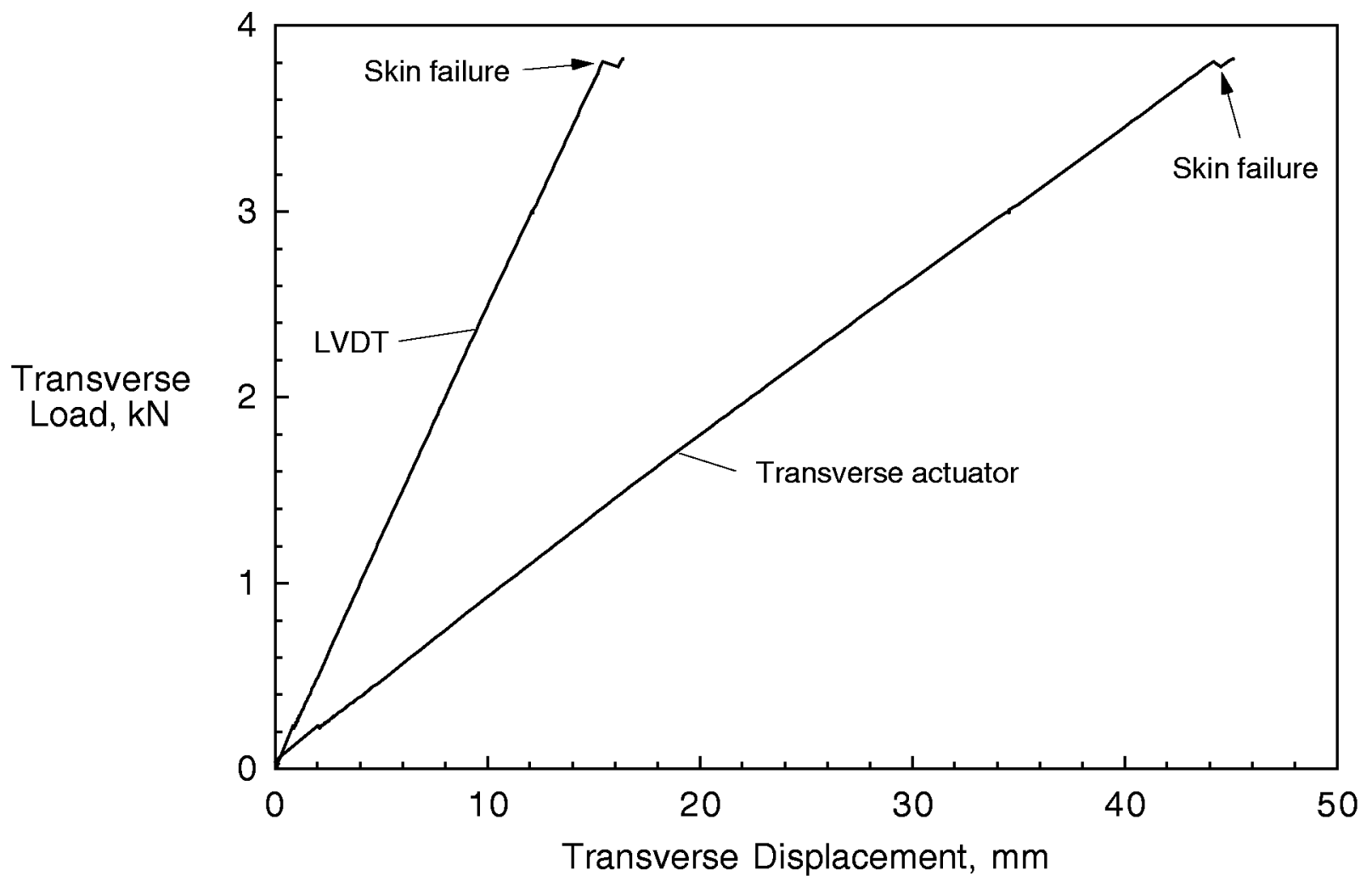

Figure 10. Typical Load-Displacement Plot for ATB Tests.

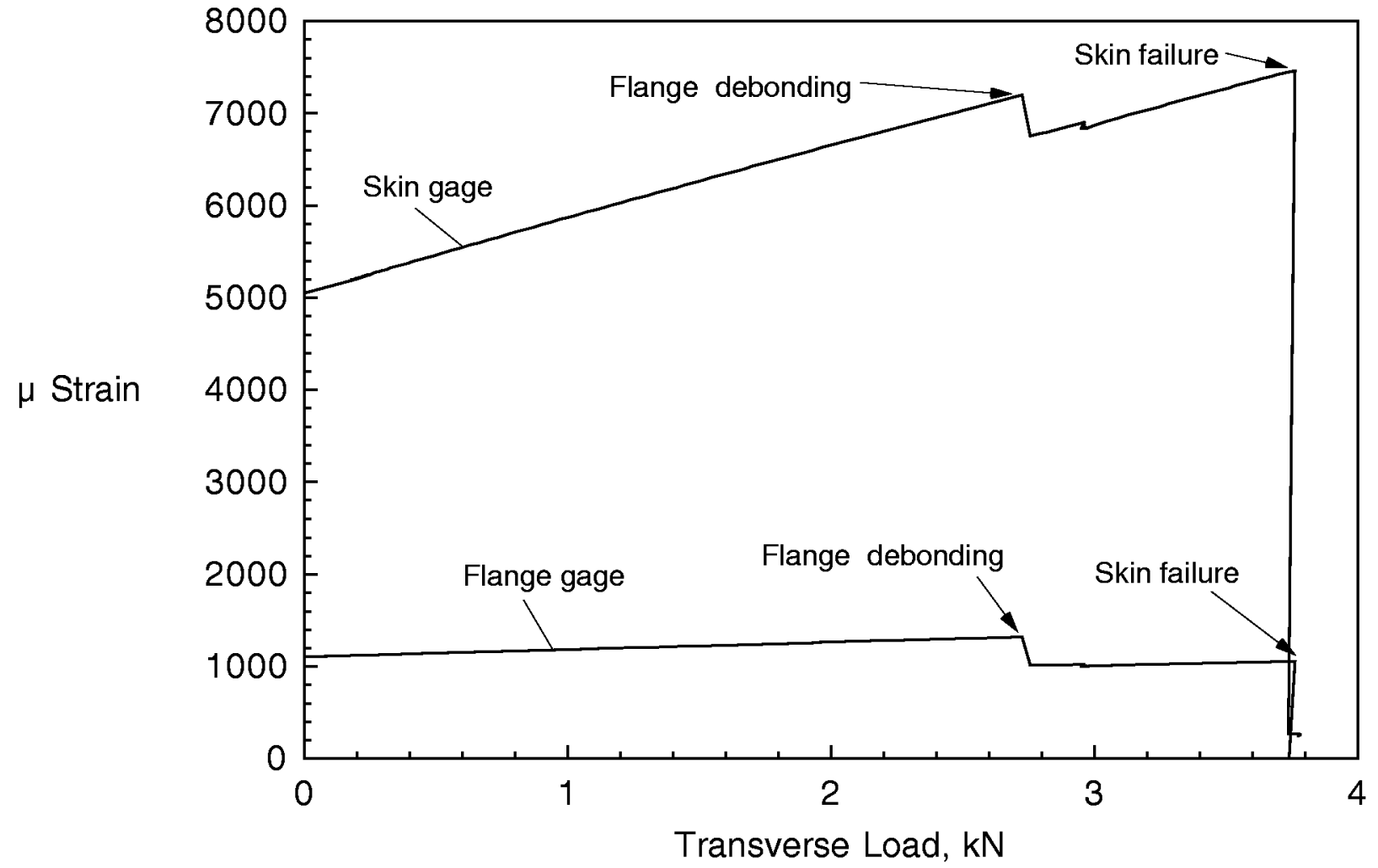

Figure 11. Typical Strain-Load Plot for ATB Tests. 


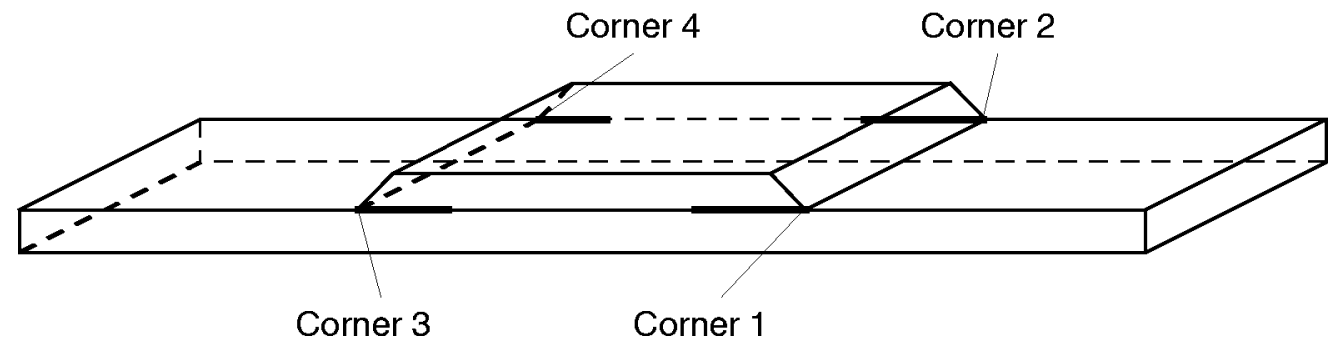

Figure 12. Specimen with Crack Locations.

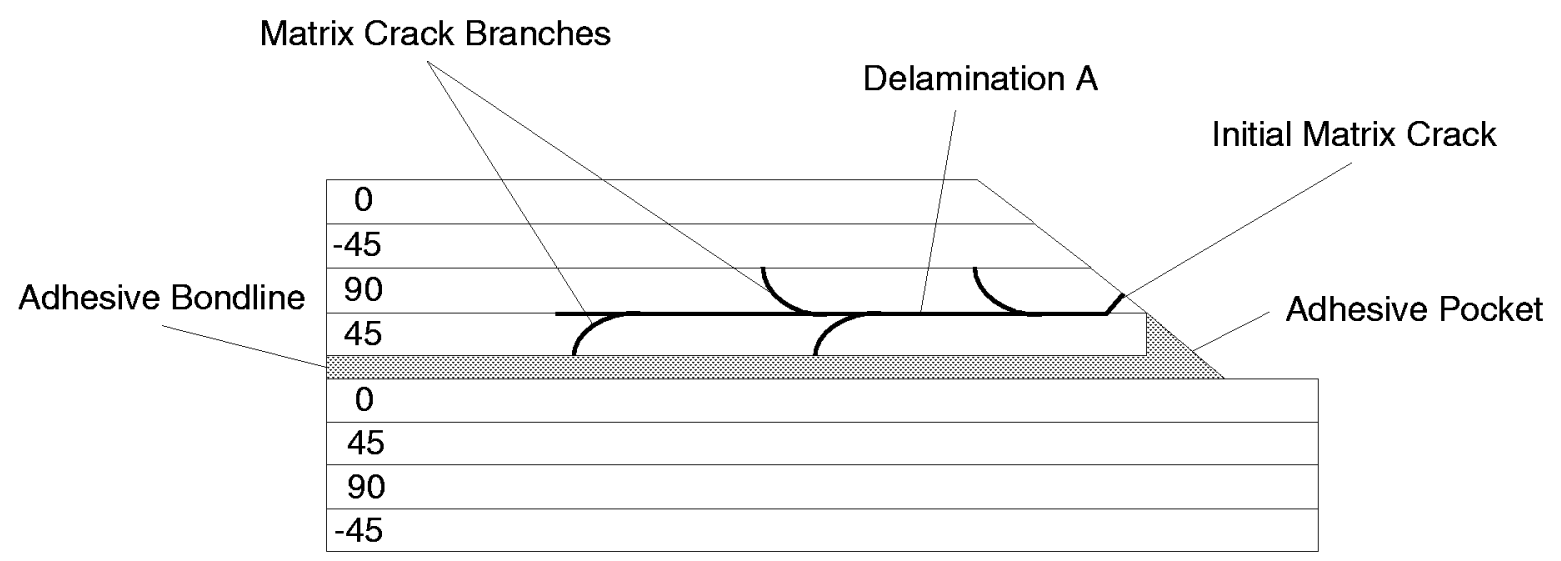

(a) Corners 1 and 4

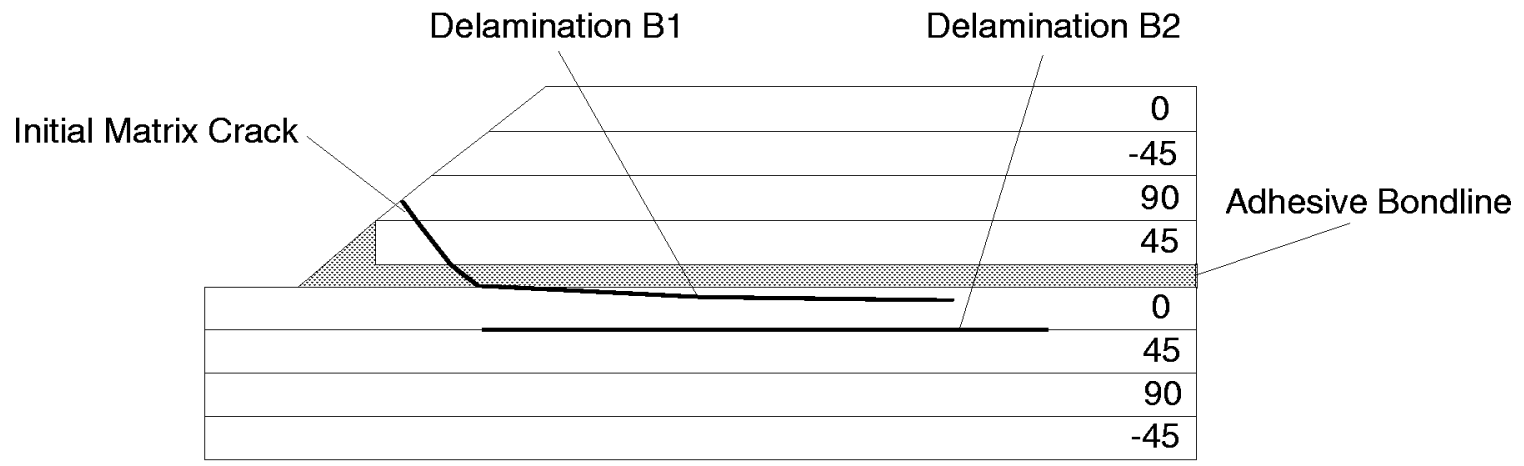

(b) Corners 2 and 3

Figure 13. Typical Damage Patterns. 


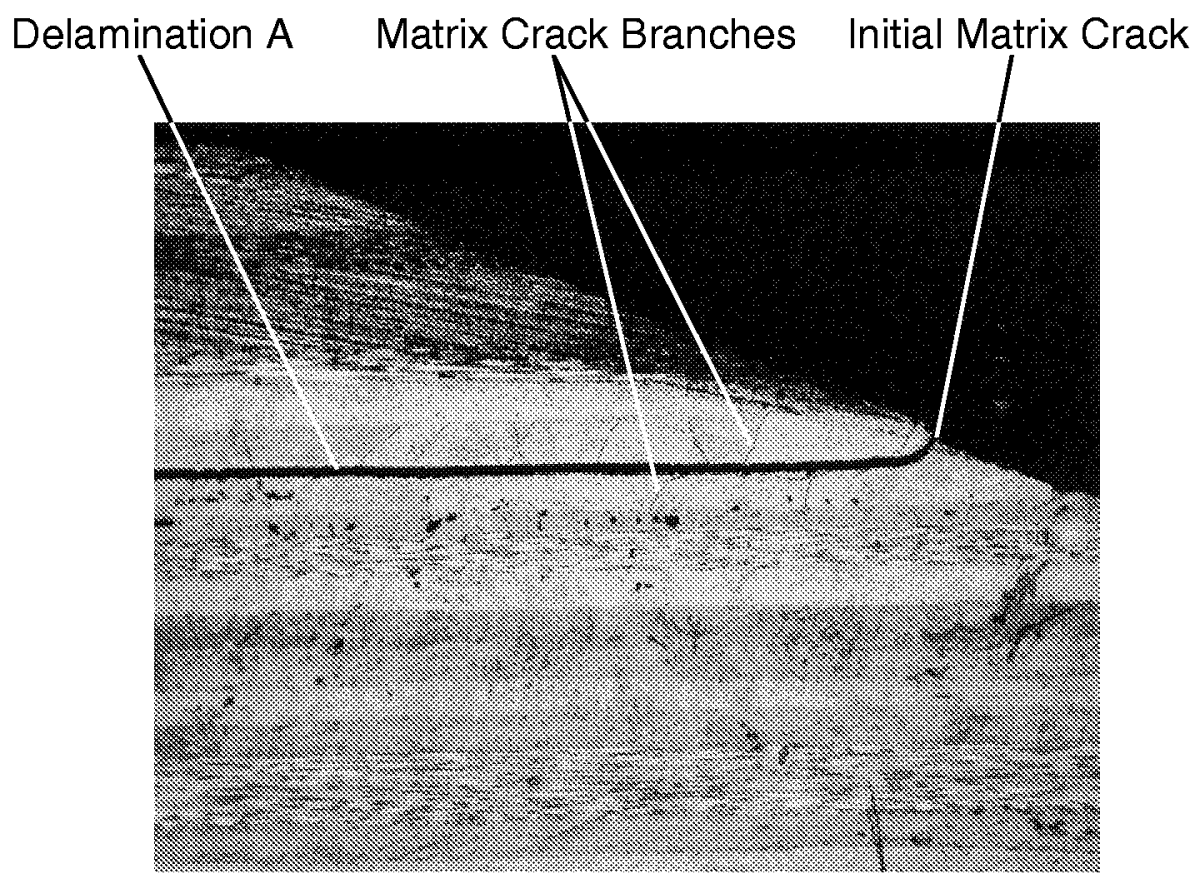

(a) Delamination $\mathrm{A}$ in the $90^{\circ} / 45^{\circ}$ Flange Ply Interface at Corner 4

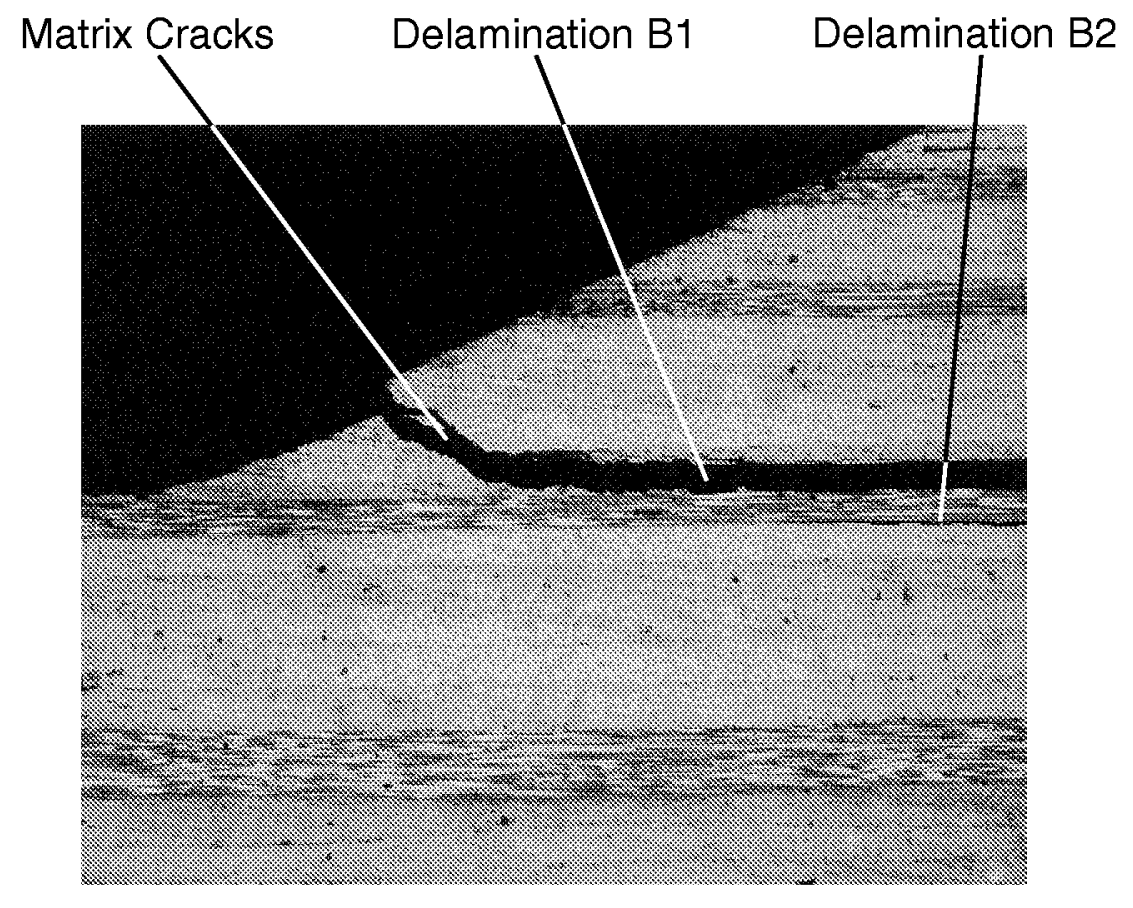

(b) Delamination B1 in the Top $0^{\circ}$ Skin Ply and Beginning of Delamination B2 in The top $0^{\circ} / 45^{\circ}$ Skin Ply Interface at Corner 2

Figure 14. Micrograph Showing the Side View of a Failed Three-Point Bending Specimen. 

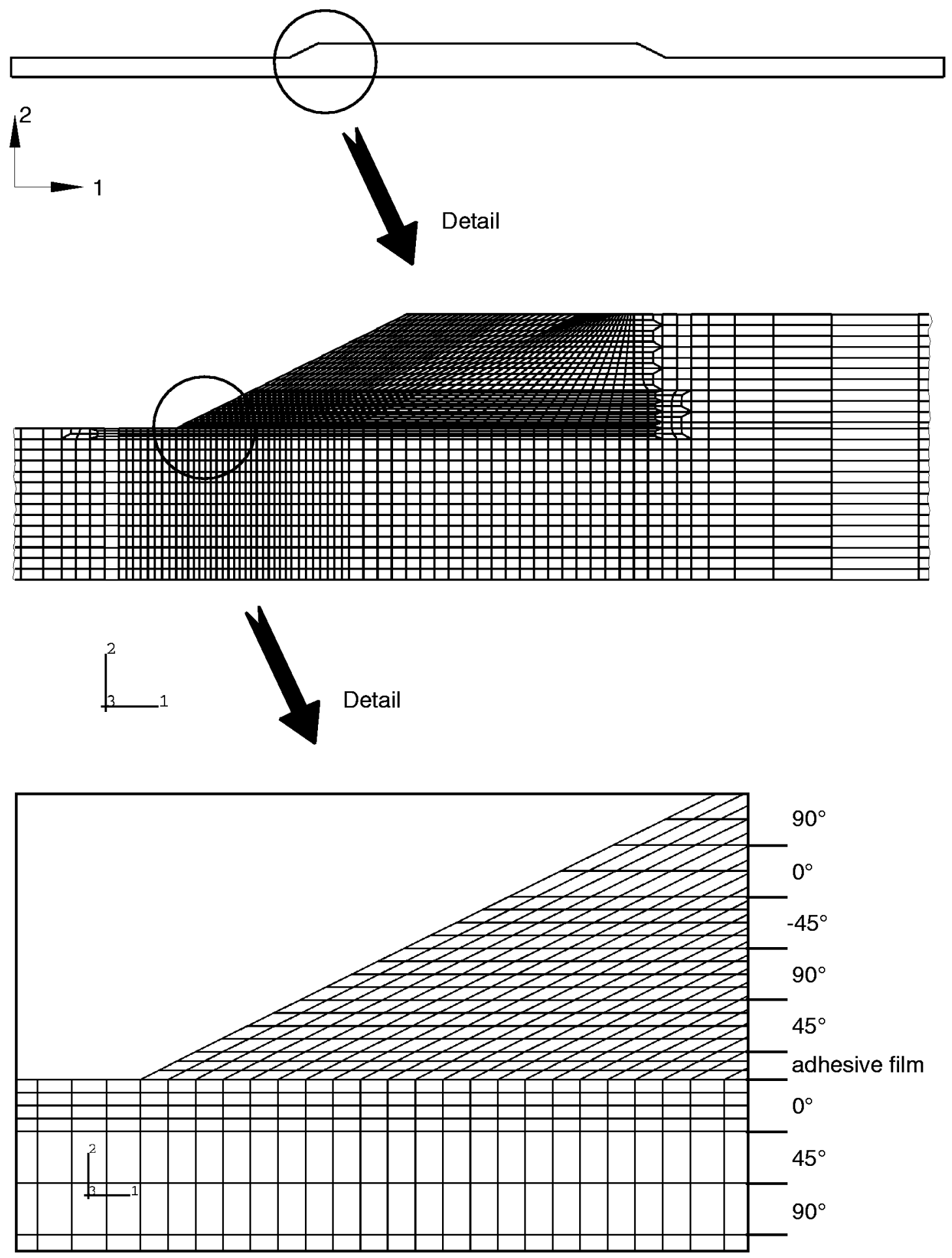

Figure 15. Finite Element Model of an Undamaged Specimen. 

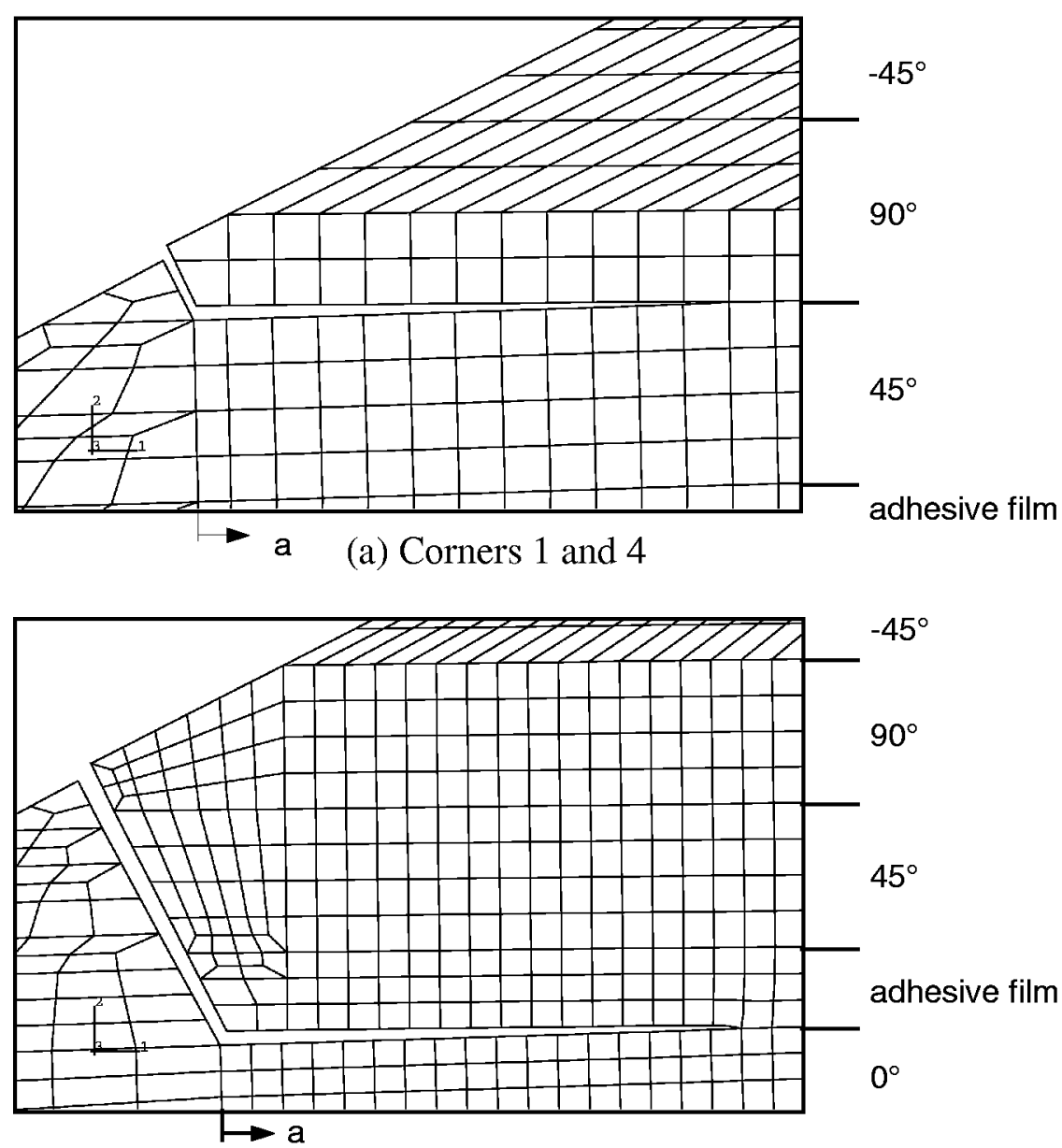

(b) Corners 2 and 3

Figure 16. Modeled Damage Patterns.

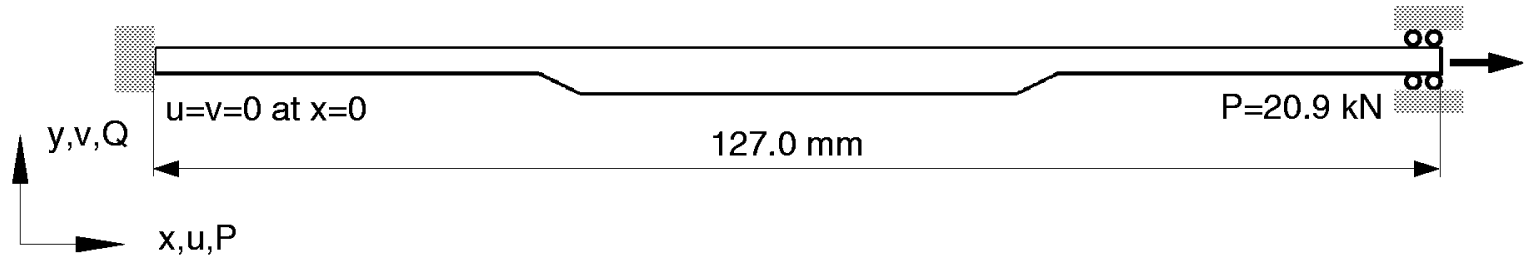

(a) Tension Specimen

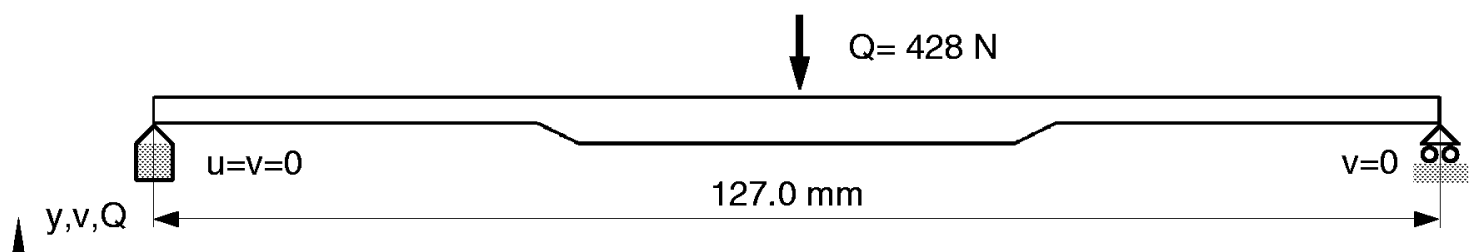

(b) Bending Specimen

Figure 17. Loads and Boundary Conditions For Tension and Three-Point Bending Case. 


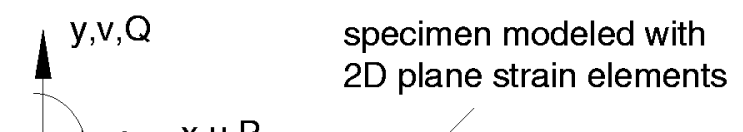

top grip, axial load cell and pin modeled with beam elements
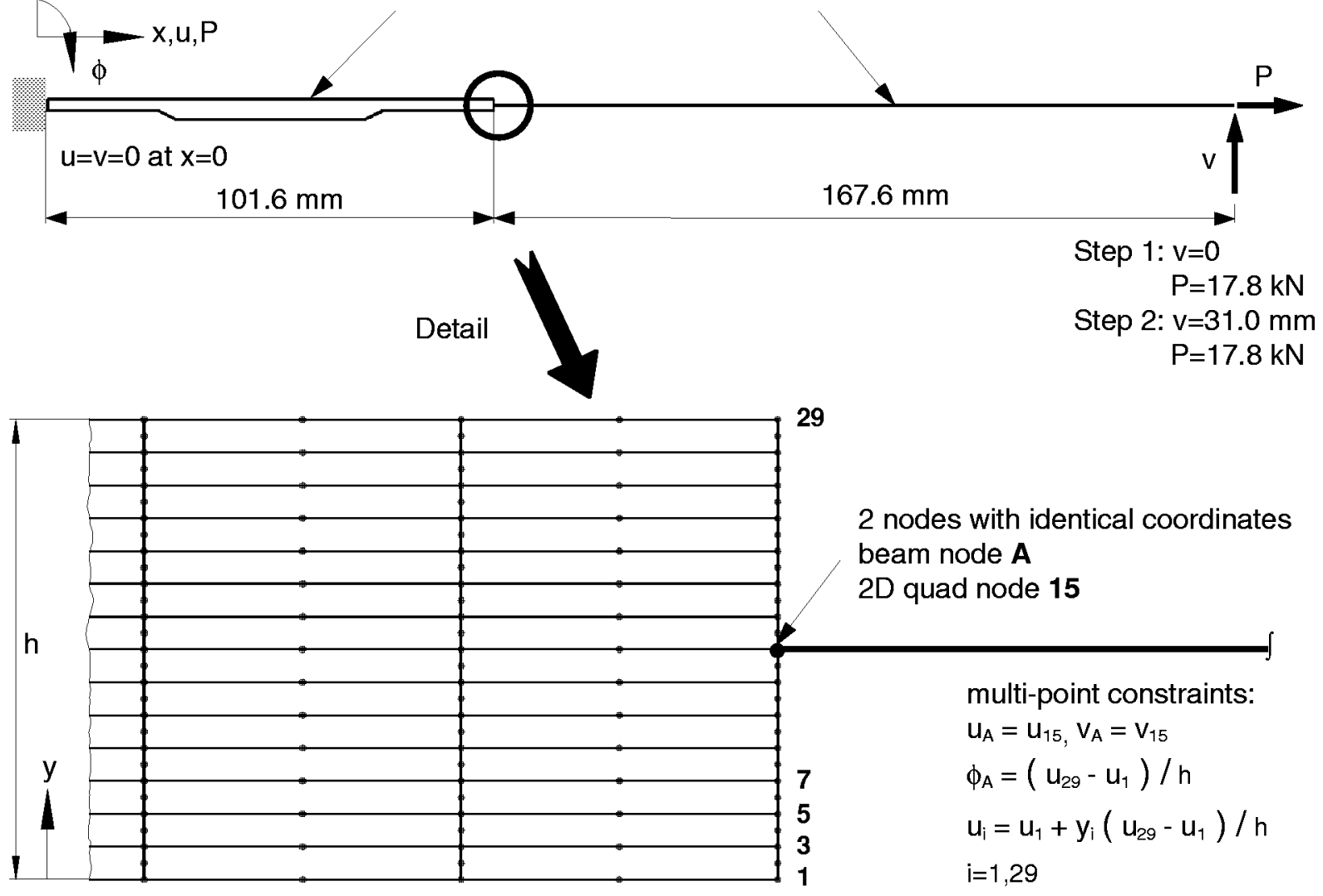

Figure 18. Loads and Boundary Conditions for ATB Test.

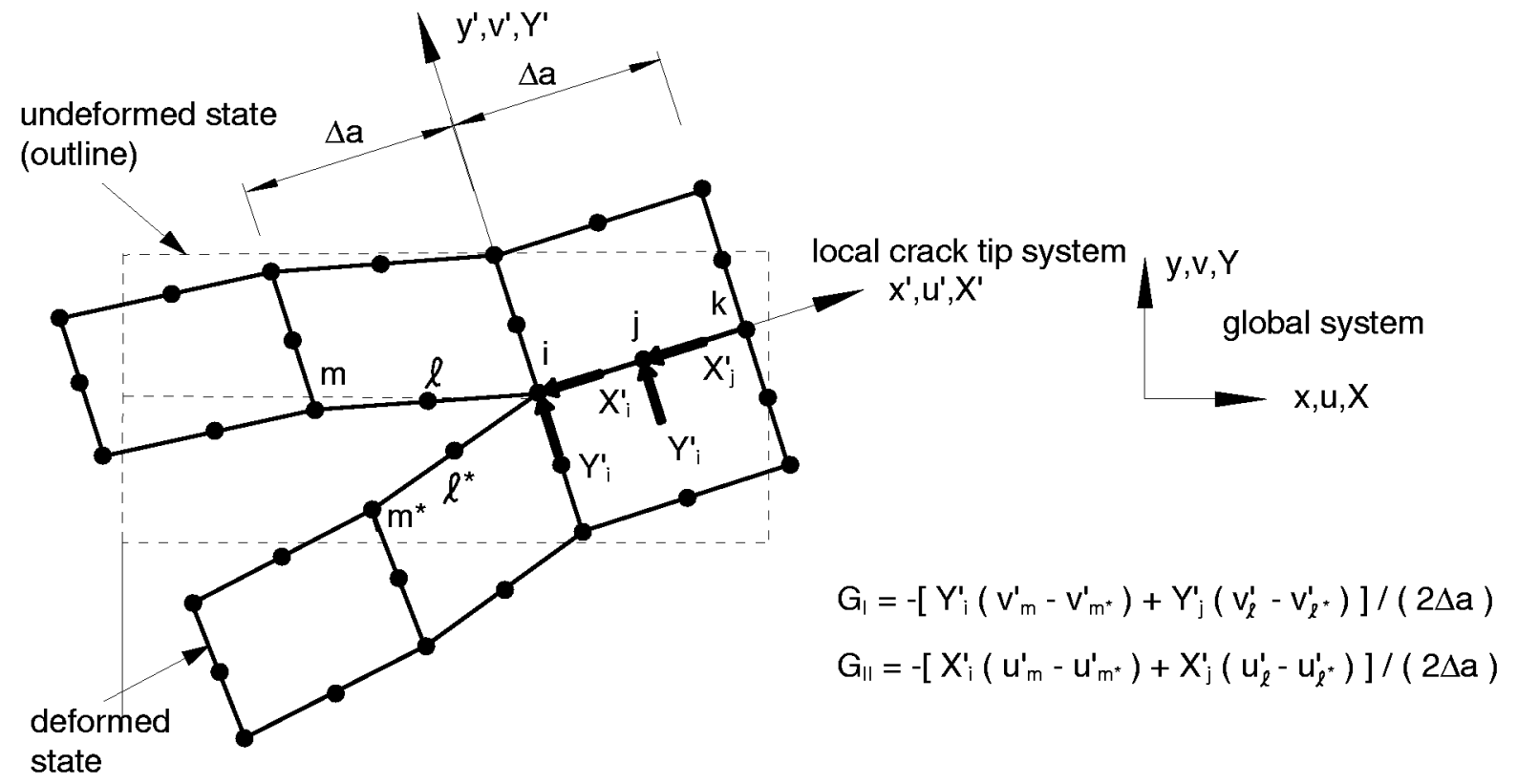

Figure 19. Virtual Crack Closure Technique (VCCT). 
undeformed center line

deformed configuration
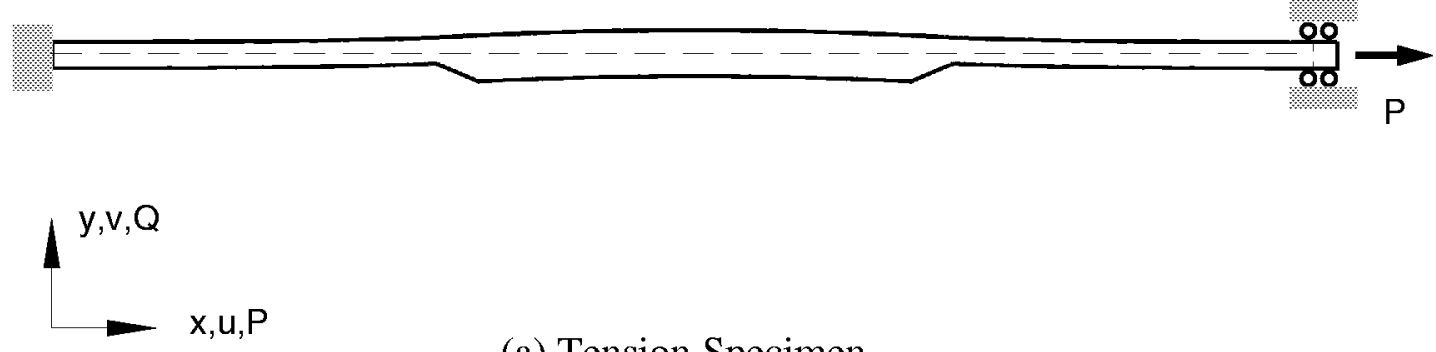

(a) Tension Specimen
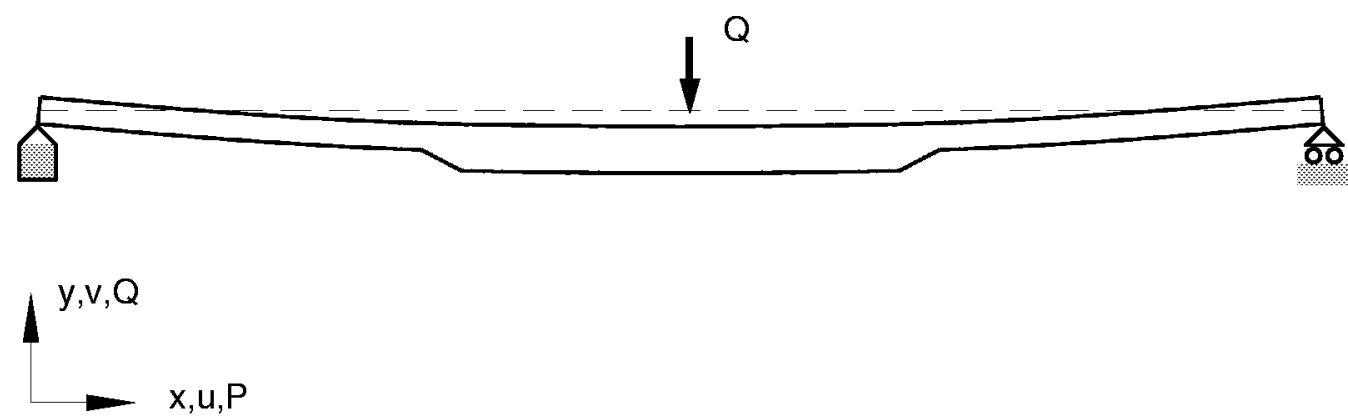

(b) Bending Specimen

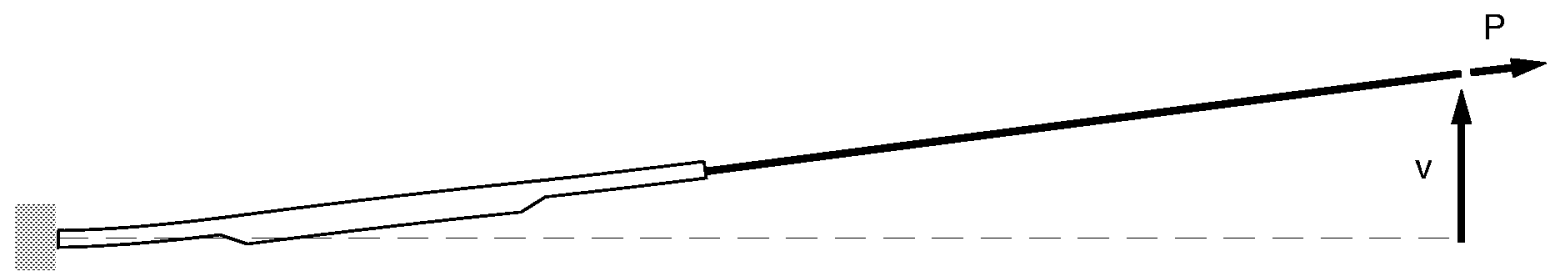

$\Lambda^{\mathrm{y}, \mathrm{v}, \mathrm{Q}}$

$m x, u, P$

(c) ATB Specimen, Scale Different from (a) and (b)

Figure 20. Deformed Test Specimen Geometries 


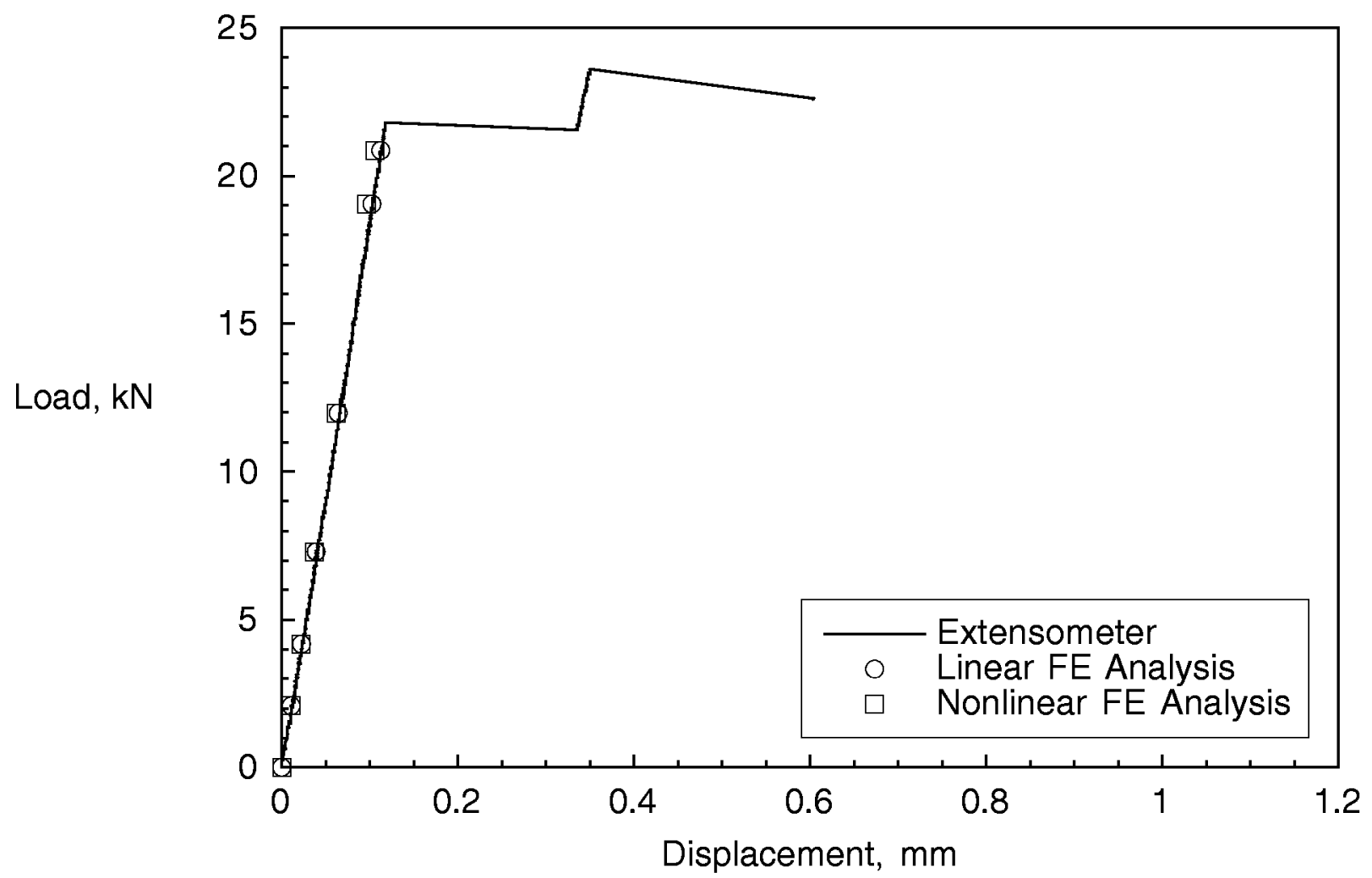

Figure 21. Comparison of Measured Displacements with Computed Results for Tension Load Case.

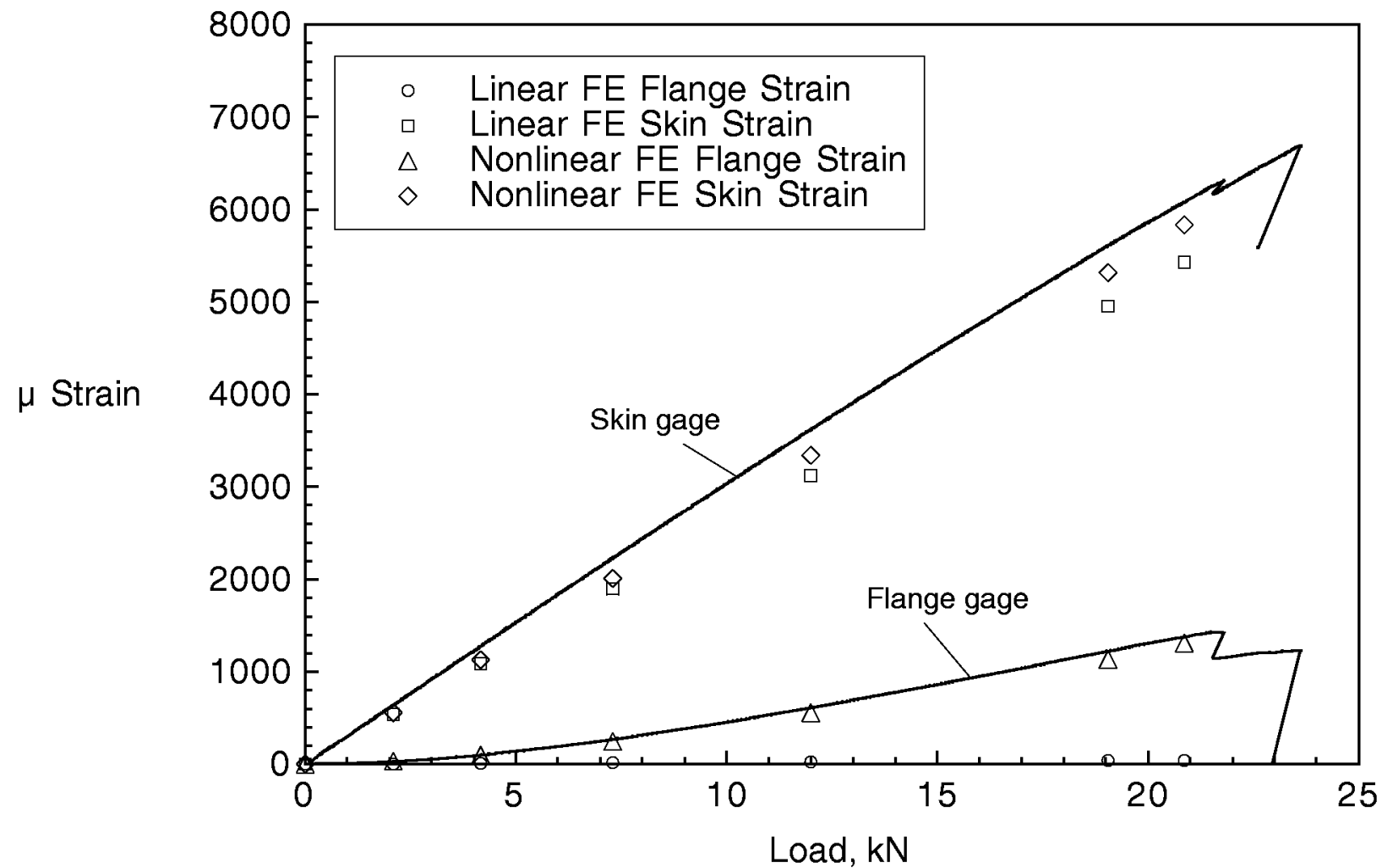

Figure 22. Comparison of Measured Strains with Computed Results for Tension Load Case. 


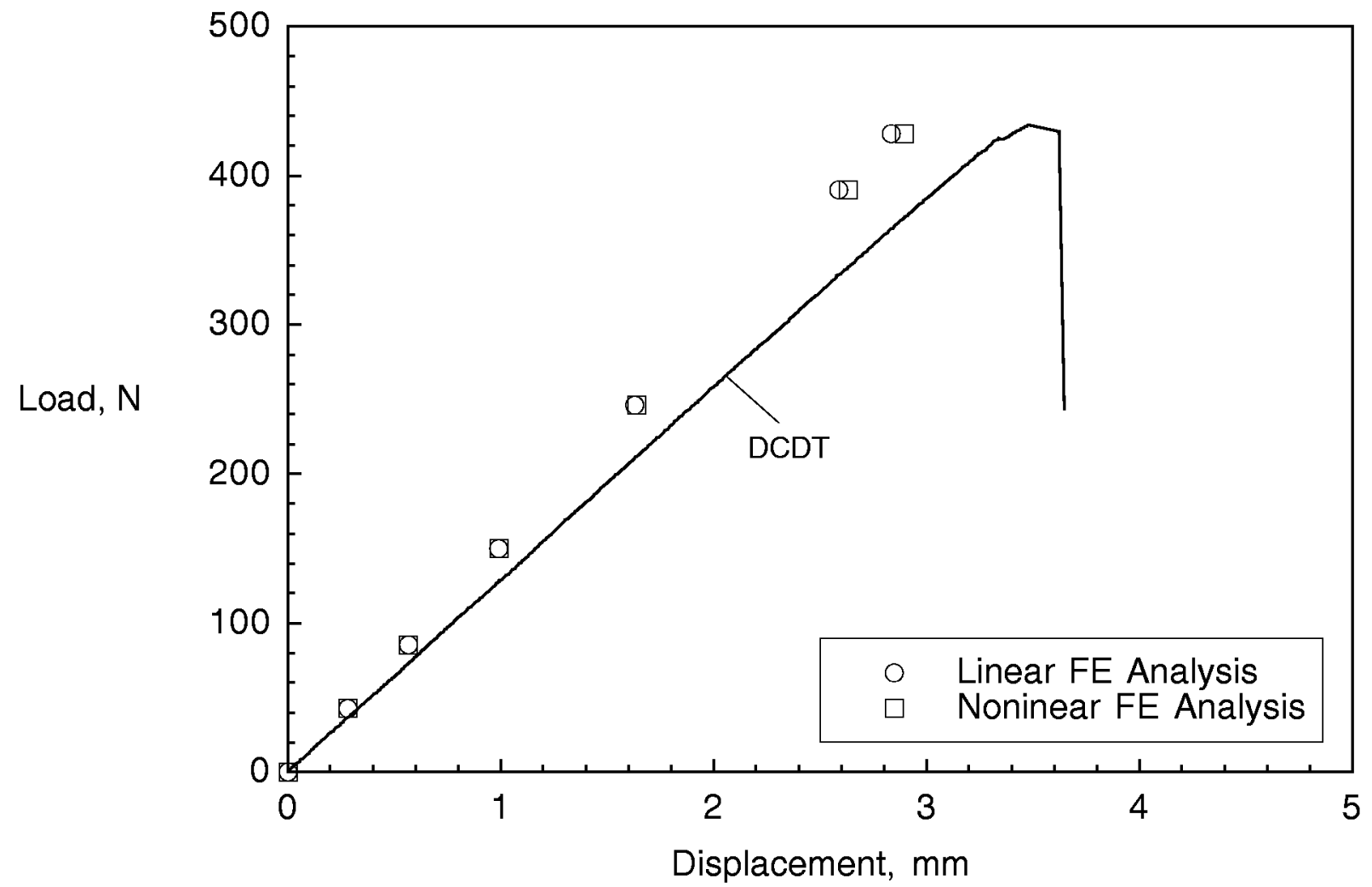

Figure 23. Comparison of Measured Displacements with Computed Results for Three-Point Bending Load Case.

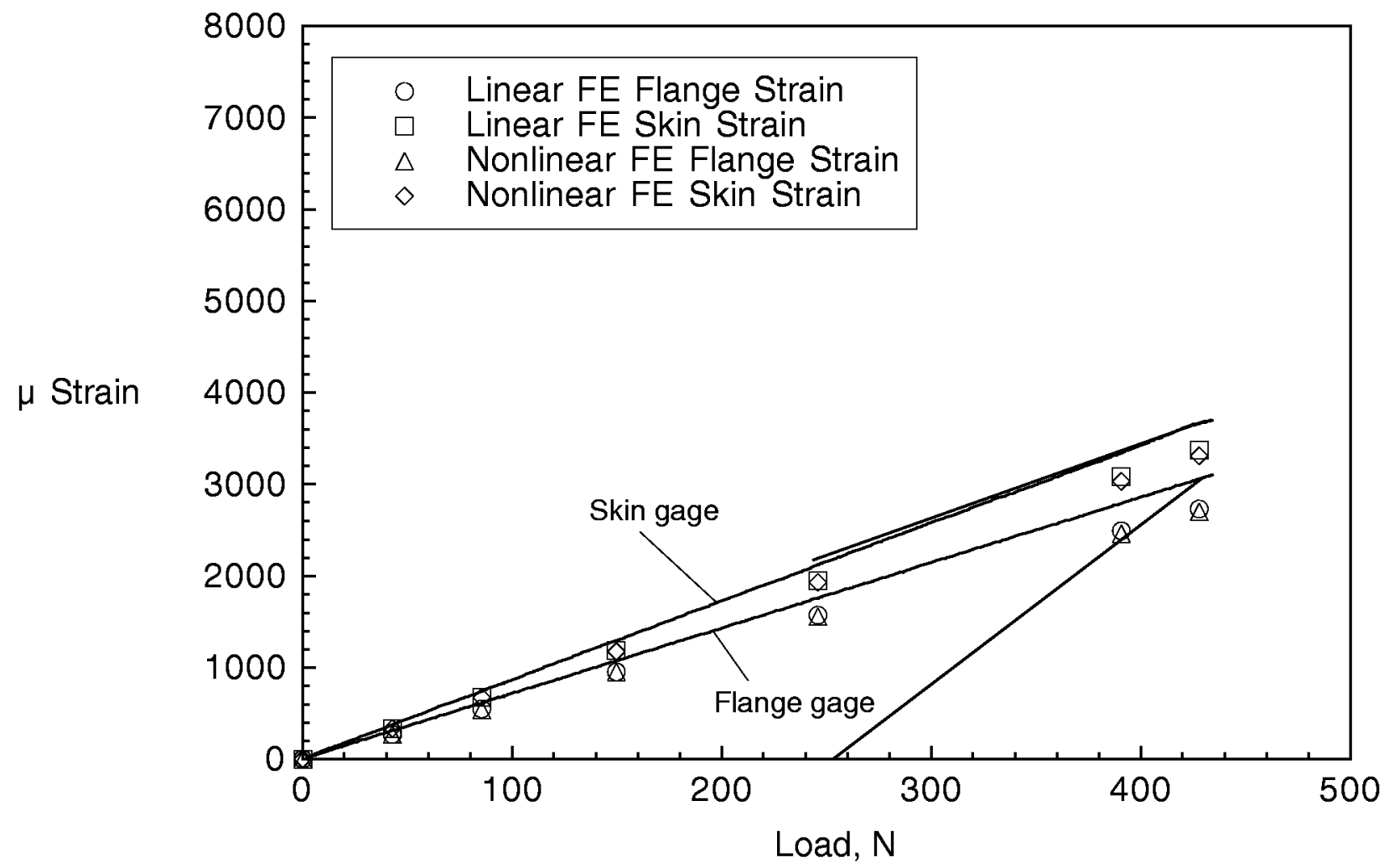

Figure 24. Comparison of Measured Strains with Computed Results for Three-Point Bending Load Case. 


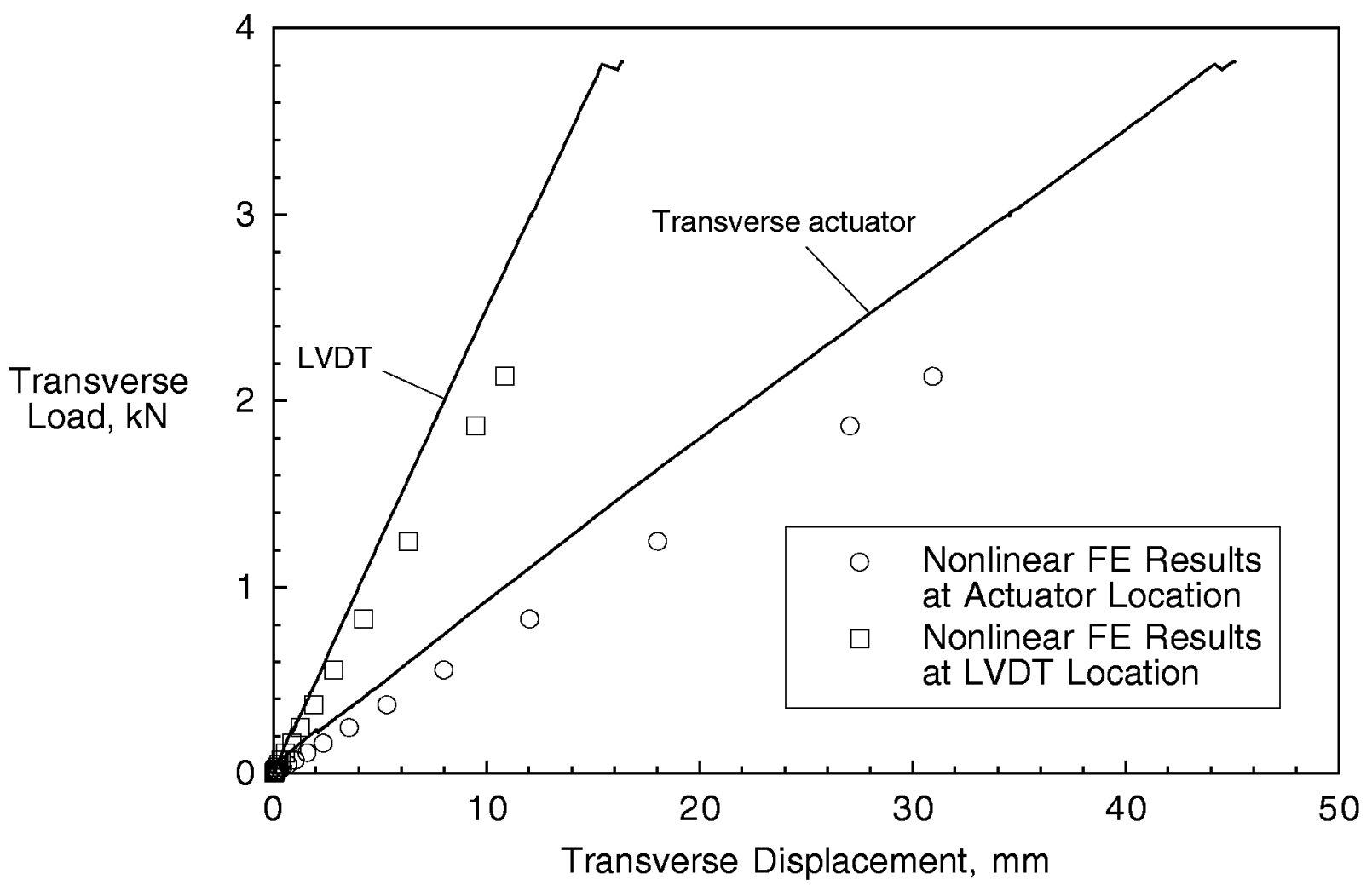

Figure 25. Comparison of Measured Displacements with Computed Results for ATB Load Case.

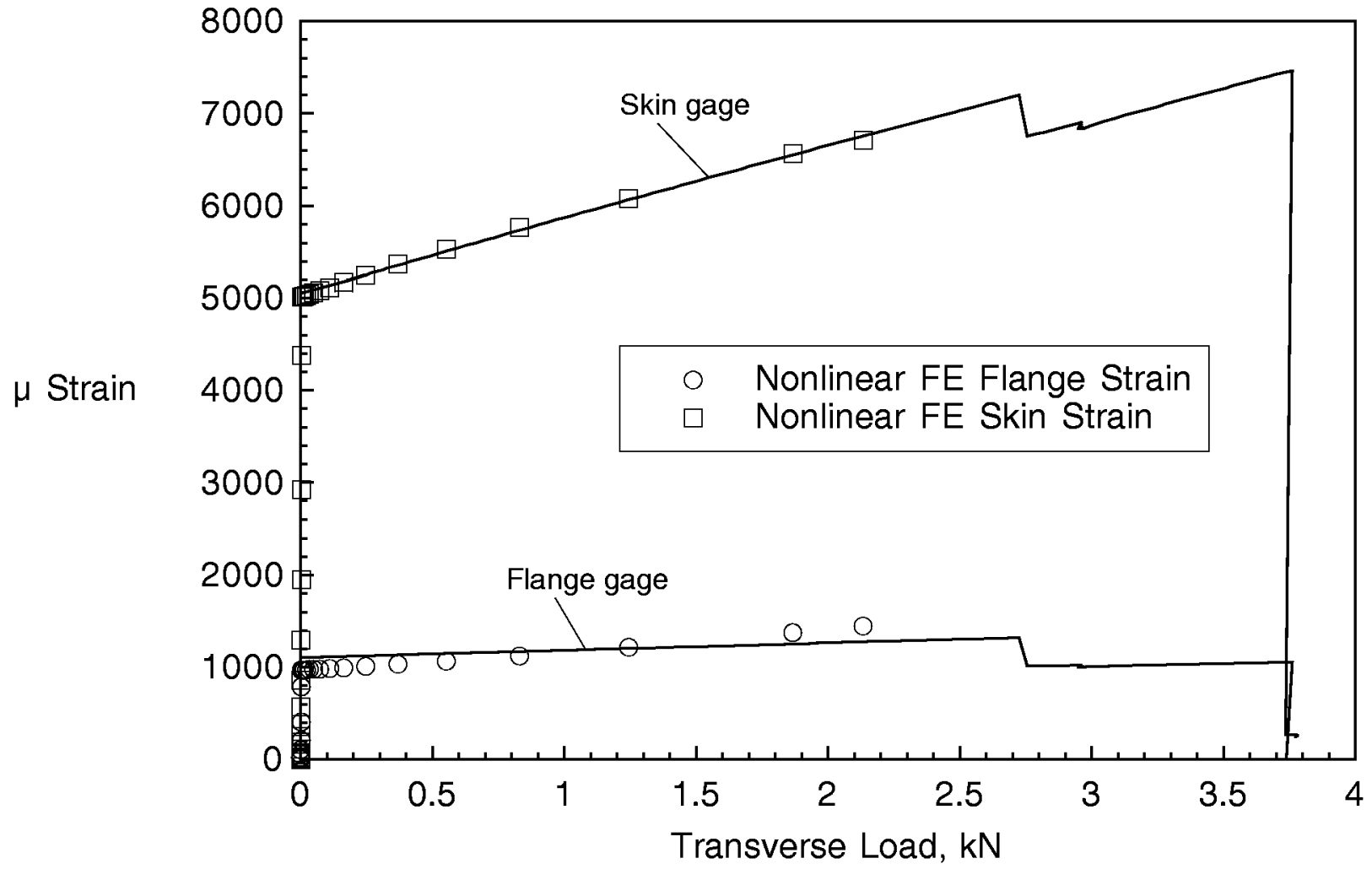

Figure 26. Comparison of Measured Strains with Computed Results for ATB Load Case. 

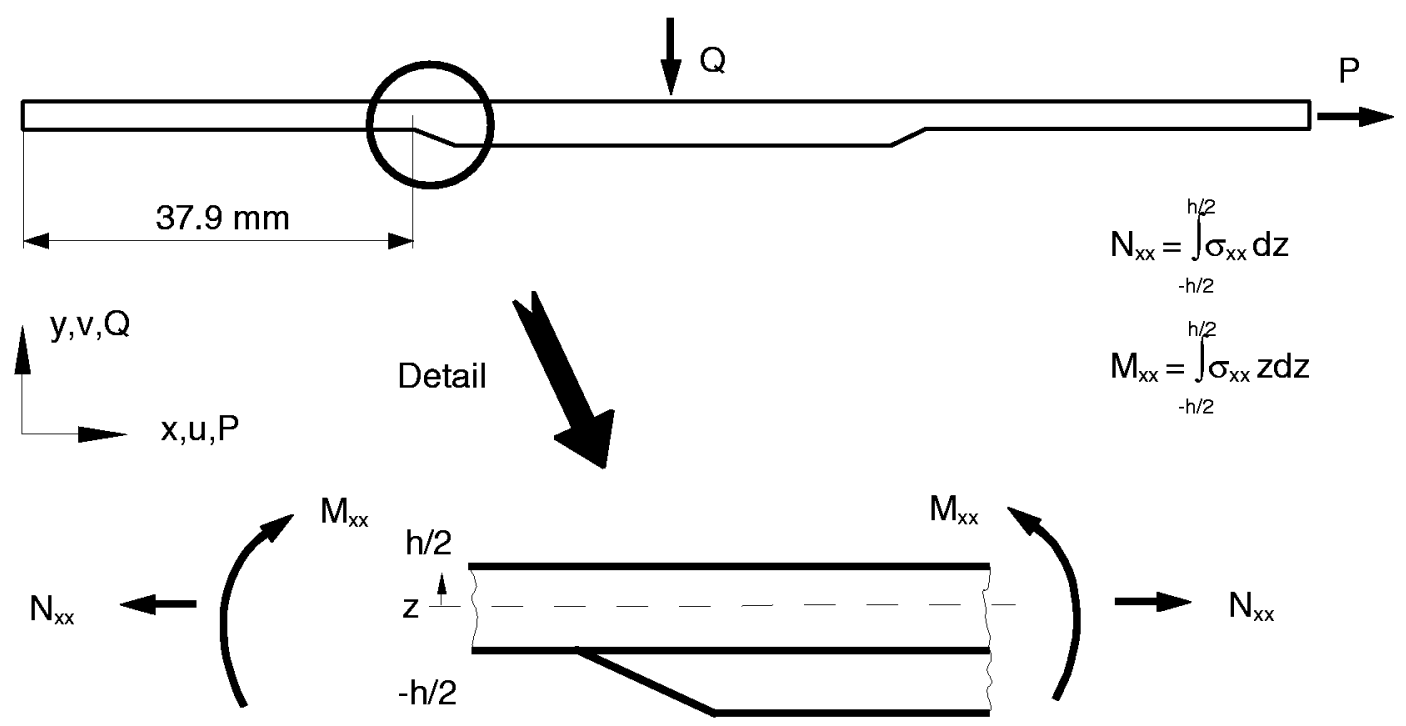

Figure 27. Calculation of Force and Moment Resultants.

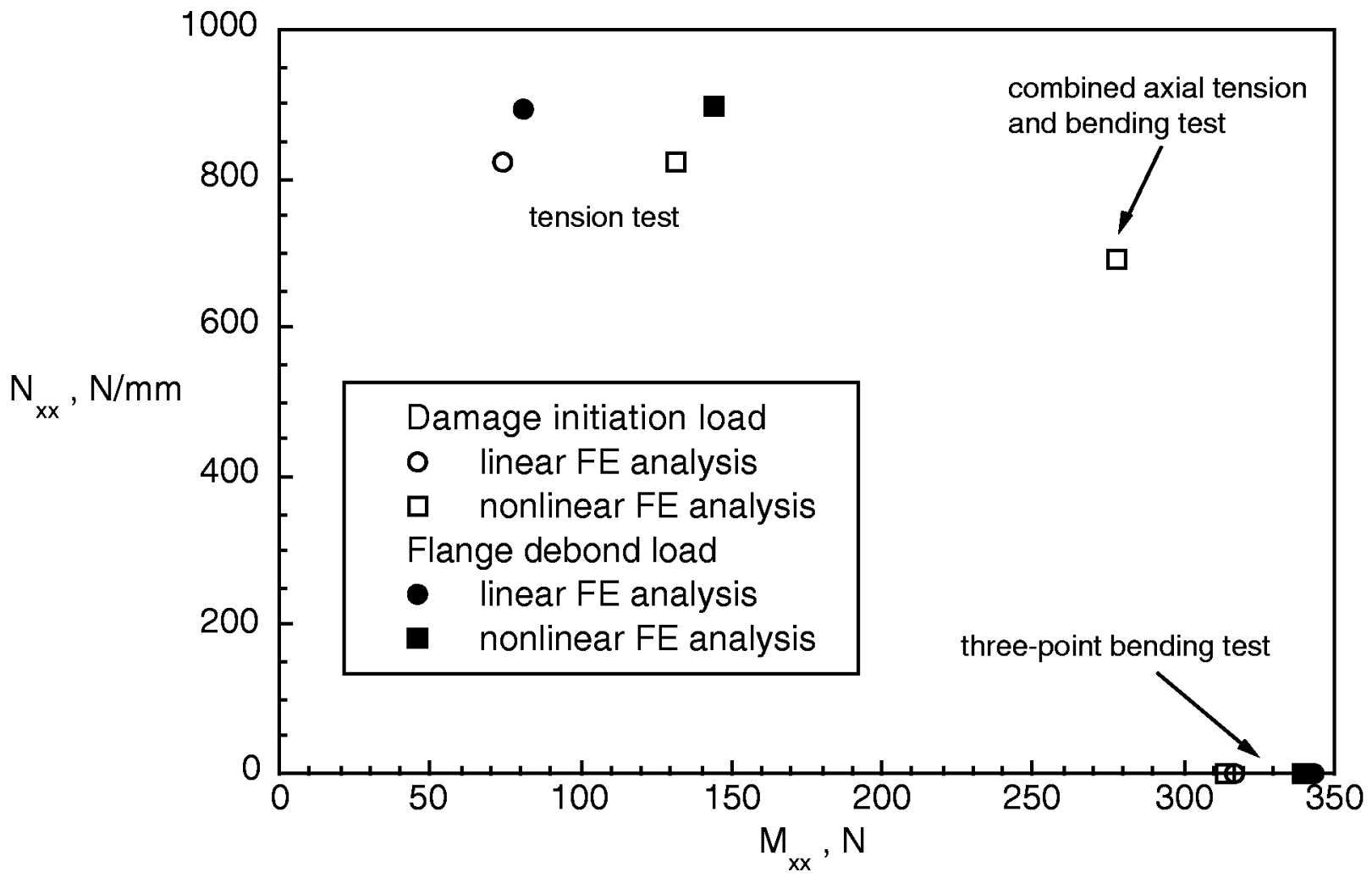

Figure 28. Computed Force and Moment Resultants at Flange Tip. 


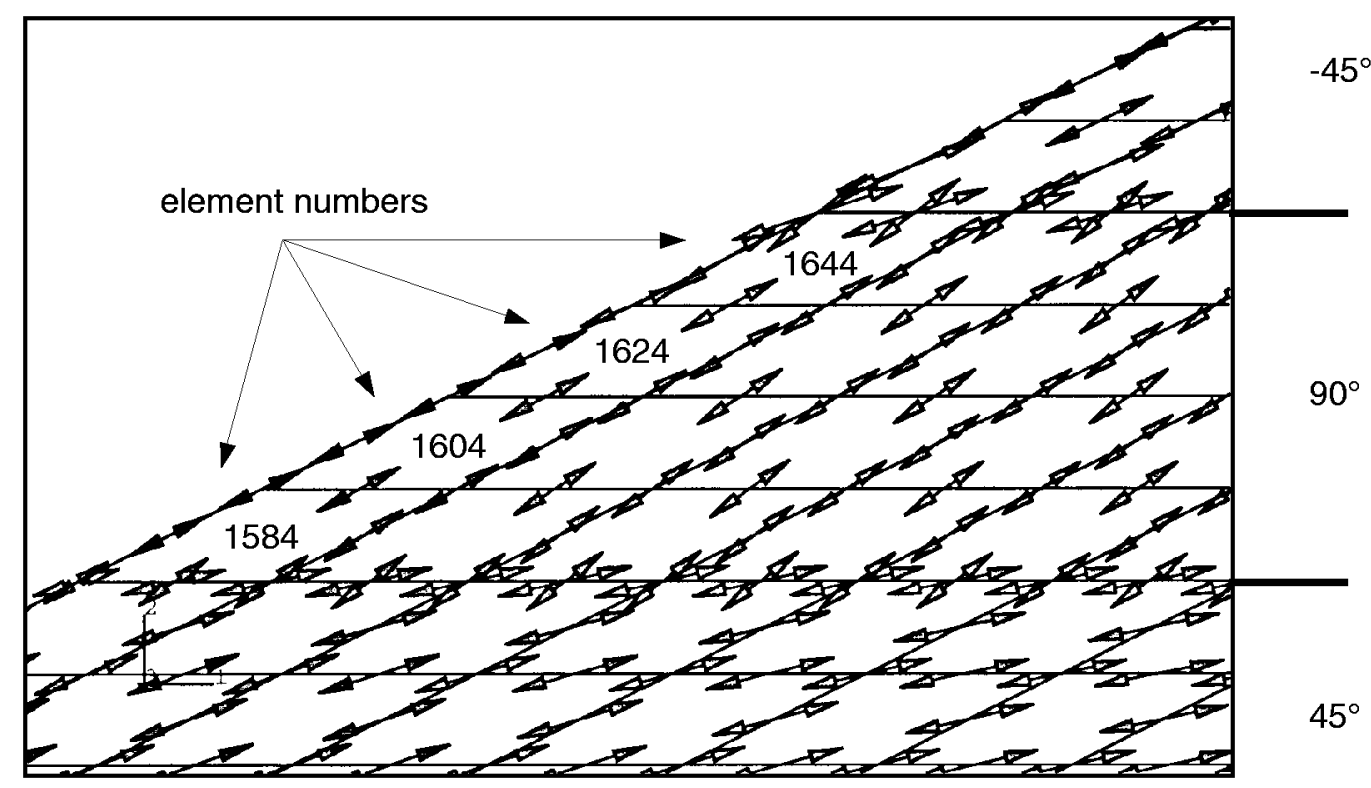

Figure 29. Trajectories of Maximum Principal Stresses.

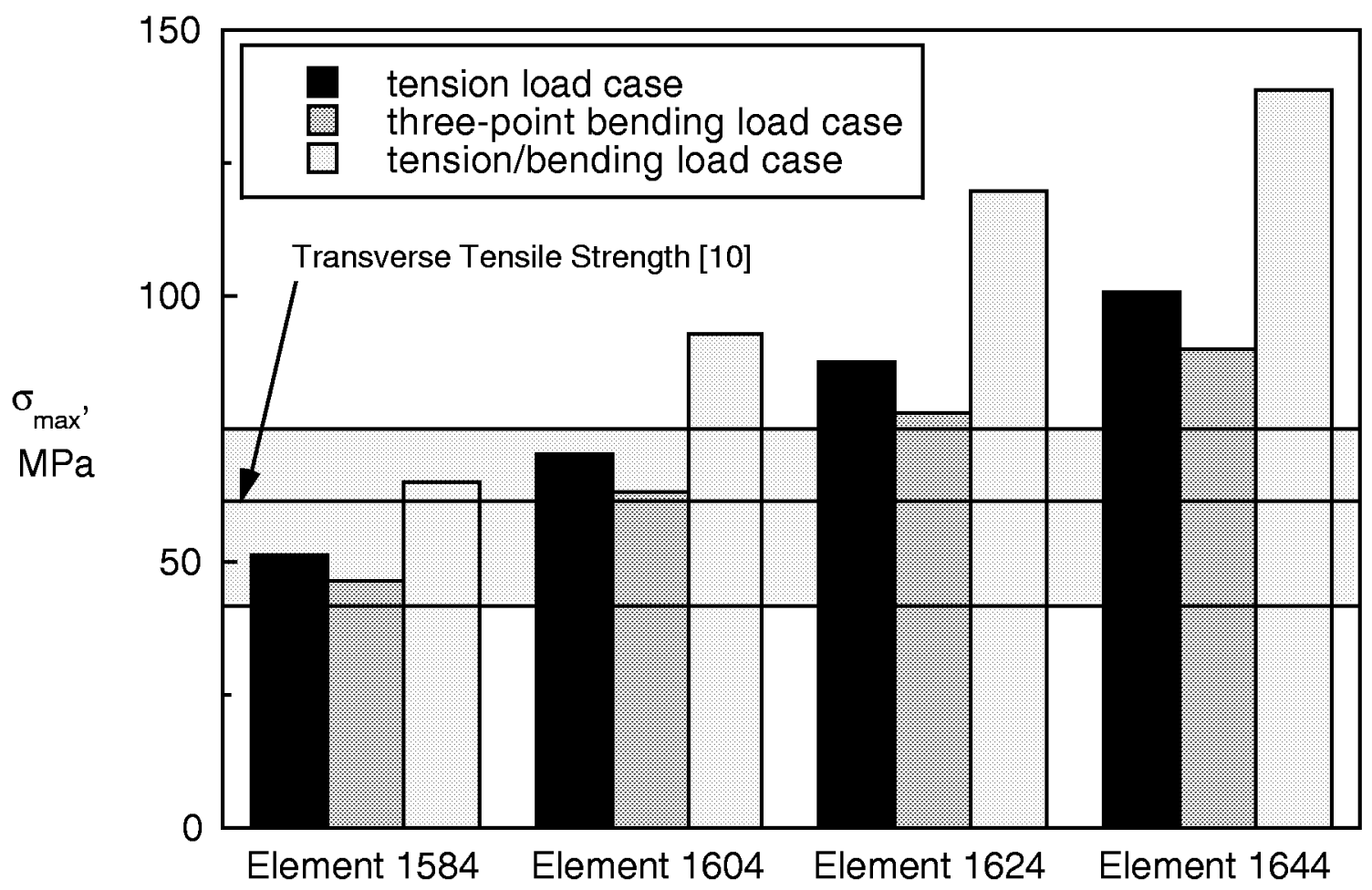

Figure 30. Comparison of Principal Tensile Stresses Computed at Damage Initiation Load. 


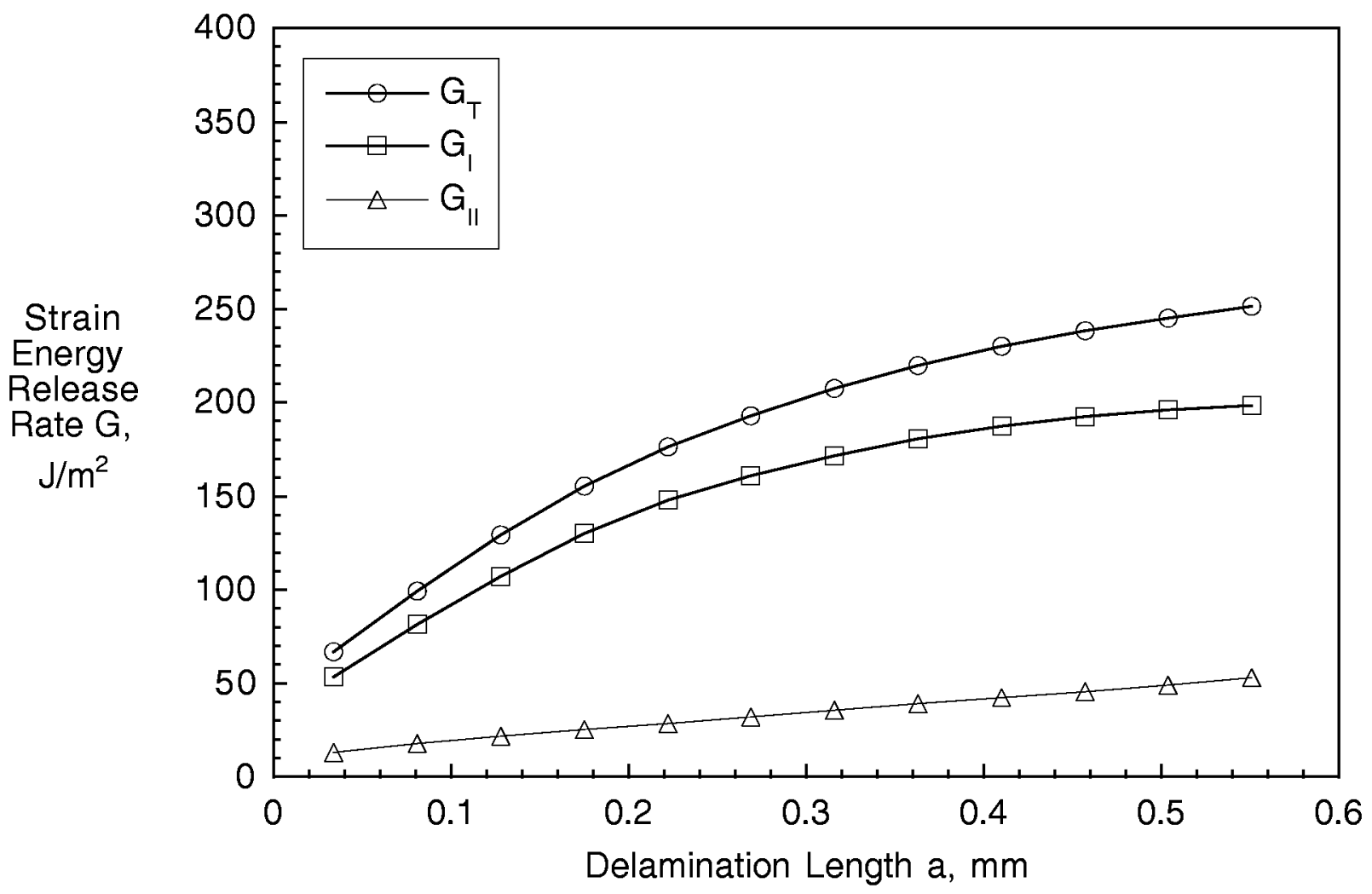

Figure 31. Computed Strain Energy Release Rates for Delamination Growth in a $90^{\circ} / 45^{\circ}$ Flange Ply Interface for Tension Tests.

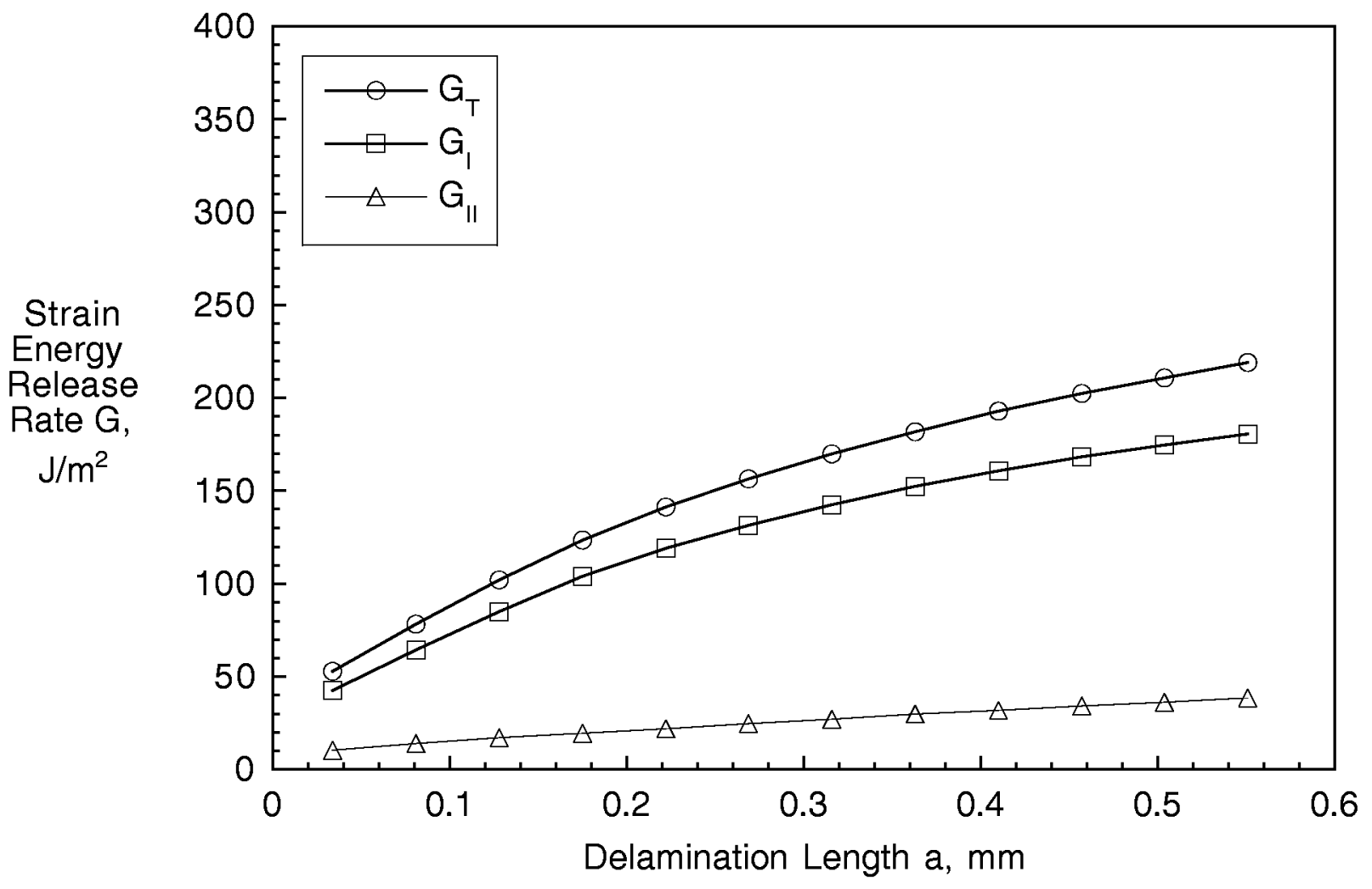

Figure 32. Computed Strain Energy Release Rates for Delamination Growth in a $90^{\circ} / 45^{\circ}$ Flange Ply Interface for Three-Point Bending Tests. 


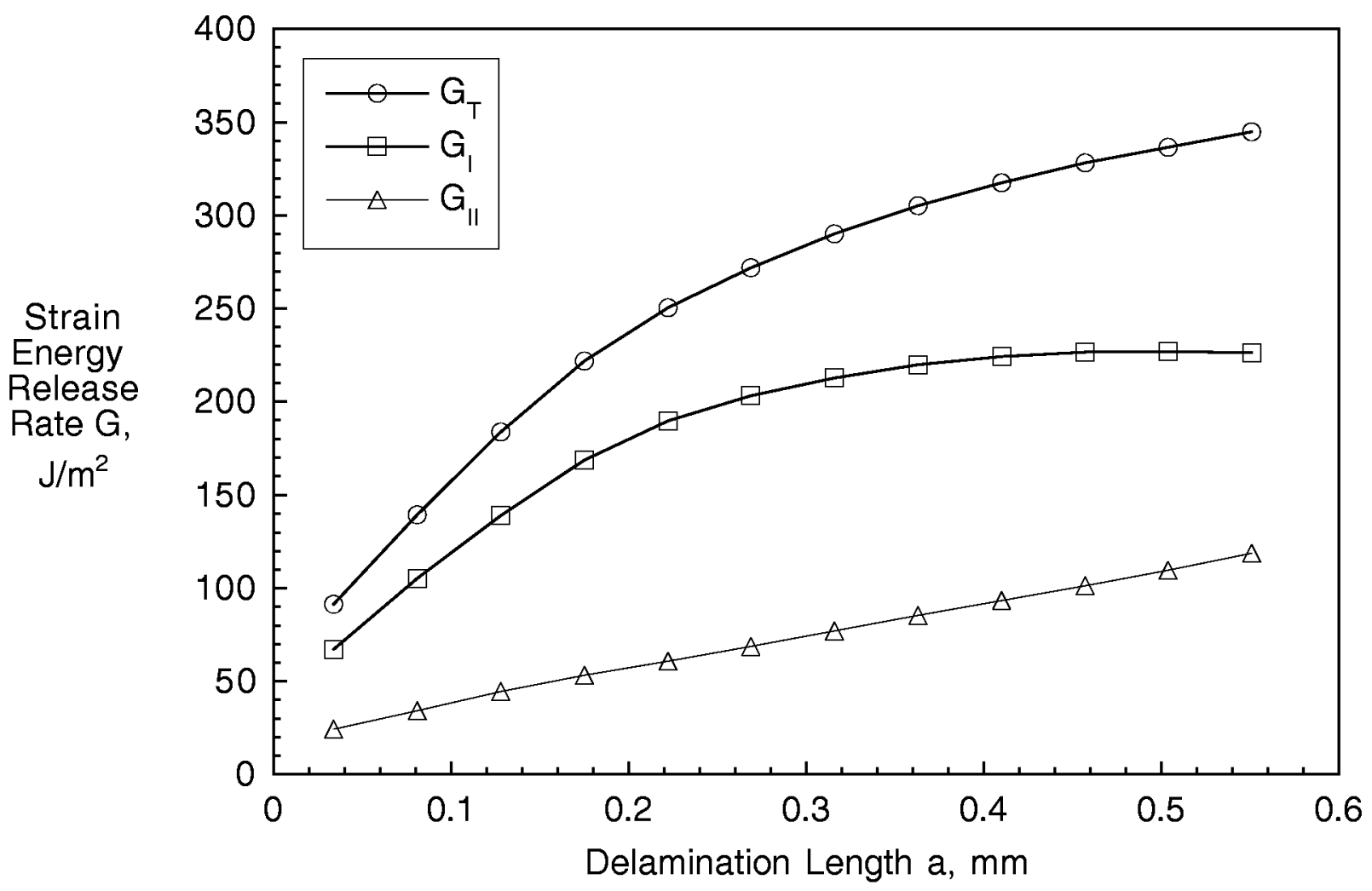

Figure 33. Computed Strain Energy Release Rates for Delamination Growth in a $90^{\circ} / 45^{\circ}$ Flange Ply Interface for ATB Tests.

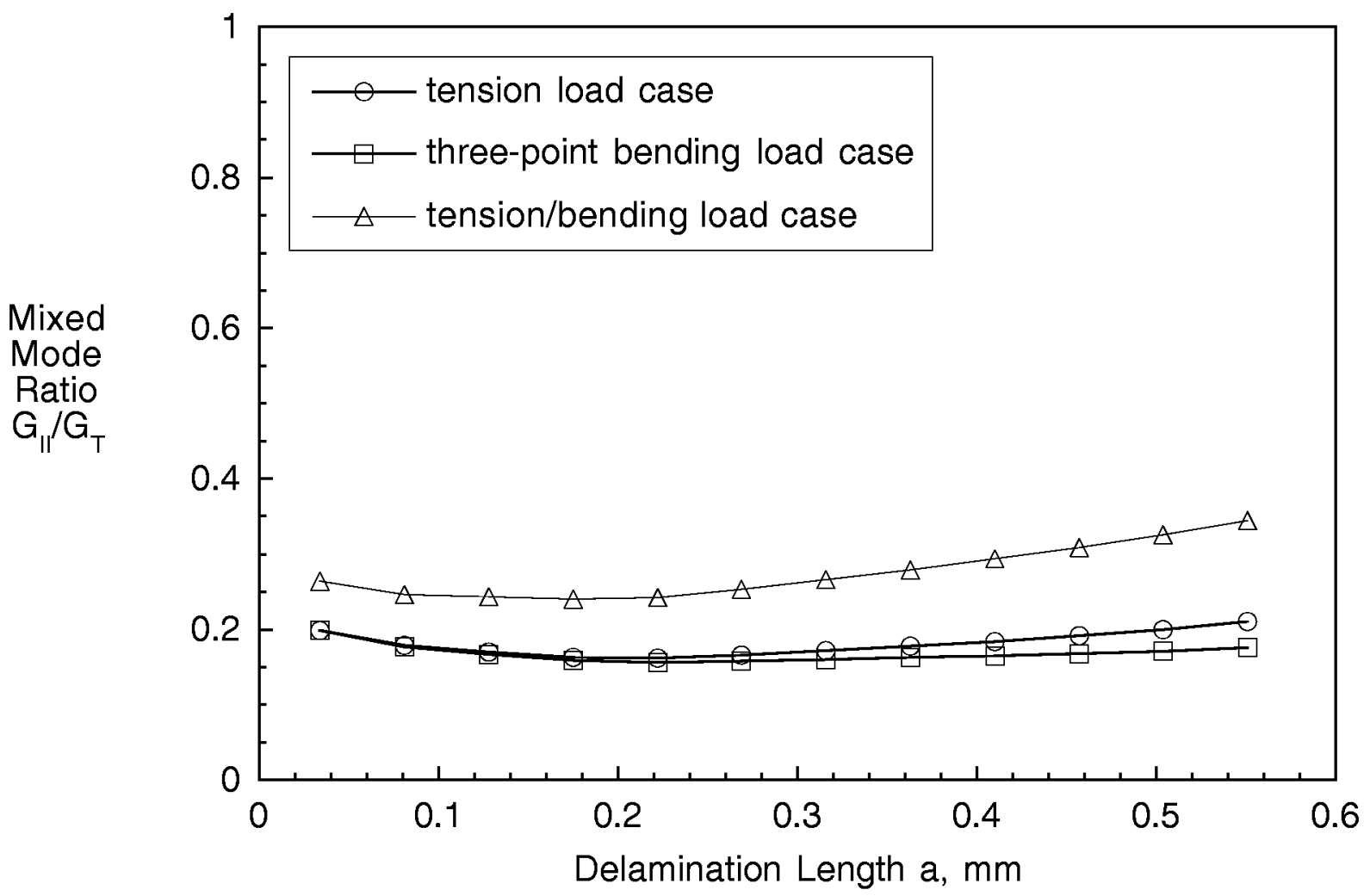

Figure 34. Computed Mixed Mode Ratios for Delamination Growth in a $90^{\circ} / 45^{\circ}$ Flange Ply Interface. 


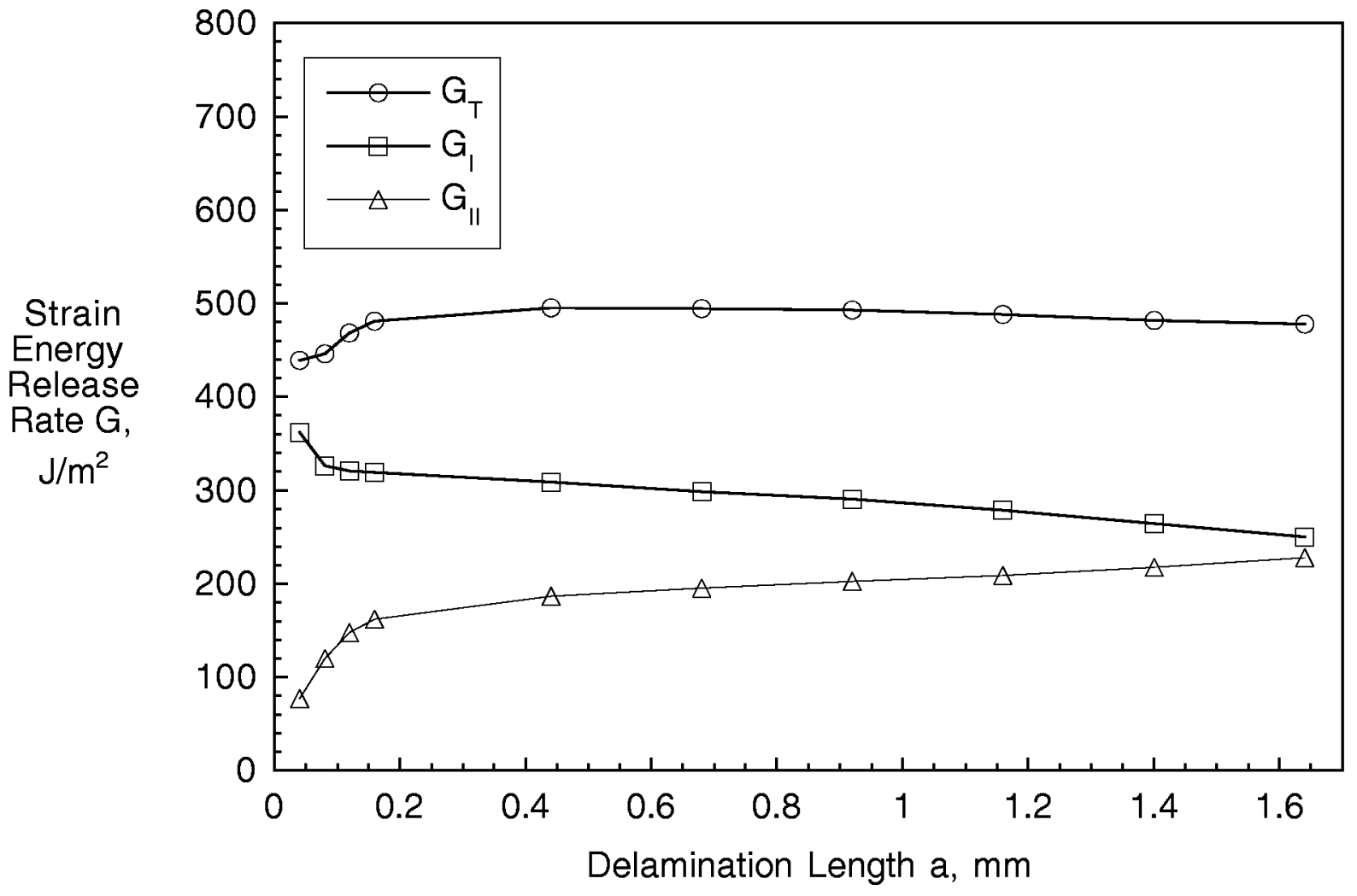

Figure 35. Computed Strain Energy Release Rates for Delamination Growth Between Adhesive and $0^{\circ}$ Skin Ply for Tension Tests.

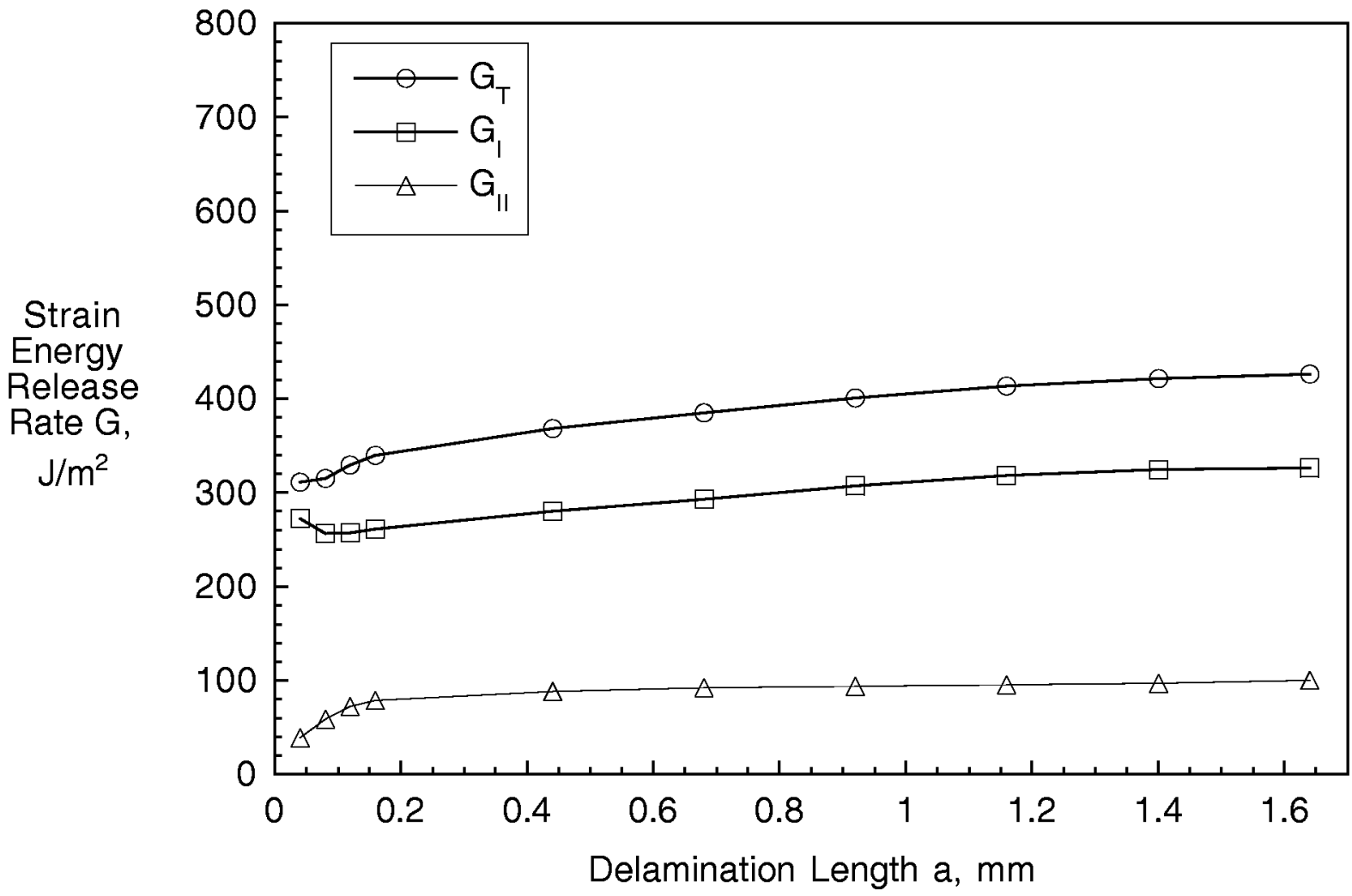

Figure 36. Computed Strain Energy Release Rates for Delamination Growth Between Adhesive and $0^{\circ}$ Skin Ply for Three-Point Bending Tests. 


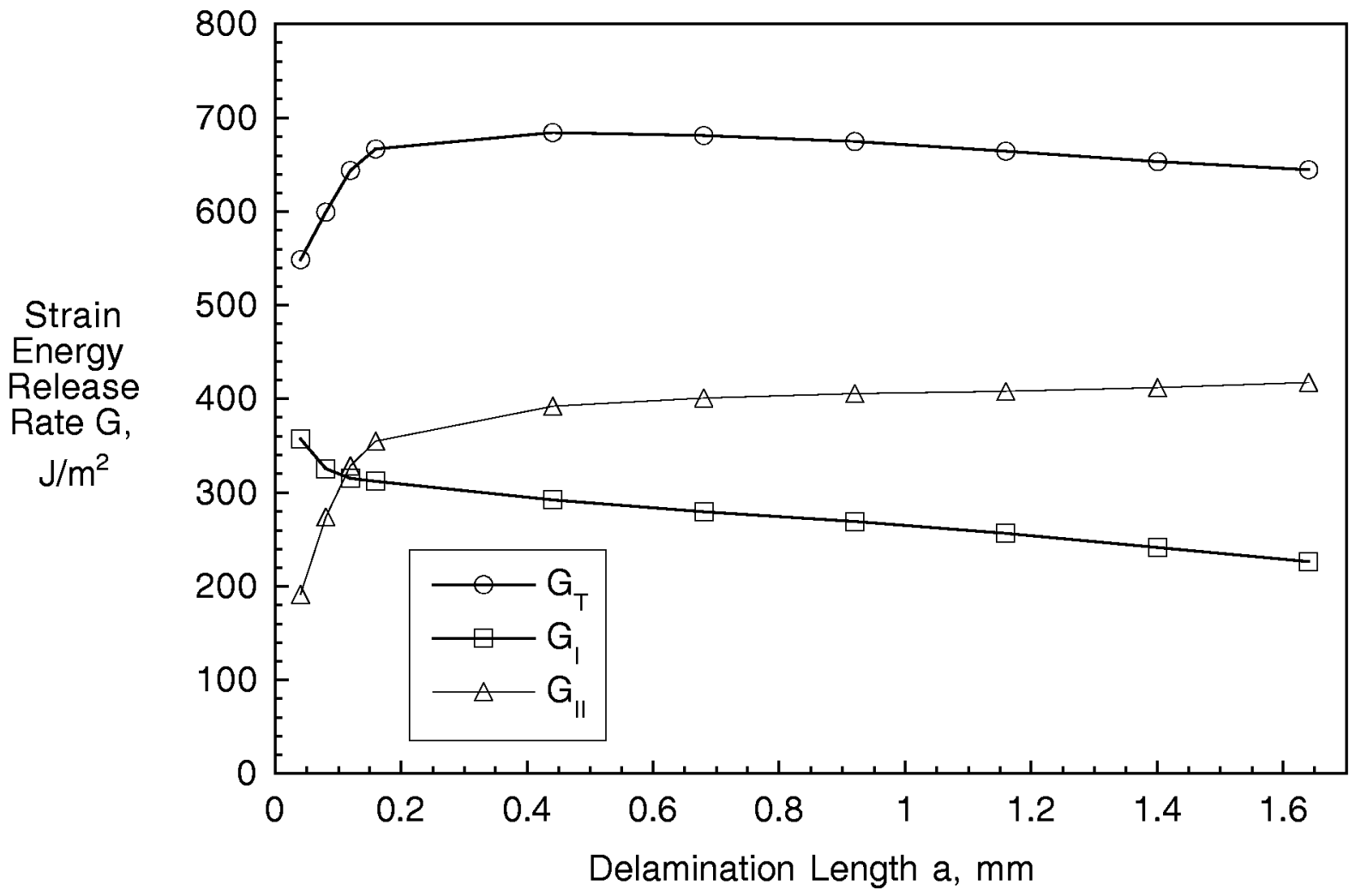

Figure 37. Computed Strain Energy Release Rates for Delamination Growth Between Adhesive and $0^{\circ}$ Skin Ply for ATB Tests.

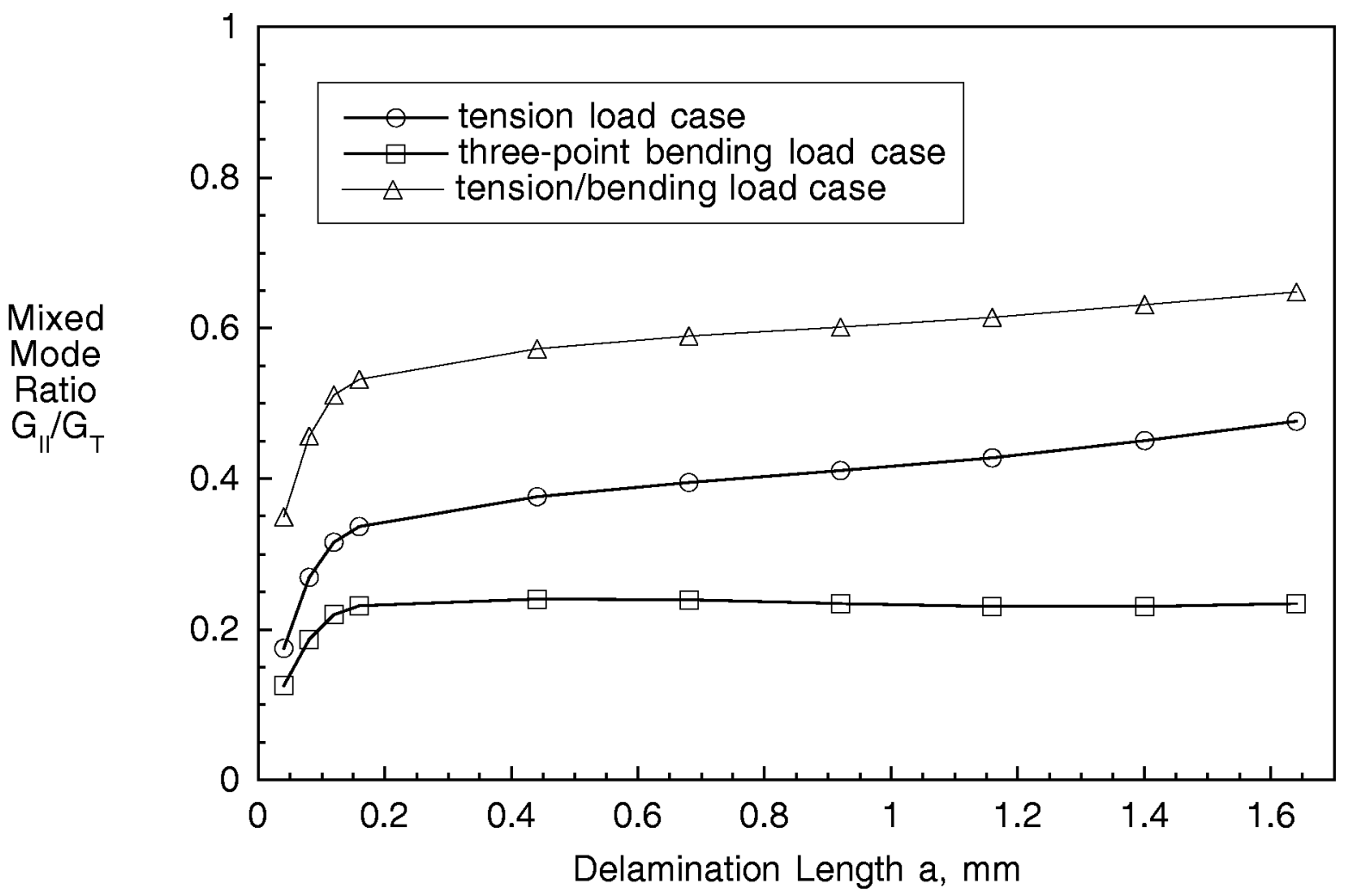

Figure 38. Computed Mixed Mode Ratios for Delamination Growth Between Adhesive and $0^{\circ}$ Skin Ply. 


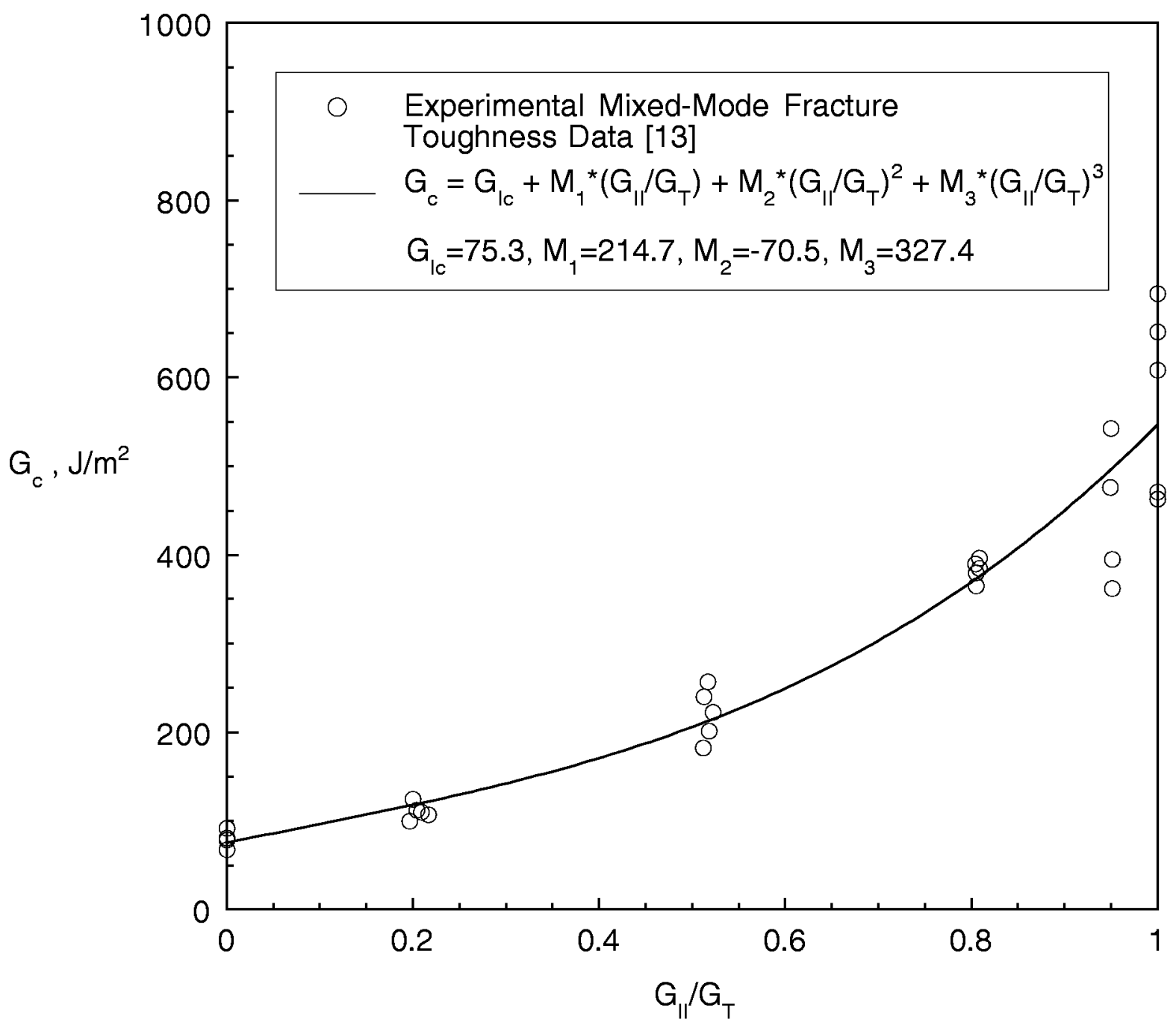

Figure 39. Mixed-Mode Delamination Criterion for AS4/3501-6 [13]. 


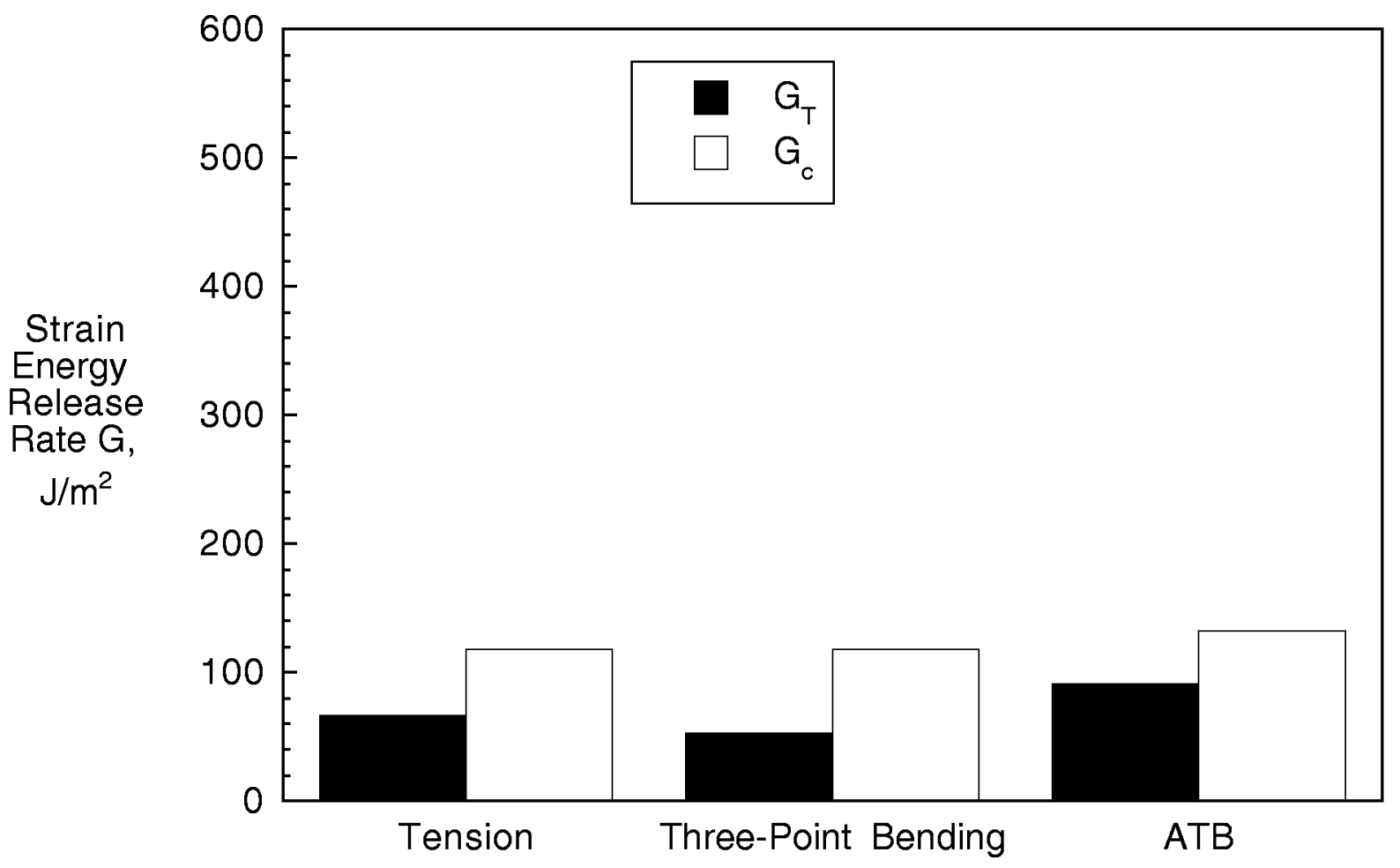

Figure 40. Comparison of Computed Total Strain Energy Release Rates in a $90^{\circ} / 45^{\circ}$ Flange Ply Interface with Mixed-Mode Fracture Toughnesses.

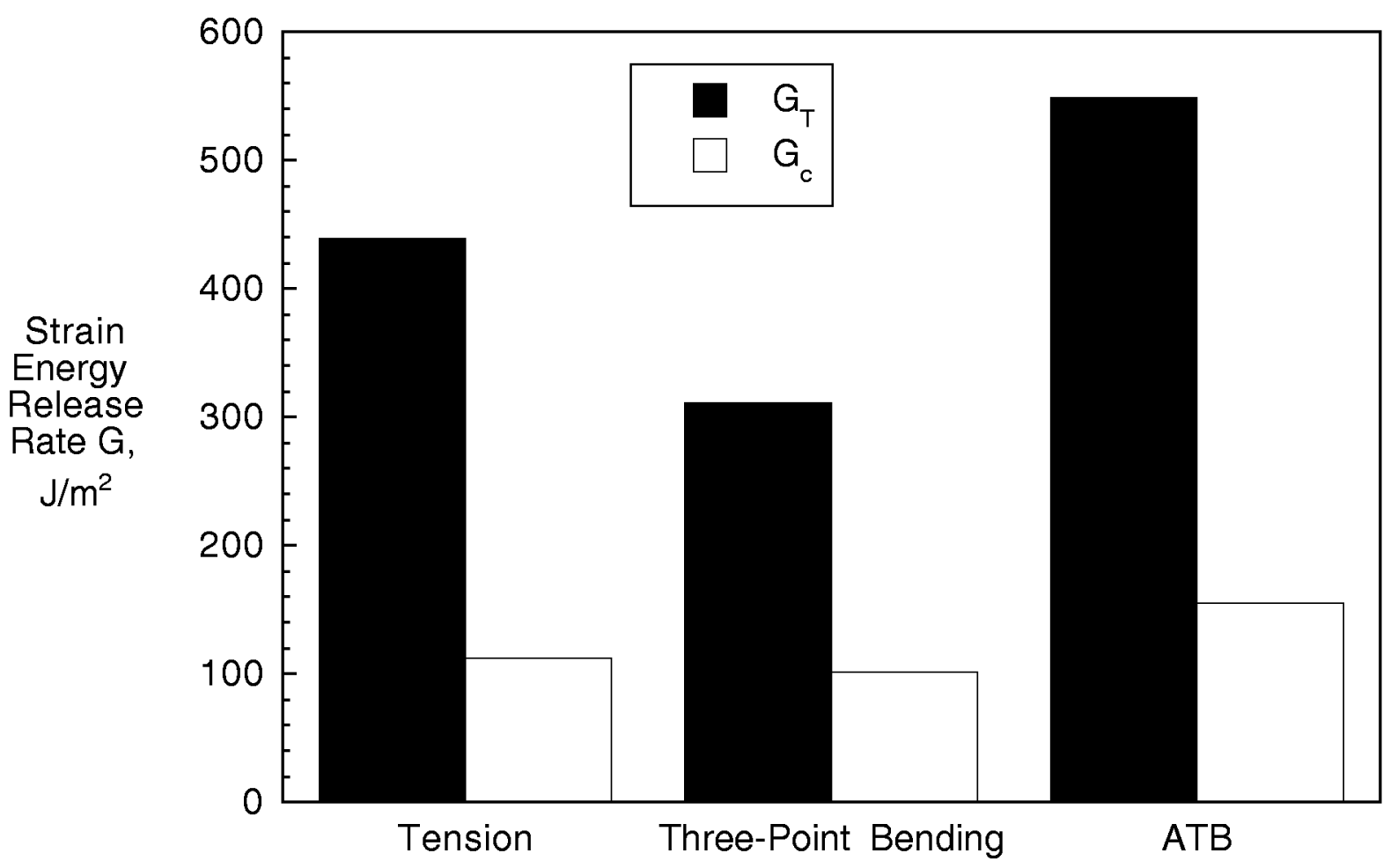

Figure 41. Comparison of Computed Total Strain Energy Release Rates in a $0^{\circ}$ Skin Ply/Adhesive Film Interface with Mixed-Mode Fracture Toughnesses. 


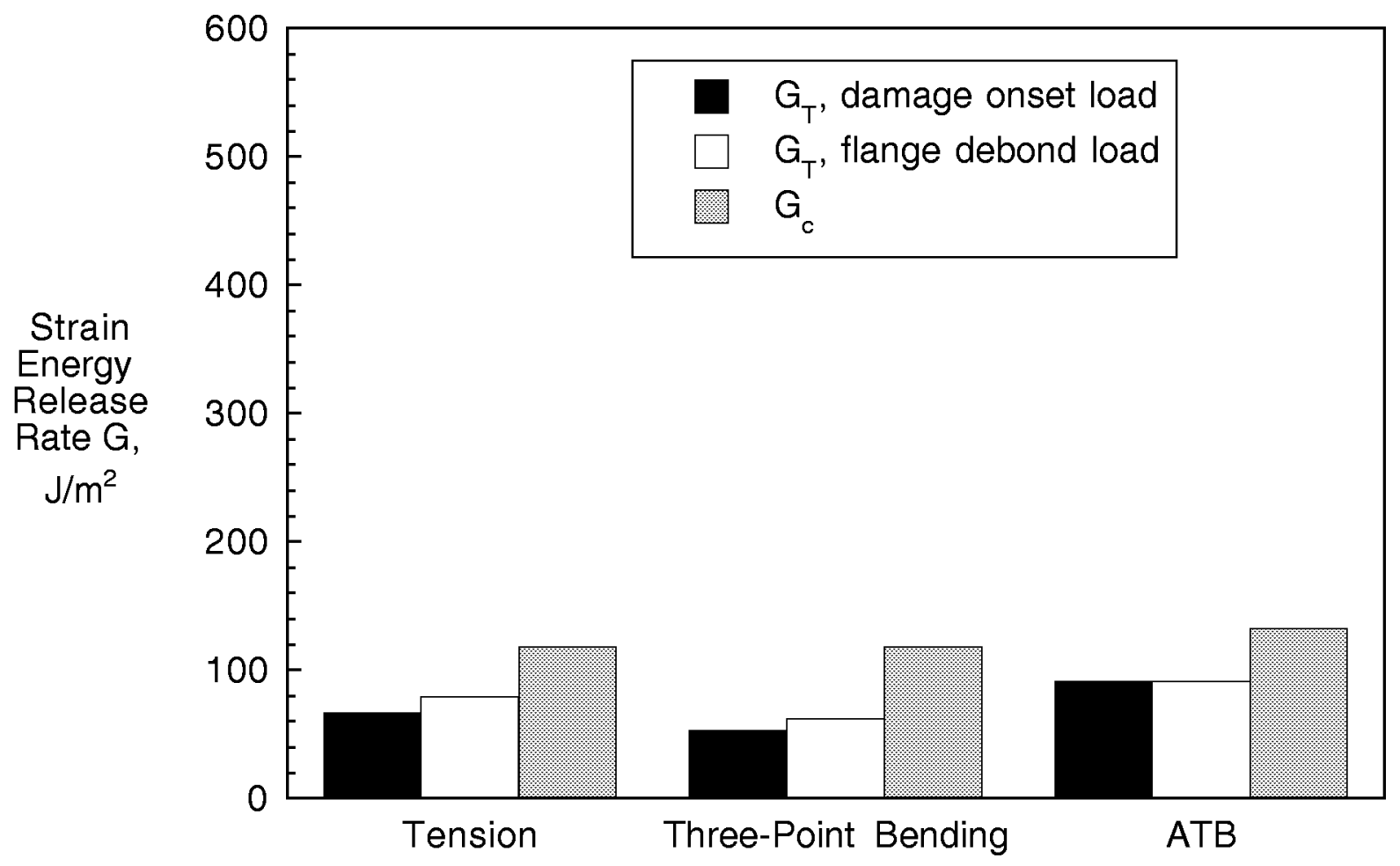

Figure 42. Comparison of Computed Total Strain Energy Release Rates in a $90^{\circ} / 45^{\circ}$ Flange Ply Interface with Mixed-ModeFracture Toughnesses. 


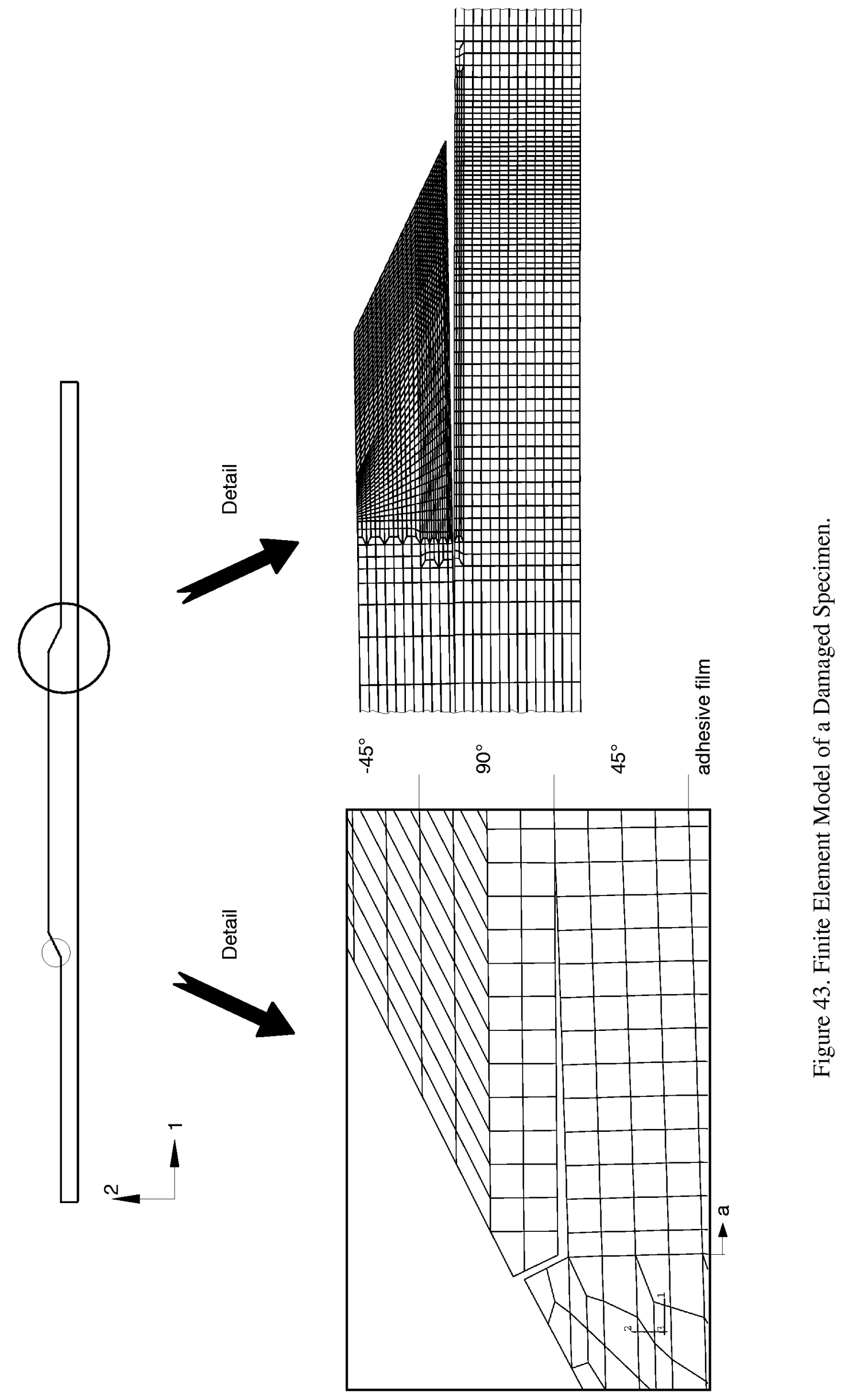




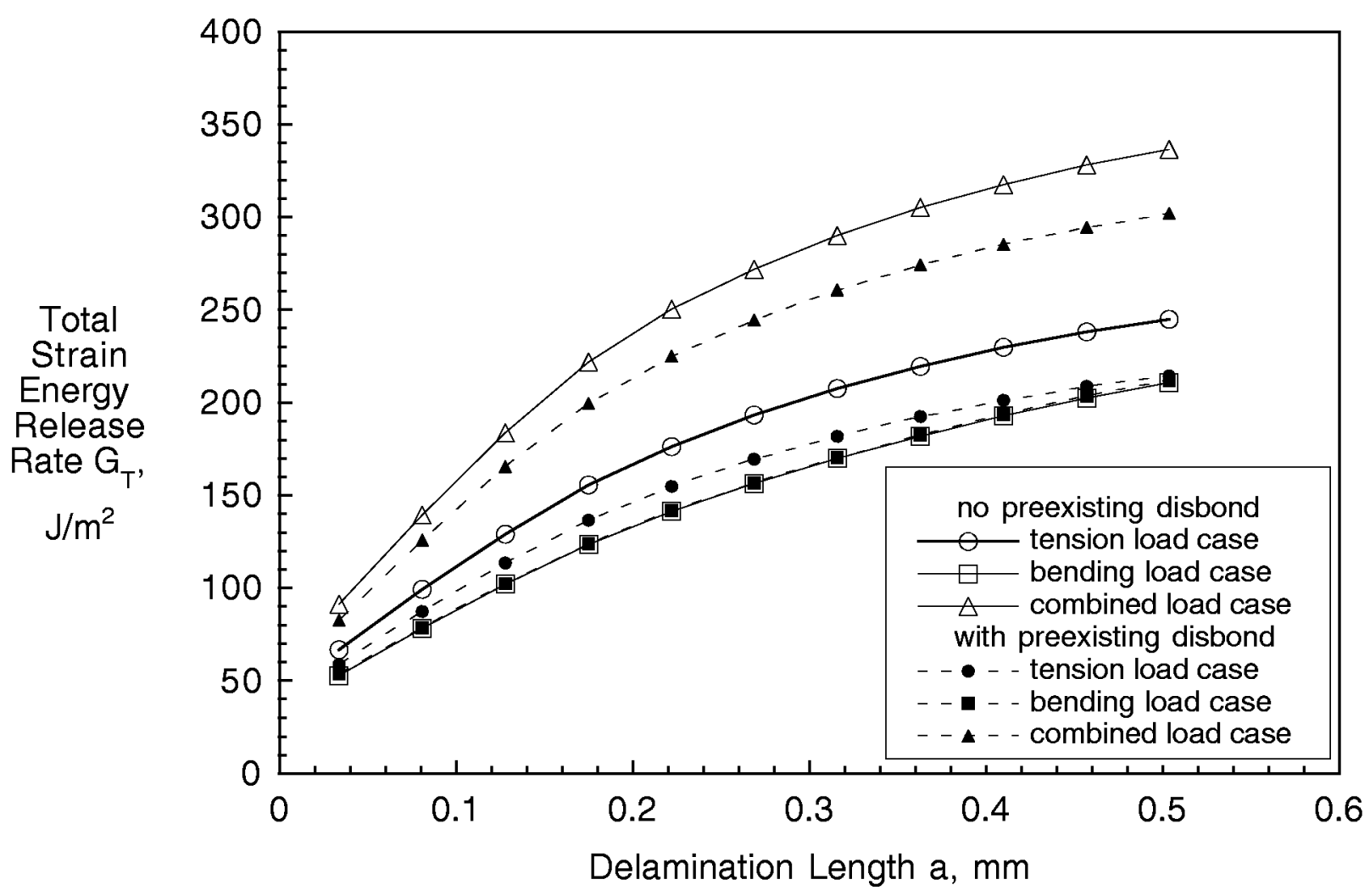

Figure 44. Computed Strain Energy Release Rates for Delamination Growth in a $90^{\circ} / 45^{\circ}$ Flange Ply Interface with and without a Preexisting Disbond Between Adhesive and $0^{\circ}$ Skin Ply.

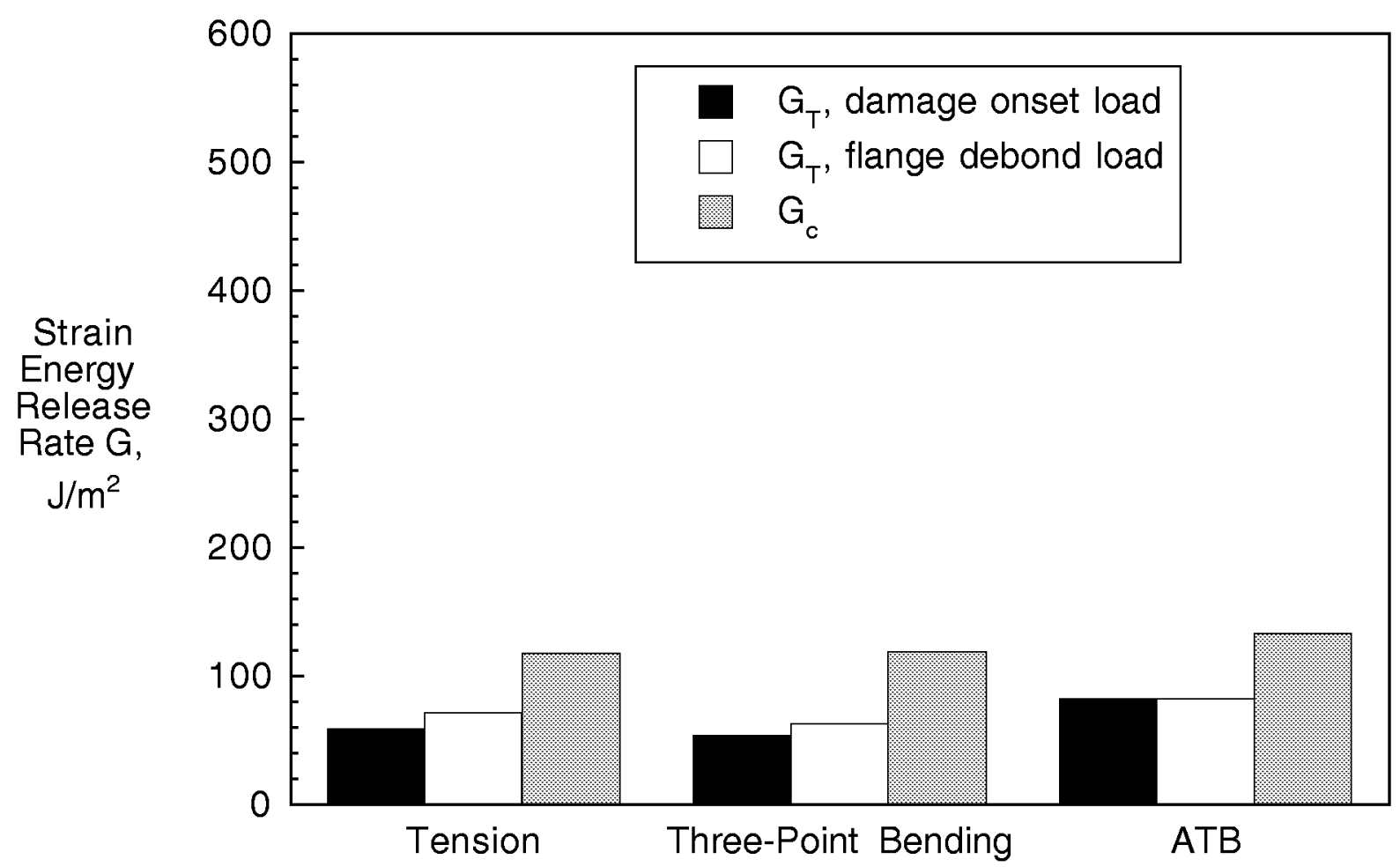

Figure 45. Comparison of Computed Total Strain Energy Release Rates in a $90^{\circ} / 45^{\circ}$ Flange Ply Interface with Mixed-Mode Fracture Toughnesses. 


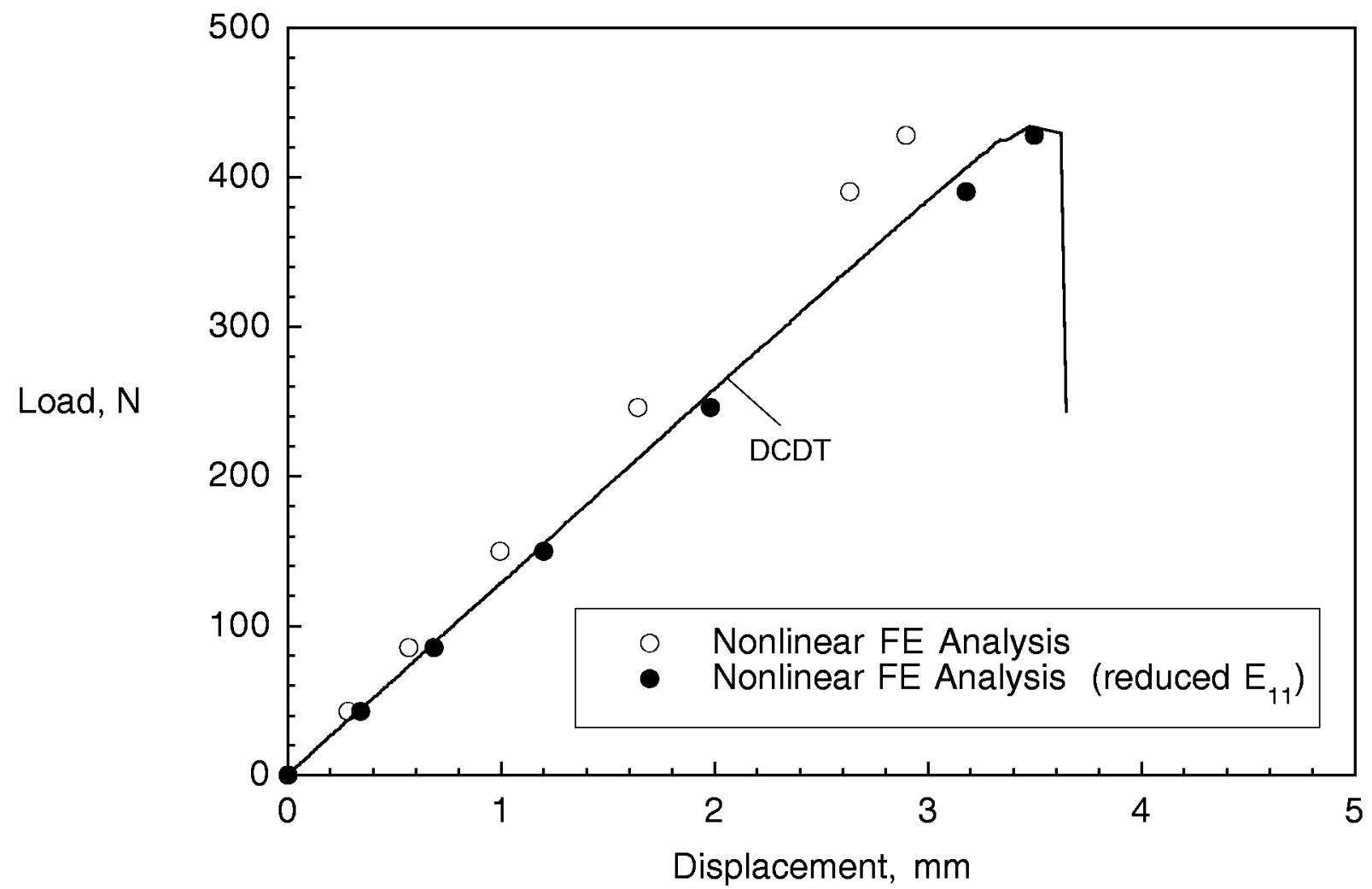

Figure 46. Comparison of Measured Displacements with Computed Results for Three-Point Bending Load Case.

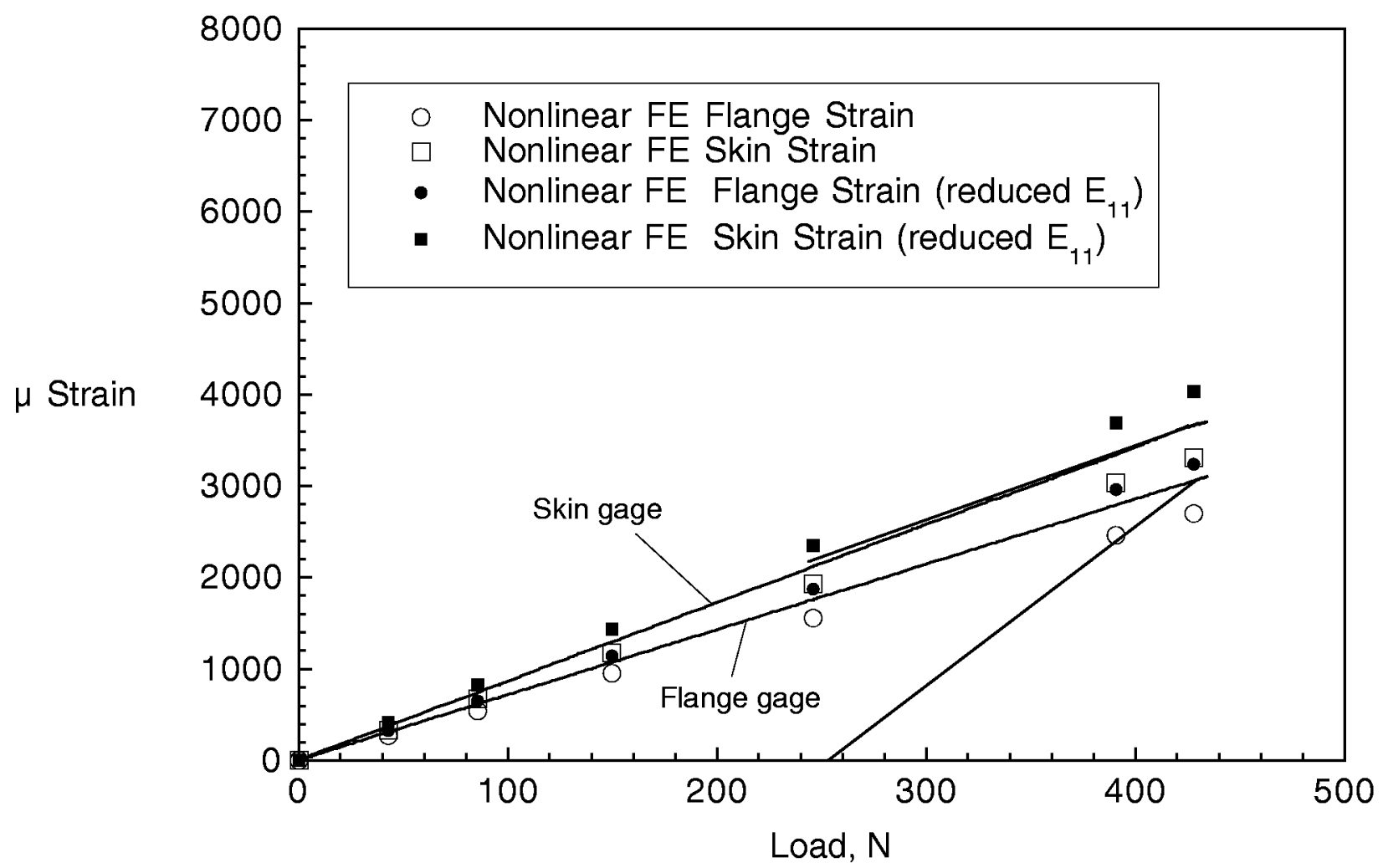

Figure 47. Comparison of Measured Strains with Computed Results for Three-Point Bending Load Case. 


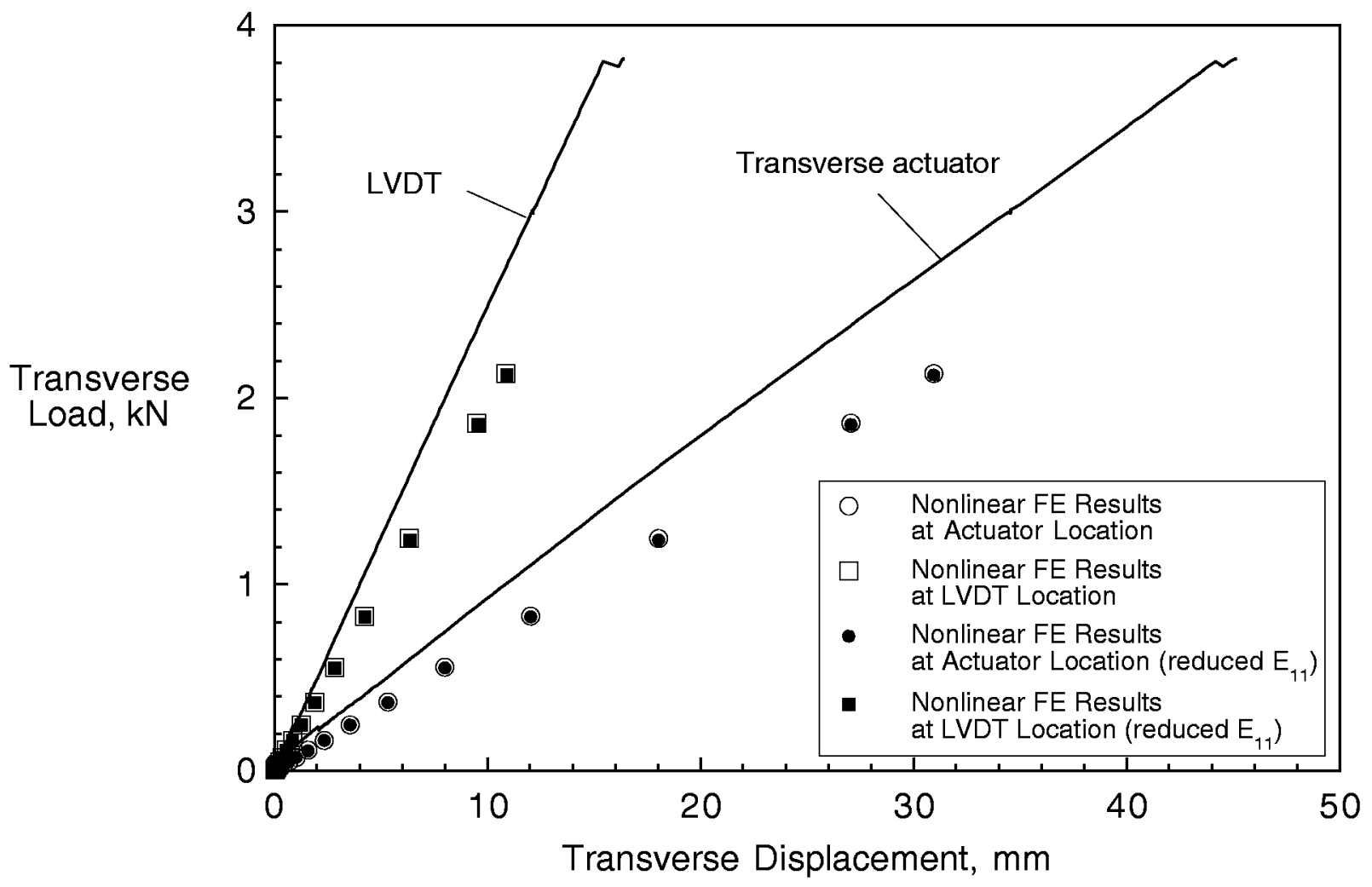

Figure 48. Comparison of Measured Displacements with Computed Results for ATB Load Case.

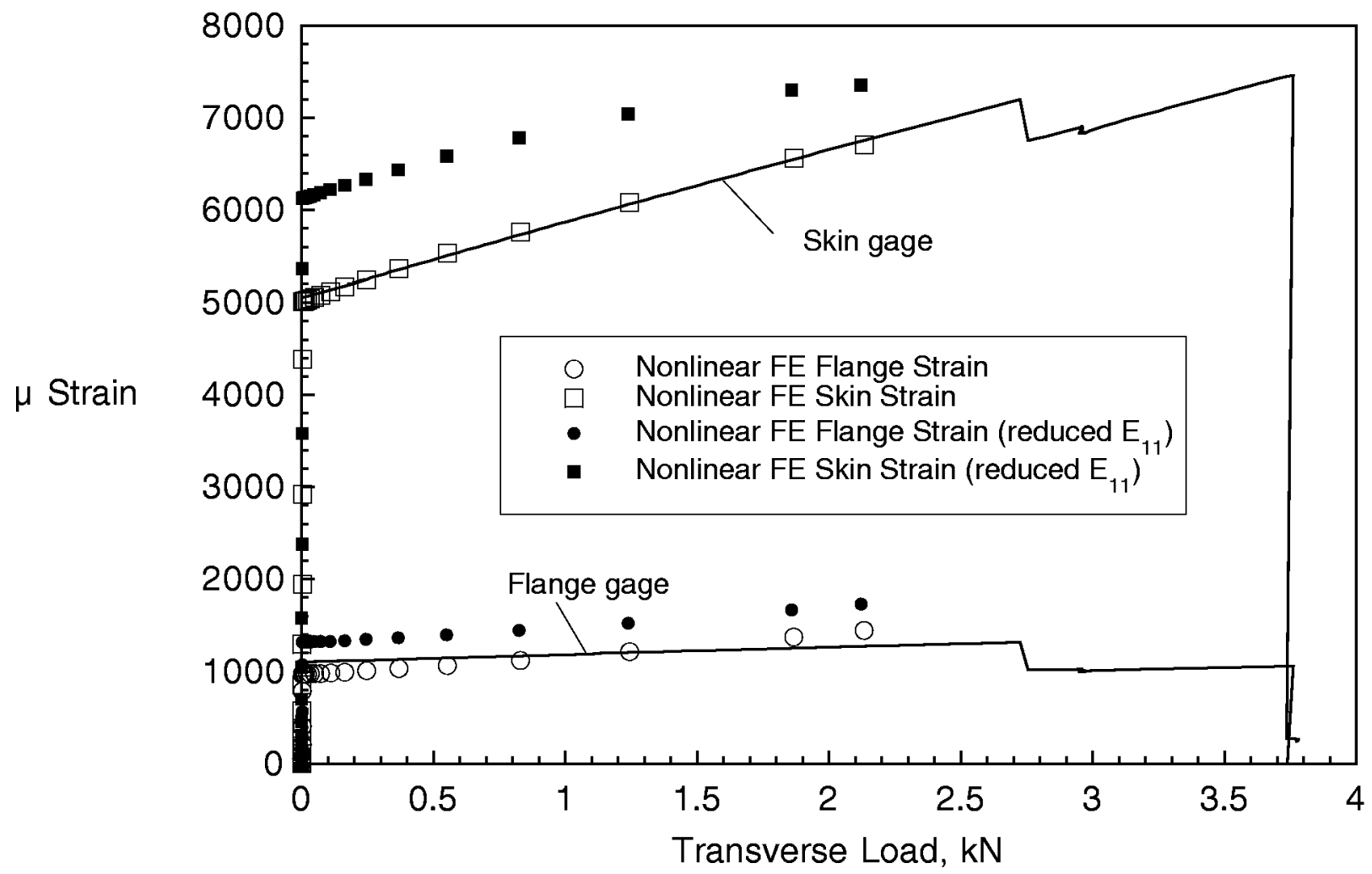

Figure 49. Comparison of Measured Strains with Computed Results for ATB Load Case. 


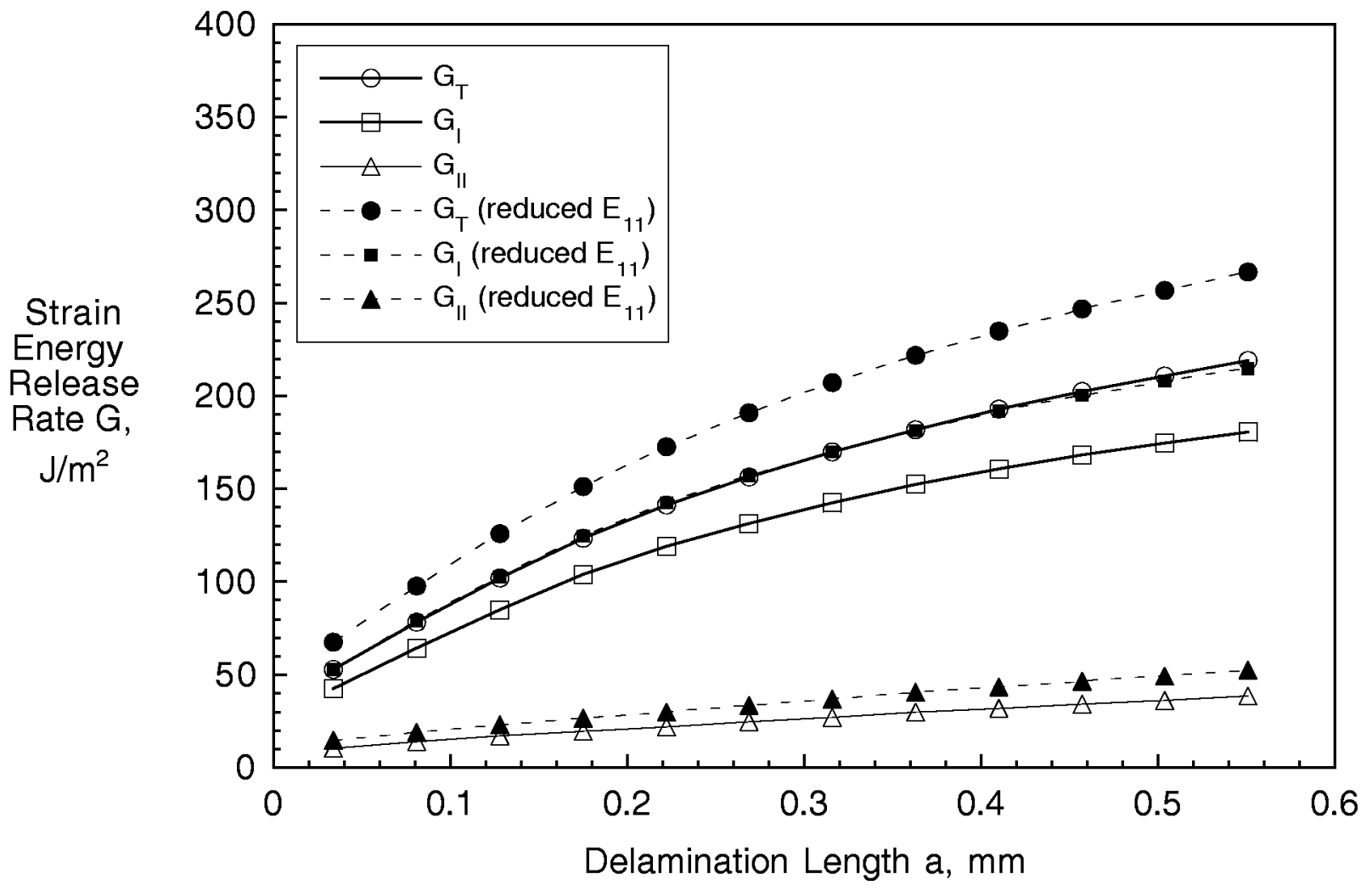

Figure 50. Computed Strain Energy Release Rates for Delamination Growth in a $90^{\circ} / 45^{\circ}$ Flange Ply Interface for Three-Point Bending Tests.

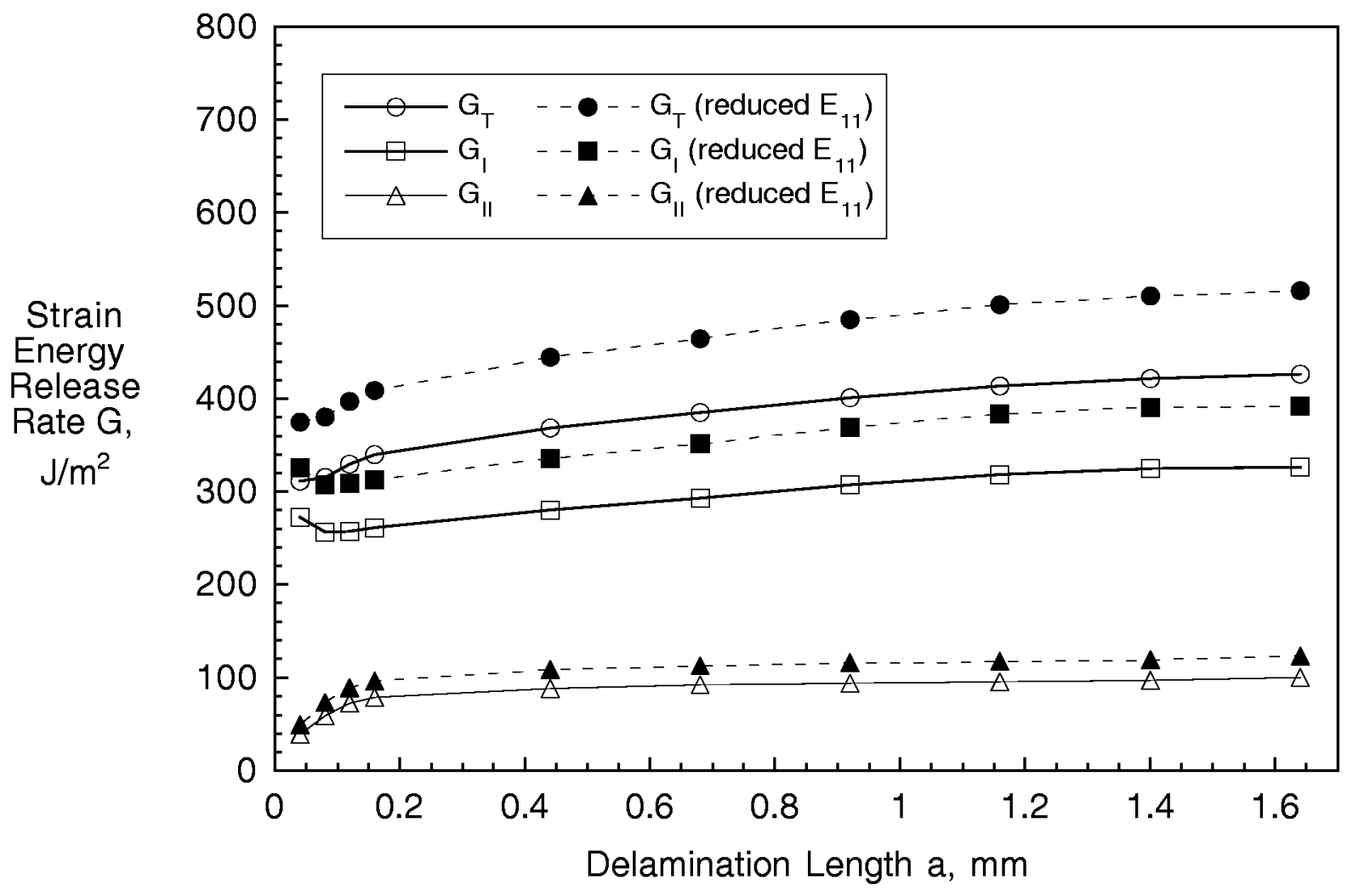

Figure 51. Computed Strain Energy Release Rates for Delamination Growth Between Adhesive and $0^{\circ}$ Skin Ply for Three-Point Bending Tests. 


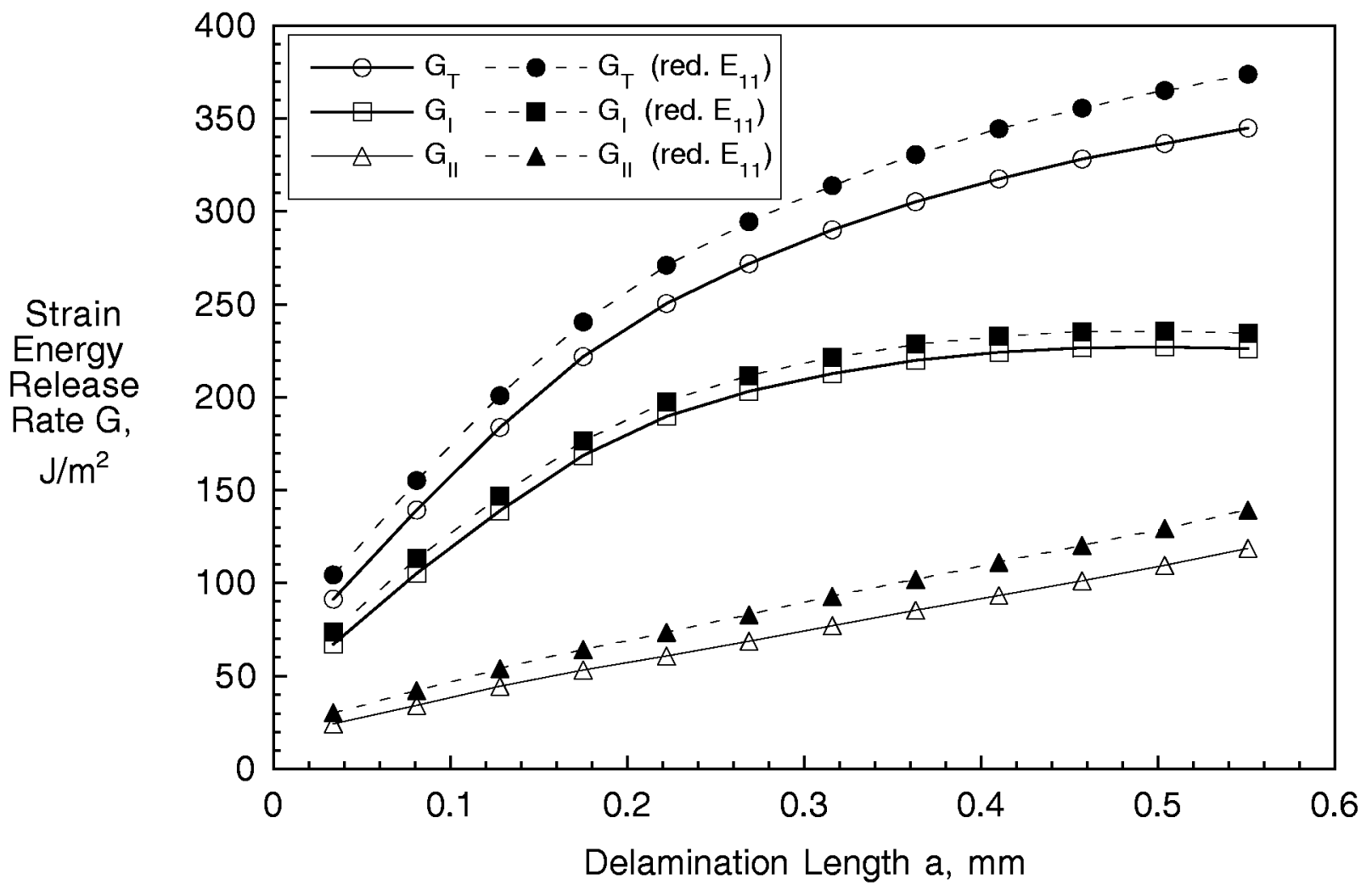

Figure 52. Computed Strain Energy Release Rates for Delamination Growth in a $90^{\circ} / 45^{\circ}$ Flange Ply Interface for ATB Tests.

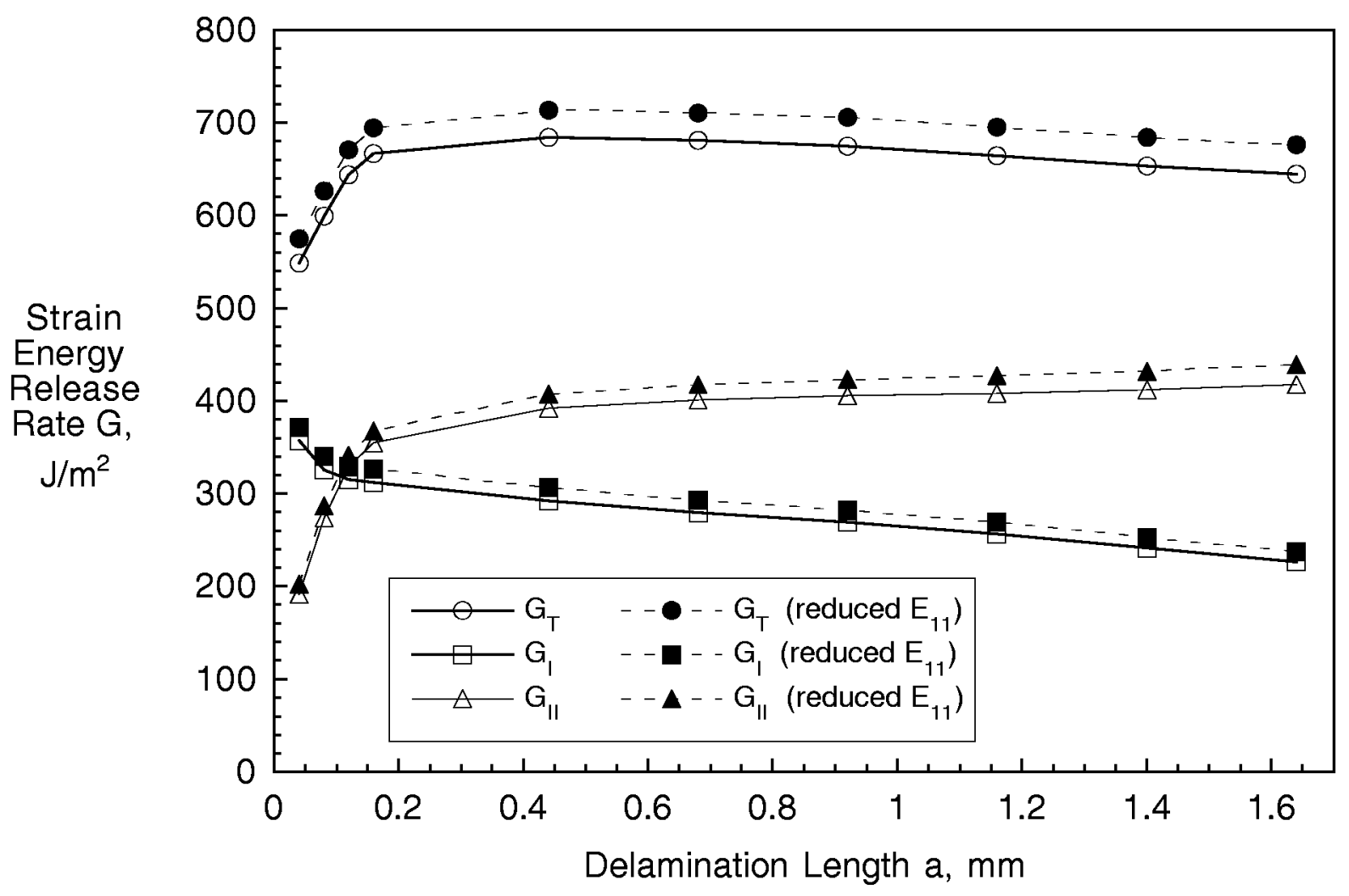

Figure 53. Computed Strain Energy Release Rates for Delamination Growth Between Adhesive and $0^{\circ}$ Skin Ply for ATB Tests. 


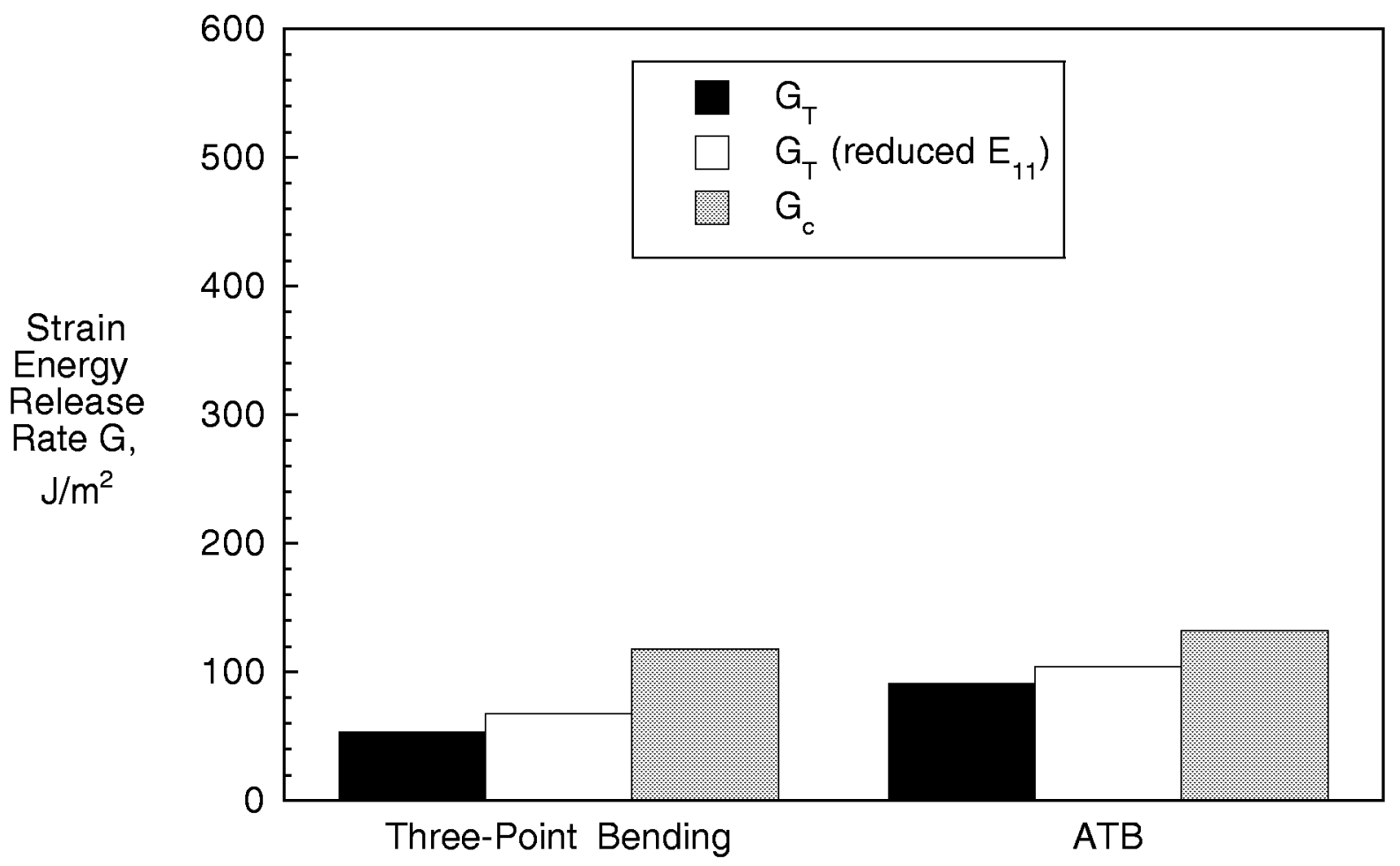

Figure 54. Comparison of Computed Total Strain Energy Release Rates in a $90^{\circ} / 45^{\circ}$ Flange Ply Interface with Mixed-Mode Fracture Toughnesses.

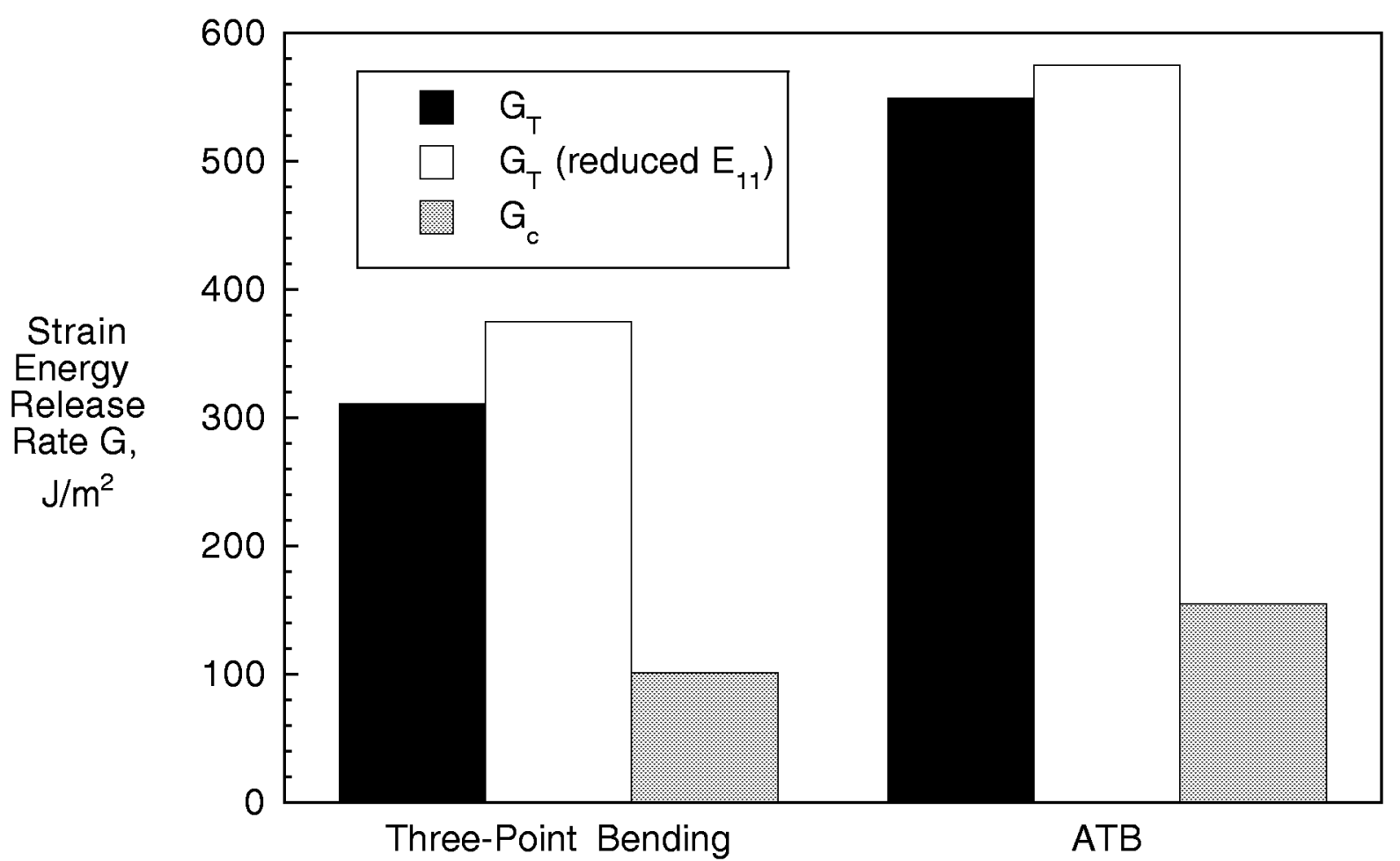

Figure 55. Comparison of Computed Total Strain Energy Release Rates in a $0^{\circ}$ Skin Ply/Adhesive Film Interface with Mixed-Mode Fracture Toughnesses. 


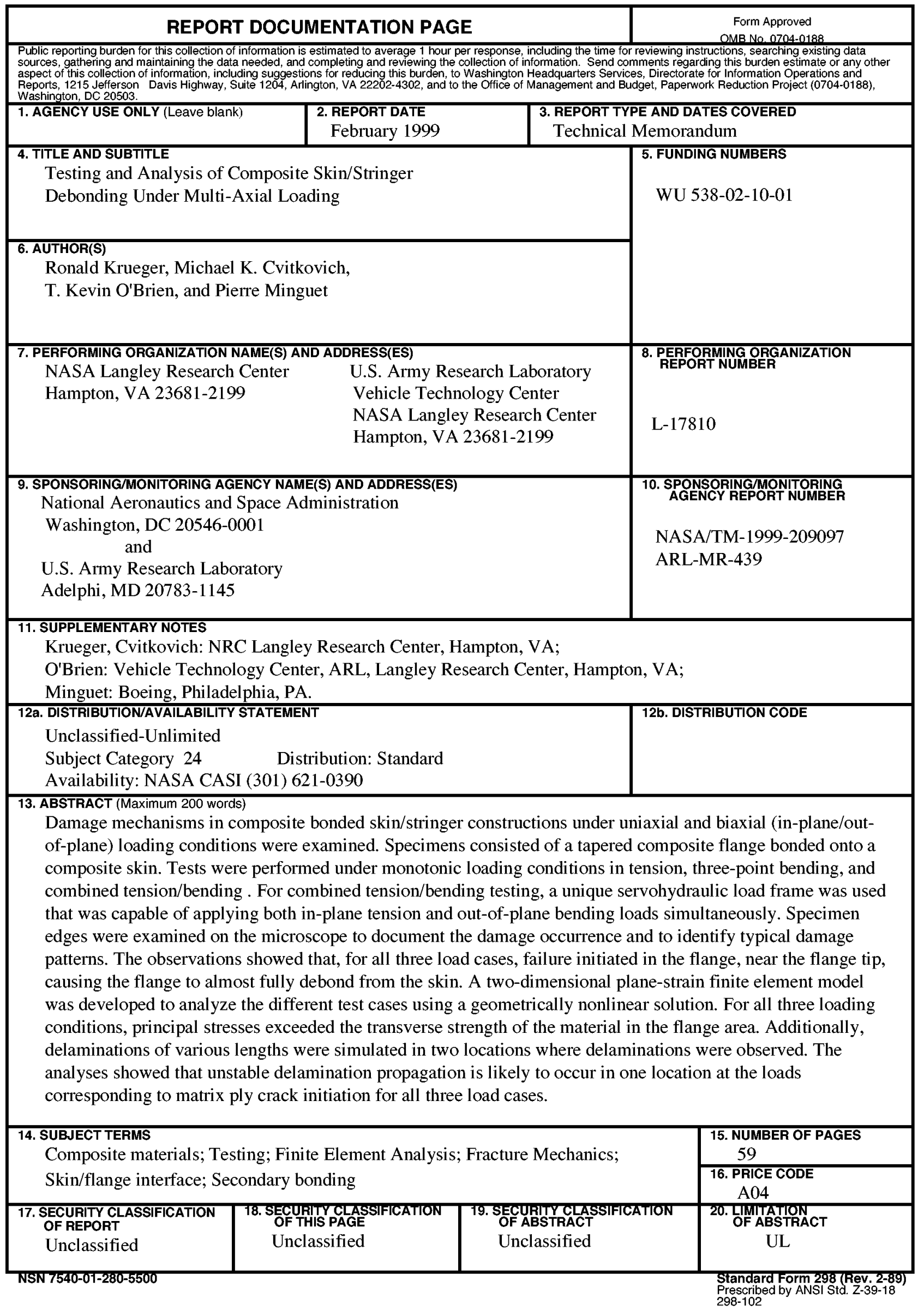

